\title{
Kernos
}

Revue internationale et pluridisciplinaire de religion

grecque antique

$15 \mid 2002$

Varia

\section{Chronique archéologique}

Athéna Tsingarida, Alain Duplouy, François Quantin, Kalliopi Chatzinikolaou, Emmanuel Voutiras, Alexis D'Hautcourt, Natacha Massar, Zozie Papadopoulou, Thierry Petit, Patrick Constancio, Isabelle Tassignon, Massimo Osanna et Nicola Cucuzza

\section{OpenEdition \\ Journals}

Édition électronique

URL : http://journals.openedition.org/kernos/1395

DOI : 10.4000/kernos.1395

ISSN : 2034-7871

Éditeur

Centre international d'étude de la religion grecque antique

Édition imprimée

Date de publication : 1 janvier 2002

Pagination : 415-481

ISSN : 0776-3824

Référence électronique

Athéna Tsingarida, Alain Duplouy, François Quantin, Kalliopi Chatzinikolaou, Emmanuel Voutiras,

Alexis D'Hautcourt, Natacha Massar, Zozie Papadopoulou, Thierry Petit, Patrick Constancio, Isabelle

Tassignon, Massimo Osanna et Nicola Cucuzza, « Chronique archéologique », Kernos [En ligne], 15 |

2002, mis en ligne le 21 avril 2011, consulté le 16 septembre 2020. URL : http://

journals.openedition.org/kernos/1395 


\section{Chronique archéologique de la religion grecque (ChronARG)}

\section{Introduction}

Voici la deuxième livraison de la Chronique archéologique de la religion grecque, dont les modalités sont identiques aux indications fournies dans le volume de 2001 (Kernos 14, p. 233-235). Elle concerne les rapports de fouilles et les publications parues en 2000 pour les régions qui ont déjà fait l'objet de la chronique de l'an dernier, et en 1999 et 2000 pour les régions qui sont traitées pour la première fois. Quant aux régions qui avaient fait l'objet d'une présentation pour l'année 1999 dans Kernos 14 (2001) et qui ne sont pas abordées ici, elles le seront pour 2000 et 2001 dans le volume 16 de Kernos en 2003.

Pour mémoire, voici l'ordre des régions dont la chronique souhaite livrer l'actualité archéologique en matière religieuse. Nous attirons votre attention sur le fait que, dans le cas des îles de l'Égée, nous avons choisi de respecter, autant que possible, l'ordre géographique des groupes d'îles, mais que, à l'intérieur de ces groupes, la présentation suit l'ordre alphabétique.

Nous sommes conscients que cet ensemble pourrait se voir élargi et des suggestions nous ont été faites en ce sens, notamment pour la Cyrénaïque. L'ampleur de la matière à traiter nous contraint néanmoins à des choix, dont rien ne dit qu'il ne seront pas à revoir dans l'avenir.

Athènes, Attique, Mégaride

Péloponnèse

Béotie, Eubée

Phocide, Locride, Étolie

Acarnanie, Épire, Illyrie méridionale, îles ioniennes

Phthiotide, Thessalie

Macédoine

Thrace

Îles de l'Égée

Crète

Chypre

Asie mineure

Grande Grèce

Sicile 
Parmi les publications générales qui touchent à l'archéologie religieuse, nous souhaiterions mentionner ici un nouveau manuel d'archéologie en langue française. Sans véritablement recourir à l'expression d' "archéologie religieuse ", celui-ci fait une place importante aux informations que fournit la recherche archéologique sur les pratiques religieuses et sur les espaces sacrés. Ainsi, après un jugement très sévère sur les études qui abordent la continuité religieuse entre le monde mycénien et la Grèce de l'époque historique, les A. présentent brièvement les données essentielles du dossier archéologique qui plaident, selon eux, en faveur d'une nette rupture (p. 57-59). La délimitation des sanctuaires et les cultes hérö̈ques sont ensuite resitués dans leur contexte historique, à savoir la genèse des cités (p. 77-82), avant que tout un chapitre (IX, p. 125-139), le plus important du point de vue de cette chronique, soit consacré à l'organisation des « espaces sacrés ». L'ambition déclarée est d'insérer l'examen des « phénomènes religieux " dans leur contexte social, à savoir celui de la cité, mais aussi d'en dresser l'histoire, une histoire conçue explicitement selon une évolution ternaire (naissance, vie et mort). Ce chapitre aborde ainsi à la fois les différentes composantes du sanctuaire, mais aussi leur évolution (y compris celle des ordres architecturaux qui ne reflète cependant pas à proprement parler l'histoire religieuse; ceux-ci auraient peut-être trouvé une place plus adéquate dans le chapitre XII, consacré aux styles et qui semble en conséquence laisser l'architecture en dehors des préoccupations stylistiques des Grecs). On mentionnera également le chapitre XI (p. 153-164) qui fait le point sur les espaces funéraires. Dans l'esprit de cette chronique - qui envisage exclusivement l'aspect rituel lié aux nécropoles -, on soulignera que ce chapitre aborde les cultes funéraires du $\mathrm{XI}^{\mathrm{e}}$ au $\mathrm{IV}^{\mathrm{e}} \mathrm{S}$. av. J.-C. à Athènes avant de proposer des synthèses très rapides sur la Crète (Éleutherna), la Macédoine (Sindos), Chypre ou encore la Lycie. Les parties consacrées au monde grec hellénistique et romain, pour leur part, ne traitent d'archéologie religieuse qu'à travers des problématiques beaucoup plus générales ou par des éclairages tangents (le "dionysisme " des rois hellénistiques, le développement de Délos à l'époque romaine, l'appropriation des centres anciens...). Répondant à une nette volonté de poser l'histoire comme un déroulement séquentiel, les $\mathrm{A}$. de ce Manuel en arrivent ainsi à interrompre parfois artificiellement des évolutions ou à aborder les mêmes espaces selon des points de vue différents en fonction de la seule chronologie. Ceci fait à la fois l'originalité du livre, clair et critique, en même temps qu'il suscitera plus d'une interrogation chez l'historien du temps long que demeure l'historien des religions.

R. Etienne, Chr. Müller, Fr. Prost, Archéologique bistorique de la Grèce antique, Paris, 2000. 


\section{Athènes, Attique, [Mégaride] (Athéna Tsingarida)}

\subsection{0 - Généralités}

- Dans un article consacré à un ensemble de skyphoi attiques, groupés par Beazley sous la Classe de Héron, I. Scheibler tente de lier l'usage de cette catégorie de vases, caractérisés par leur grande taille, à des rites cultuels pratiqués en Attique lors de certaines fêtes religieuses. L'analyse de la diffusion du matériel montre en effet une présence significative de ces skyphoi en Attique par rapport à leur exportation sur le pourtour méditerranéen. Partant de cette observation, l'A. étudie les thèmes iconographiques qui décorent ce matériel et s'interroge sur le rapport possible entre certaines scènes représentées et l'usage de cette céramique dans un contexte cultuel. De l'aveu même de l'A., cette analyse ne fournit pas d'éléments suffisants pour confirmer cette thèse. Elle souligne cependant la présence peut-être significative de scènes cultuelles agraires et de représentations d'Héraclès recevant des libations qui pourraient renvoyer soit à l'usage des skyphoi lors de festivals champêtres soit aux rites des Apatouries. L'A. mentionne, par ailleurs, le mega poterion, associé par Athénée (XI, 494) à ces fêtes, et l'identifie, pour la fin de l'époque archaïque, aux skyphoi étudiés. Même s'il est extrêmement difficile de vérifier un rapport direct entre une iconographie, en somme assez commune, et l'usage cultuel du vase, cet article a le grand mérite d'aborder cette classe d'objets suivant la problématique de leur usage en contexte attique. Cette approche, qui ne se limite pas à l'analyse stylistique ou purement iconographique du décor figuré, s'inscrit dans les recherches récentes en céramique grecque qui mettent en valeur les usages et détournements des vases en contexte grec et non grec (voir à ce sujet le chapitre III : "Diffusion et clientèle", in Céramique et peintures grecques. Modes d'emploi. Rencontres de l'École du Louvre. Actes du Colloque International 26-28.04.1995, Paris, 1999).

I. Scheibler, "Attische Skyphoi für attische Feste", $A K 43$ (2000), p. 17-41.

01.01 - Atbènes, Station Acropole (Makriyiannis) - Ie Éphorie des antiquités prébistoriques et classiques - Les fouilles de sauvetage, réalisées à l'occasion des travaux du métro athénien au S de l'Acropole, près du sanctuaire de Dionysos Eleutheros et de l'espace attenant au théâtre, ont mis au jour les fondations d'une petite construction en poros, située le long d'une rue antique traversant du $\mathrm{N}$ au $\mathrm{S}$ le secteur fouillé. P. Kalligas y voit les restes d'un autel, typologiquement proche de celui dégagé un an plus tôt sur l'angle NE du péribole du sanctuaire de Dionysos. Ces structures sont identifiées par le fouilleur aux autels érigés aux carrefours et consacrés à des divinités telles qu'Apollon Agyieus, Hermès ou Hécate. Aucune inscription ne vient cependant confirmer cette hypothèse.

Sur plusieurs secteurs du site, le fouilleur mentionne également la présence de nombreuses fosses comportant des ossements de petits animaux calcinés et des offrandes de vases miniatures également brûlés. Ces pyrai de cérémonie, à usage privé et de caractère chthonien, devaient soit célébrer la construction ou la réutilisation de certains bâtiments soit protéger du mauvais œeil. Alors que les fouilles de l'Agora et de l'Aréopage situaient cette pratique entre le $v^{\mathrm{e}}$ et le III $^{\mathrm{e}} \mathrm{s}$. av. J.-C., les trouvailles de Makriyianni permettent d'étendre la fourchette chronologique de cet usage jusqu'au premier quart du $\mathrm{I}^{\text {er }} \mathrm{s}$. av. J.C. Dans le catalogue de l'exposition consacrée aux fouilles du métro, P. Kalligas publie un exemple de ces ensembles, la pyrè $\mathrm{n}^{\circ} 7$, datée du $\mathrm{I}^{\mathrm{er}} \mathrm{s}$. av. J.-C.. et découverte dans une pièce appartenant à une maison.

Parmi les objets mis au jour lors de ces fouilles, on doit mentionner une statuette à trois faces d'Hécate du $\mathrm{I}^{\mathrm{er}} \mathrm{s}$. av. J.-C. ( $\mathrm{n}^{\circ} 41$ dans le catalogue), qui provient soit de ces petits sanctuaires des carrefours soit d'un culte privé (souvent célébré à l'entrée des maisons) et une lampe anthropomorphe en terre cuite représentant une divinité enfantine (Téles- 
phoros) de la fin du $\mathrm{II}^{\mathrm{e}}-$ début du $\mathrm{II}^{\mathrm{e}}$ s. av. J.-C. $\left(\mathrm{n}^{\circ} 62\right.$ dans le catalogue), découverte dans le puit 11 de ce secteur.

P. Kalligas, "The Acropolis station", in The City beneath the City. Finds from the Excavations for the Metropolitan Railways of Atbens, Exposition au Musee Cycladique 29.02.2000 - 31.01.2001, Athènes, 2000, p. 32-33, 74, 92-93.

01.02 - Athènes, Céramique - III Éphorie des antiquités prébistoriques et classiques Les fouilles réalisées à l'occasion des travaux pour la station de métro du Céramique, finalement déplacée, ont révélé une section du cimetière sous la route actuelle de l'Hiera Odos à sa jonction avec la rue du Pirée. Dans ce secteur, on mentionne la présence d'un dépôt votif, taillé dans le rocher et contenant de nombreux vases et figurines portant des traces de feu. La présence de figurines majoritairement féminines et de terres cuites sous forme de mains (ex-voto ?) indiquerait un usage rituel funéraire sans doute lié à une tombe de femme.

E. Baziatopoulou-Valavani, I. Tririgoti-Diakotou, "Céramique", in The City beneath the City (supra 01.01), p. 271.

01.03 - Atbènes, station Prophitis Daniil (sur la ligne 3 du métro athénien, vers Aigaléo) - III Éphorie des antiquités prébistoriques et classiques - Lors de fouilles de sauvetage effectuées le long de l'Hiera Odos pour la construction de la station Prophitis Daniil à l'occasion des travaux du métro athénien, on a découvert une voie antique et un dépôt contenant du matériel. A trois mètres de profondeur, les fouilles ont mis au jour une section de l'antique Hiera Odos avec son mur $\mathrm{N}$ d'analemma. Au $\mathrm{N}$ de ce segment, situés à une plus grande profondeur, subsistaient des lambeaux d'une voie encore plus ancienne composée de petits gallets, en partie détruits par l'installation d'un dépôt circulaire. Le matériel contenu dans ce dépôt, constitué essentiellement de kernoi éleusiniens, reflèterait le caractère votif de cette structure. La chronologie du dépôt, vraisemblablement associé à un sanctuaire, indiquerait que ce dernier avait fonctionné depuis l'époque archaïque jusqu'à la fin de l'époque classique. Il est par ailleurs probable que le mur d'analemma de l'Hiera Odos appartenait à une partie du péribole initial du sanctuaire dont on n'a pas encore trouvé de traces. L'importance de ces découvertes a entrainé le déplacement de cet arrêt du métro pour permettre la poursuite des fouilles.

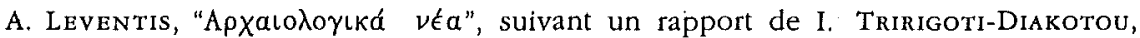

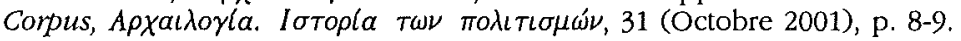

01.04 - Athènes, Avenue Herodotou Attikou - III Éphorie des antiquités prébistoriques et classiques - On a découvert et publié une tête archaique en bronze intégrée depuis l'antiquité dans un bloc rectangulaire, qui devait appartenir au grand bâtiment d'époque romaine, situé aux abords $O$ du Jardin Național. Ce montage devait sans doute remplir une fonction apotropaïque.

O. Zachariadou, "Sondage Herodotou Attikou", in The City beneath the City (supra 01.01), p. 198-199.

01.05 - Atbènes, Koukaki (rue Petmeza) - III Éphorie des antiquités prébistoriques et classiques - Les fouilles de sauvetage effectuées pour la construction du métro entre avril 1996 et mai 1997 ont mis au jour un dépôt votif, situé au croisement des rues Petmeza et Phalirou. Ce dépôt, fort perturbé, contenait des fragments de vases à figures rouges de qualité, datant du début du $v^{\mathrm{e}}$ s. Il appartient à un secteur entouré d'un enclos funéraire qui a livré des tombes des époques archaïque et paléochrétienne.

E. Lygouri-Tollia, "Petmeza Shaft", in The City beneath the City (supra 01.01), p. 119.

01.06 - Atbènes, Zappeion (avenue Amalias 2)-III Éphorie des antiquités prébistoriques et classiques - Dans le catalogue de l'exposition consacrée aux trouvailles des fouilles du métro, $\mathrm{O}$. Zachariadou mentionne la construction trapézoïdale et l'autel 
d'époque classique (déjà décrits dans CbronARG 2001, 01.04) qu'elle identifie à un des sanctuaires consacrés près de l'llissos et dédié soit aux Muses, soit aux Nymphes et à Achéloos, soit encore à Pan. Elle annonce, par ailleurs, le compte rendu de ces fouilles dans la II ${ }^{\mathrm{e}}$ Rencontre scientifique de la III ${ }^{\mathrm{e}}$ Éphorie en février 1999 (à paraître).

O. Zachariadou, "Zappeion", in The City beneath the City (supra 01.01), p. 133-135.

01.07 - Kalamos - II Éphorie des antiquités prébistoriques et classiques - On mentionne la découverte de deux reliefs votifs datant du $v^{e}-{ }^{-} v^{e} s$, av. J.-C., remployés dans le sol de la nef de l'église cimétériale d'Agios Nikolaos.

$$
A D 50 \text { (1995) [2000], B'1, p. 73-74. }
$$

01.08 - Skala Oropou - Société archéologique d'Athènes - A. Mazarakis-Ainian a examiné en profondeur le bâtiment, dégagé en 1985 et situé à l'O des installations d'époque géométrique. La fouille dans le secteur $S$ de ce complexe, identifié par le fouilleur à un camp militaire, a révélé l'existence, sous la tour $\mathrm{S}$, de deux constructions ellipsoüdales d'époque géométrique et d'une structure en pierre et en argile $(3 \times 9 \mathrm{~m})$ qui contenait des cendres et de nombreux ossements calcinés d'animaux, sans doute des restes de sacrifices.

A. Mazarakis-Ainian, Ergon 47 (2000), p. 47.

01.09 - Rhamnonte - Société archéologique d'Athènes - À l'occasion de la poursuite des fouilles du fort à l'E du théâtre, V. Petrakos rapporte la découverte d'une plaque qui avait appartenu à un autel en marbre. Les témoignages matériels du culte de Dionysos sont nombreux dans le fort mais la découverte de cette plaque, qui porte une inscription la consacrant au dieu, nous révèle qu'à l'intérieur du petit temple dédié à la divinité devait se trouver un autel en marbre, richement décoré de motifs floraux.

V. Petrakos, Engon 47 (2000), p. 23.

01.10 - Gerakas (Stavros) - II Éphorie des antiquités prébistoriques et classiques - Une partie de mur en brique pilée, formant un angle avec un autre mur taillé dans le rocher, a été mis au jour dans la rue Zalongou. Ces deux murs composent la moitié $\mathbf{E}$ d'une salle hypostyle, qui doit être associée aux bâtiments civiques du sanctuaire d'Athéna Pallènè, dont le temple est situé $50 \mathrm{~m}$ à l'ouest de cette construction. Au croisement des rues Androutsou et Zalongou, on a continué les fouilles des fondations du temple, découvert en 1994 (voir ChronARG 2001, 01.10). On a ainsi dégagé les côtés $\mathrm{O}$ et $\mathrm{N}$ de la plateforme du bâtiment, l'aile $\mathrm{O}$, les fondations $\mathrm{E}$ et $\mathrm{N}$ des murs de la cella et le mur $\mathrm{N}$ du prodomos. Parmi le matériel, on mentionne le présence de nombreuses figurines d'oiseaux et une quantité importante de céramique d'époque classique.

$$
\text { M. Platonos-Giota, } A D 50 \text { (1995) [2000], B'1, p. 67-68. }
$$

01.11 - Thorikos, Kalivia - II Éphorie des antiquités prébistoriques et classiques - En 1990, les fouilles du service archéologique dans la région de Kitéza ont mis au jour un petit complexe composé d'un bâtiment à pièce unique et d'un péribole. La présence d'un kernos indiquerait que cet ensemble serait un sanctuaire consacré à Déméter dont l'usage familial serait indiqué par sa situation, au milieu d'un habitat.

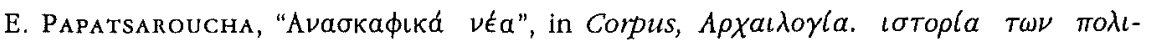
$\tau \iota \sigma \mu \omega \dot{\nu}, 31$ (Octobre 2001), p. 22-23.

01.12 - Salamine (Peristéria) - Université de Ioannina - Dans son rapport, Y.G. Lolos mentionne la foulle (de 1998 à 2000) du sanctuaire de Dionysos, situé à Peristéria sur la côte $\mathrm{S}$ de Salamine. Ce sanctuaire, en activité durant les $\mathrm{III}^{\mathrm{e}}-\mathrm{II}^{\mathrm{e}} \mathrm{s}$. av. J.-C., est placé devant une source naturelle, proche de la "grotte d'Euripide" (voir Dodoni 26 [1997], p. 287$326)$. Il est constitué d'une construction rectangulaire $(2,50 \times 2,30 \mathrm{~m})$, servant de lieu de 
culte doté d'une banquette en $\Gamma$, et d'un réservoir d'eau $(3,40 \times 3,20 \mathrm{~m})$ orienté d'O en $\mathrm{E}$. Parmi le matériel dégagé, le fouilleur signale deux fragments en marbre ayant appartenu à une statue de Priape ou de Pan et à une statue de Dionysos, de la céramique cnidienne et rhodienne, des amphores "gréco-italiotes " et de Kos, des fragments de lèvres discoïdes et de ruches cylindriques dont quatre exemplaires portaient en sceau la lettre ' $E$ ', rappelant la lettre initiale d'Euripide. Le fouilleur considère que ce sanctuaire rural, situé à proximité de la «grotte d'Euripide » devait être consacré au culte combiné de Dionysos et d'Euripide. Après la destruction de ce sanctuaire et le remplissage du secteur pour niveler l'ensemble de la surface à l'époque romaine, ce culte aurait été transféré au II $^{\mathrm{e}}$ s. av. J.-C. dans la grotte, qui deviendra un haut-lieu de pèlerinage en l'honneur du tragique grec. Une publication complète de ce petit complexe (architecture, histoire, matériel) est annoncée dans Dodoni 29 (2000).

Y.G. LoLos, AR 2000-2001 [2001], p. 15-16.

\section{Péloponnèse (Alain Duplouy)}

\section{Corinthie}

02.01 - Corinthe - École américaine d'Athènes - En attendant la synthèse par les soins de R.S. Stroud et de N. Bookidis, on signalera la publication, par G. Merker, des figurines en terre cuite du sanctuaire de Déméter et Koré, fouillé entre 1961 et 1975 sur l'Acrocorinthe. Les découvertes archaïques feront l'objet d'un fascicule séparé.

G.S. Merker, Corinth. Results of Excavations Conducted by the American School of Classical Studies at Athens. Volume XVIII, Part IV. The Sanctuary of Demeter and Kore. Terracotta Figurines of the Classical, Hellenistic, and Roman Periods, Princeton, 2000.

- N. Bookidis publie une cinquantaine de fragments de sphinx en terre cuite, découverts lors des fouilles du temple d'Apollon à Corinthe de 1968 à 1976. Se rapportant probablement à des acrotères, toutes ces pièces se situent entre le $\mathrm{vi}^{\mathrm{e}}$ et le milieu du $\mathrm{v}^{\mathrm{e}} \mathrm{s}$. et sont d'importants témoins de la plastique corinthienne archaïque.

N. Bookidis, "Corinthian Terracotta Sculpture and the Temple of Apollo", Hesperia 69 (2000), p. 381-452.

02.02 - Isthmia - École américaine d'Atbènes, Université de Chicago - La campagne de 1999 fut essentiellement consacrée à l'examen du matériel en vue de sa publication. Dans ce cadre, J. Hanges a repris l'étude des dépôts votifs du sanctuaire du héros Palaimon, tout en mettant en évidence l'existence d'un adyton antérieur à l'époque d'Antonin.

E.R. Gebhard, $A R$ 1999-2000 (2000), p. 26.

02.03 - Galataki - En 1957 et 1958, N. Verdelis effectuait la fouille d'un riche dépôt votif archaïque sur le site de l'antique Solygeia; R. Lorandou-Papantoniou en publie à présent le matériel. Les offrandes avaient été déposées dans la chambre d'une petite tombe mycénienne ruinée de l'HR II. Le dépôt semble toutefois devoir être associé à un petit temple absidial, repéré et naguère fouillé à une cinquantaine de mètres au N. La tombe a livré quantité de vases miniatures du subgéométrique à la fin $\mathrm{du}_{\mathrm{vI}}{ }^{\mathrm{e}} \mathrm{s}$., ainsi qu'une cinquantaine de figurines féminines. Le sanctuaire pourrait avoir été le siège d'un culte à Déméter et Koré (bien qu'Héra ne soit pas exclue), dont la vénération se serait étendue aux tombes mycéniennes voisines, en signe de respect des morts.

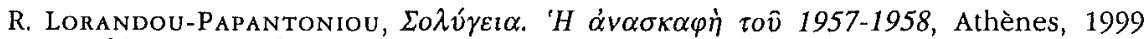

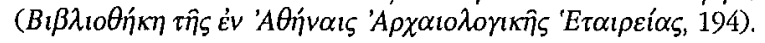


02.04 - Némée - École américaine d'Atbènes, Université de Californie (Berkeley) - En 1999, les travaux se sont notamment concentrés au NO du sanctuaire du héros Opheltès. Le richesse des niveaux de la fin de l'époque classique et du début de l'époque hellénistique atteste une activité importante dans cette zone, dont la nature ne peut toutefois pas encore être précisée.

S.G. MilLer, $A R$ 1999-2000 (2000), p. 26-28.

02.05 - Plaine de Phlionte - Université de Heidelberg - En 1998 et 1999, l'Institut de pré- et protohistoire a mené un programme de prospection archéologique dans la plaine de Phlionte. On relèvera qu'un dépôt votif (figurines en terre cuite et fragments architectoniques) a été localisé sur les pentes du mont Koukouyera.

G. Touchass, BCH 123 (1999), Chron. p. 677; BCH 124 (2000), Chron., p. 796.

\section{Argolide}

02.06 - Chonikas - IVe Éphorie des antiquités prébistoriques et classiques - La découverte de plusieurs éléments d'architecture à proximité de l'église des Saints-Anargyres laisse supposer l'existence d'un site antique; un pilier inscrit avec une dédicace de la première moitié du $\mathrm{v}^{\mathrm{e}} \mathrm{s}$. invite à y voir un sançtuaire de Zeus.

Chr. Piteros, $A D 50$ (1995) [2000], B'1, p. 109-110.

02.07 - Argos - IVe Éphorie des antiquités préhistoriques et classiques - En 1988, la IVe Éphorie procédait à la fouille d'un espace situé près du rempart SE de la ville d'Argos, à $700 \mathrm{~m}$ au NE de l'agora. La fouille avait alors livré quantité de figurines en terre cuite et de vases miniatures ainsi que des éléments de terres cuites architecturales, suggérant l'existence d'un culte à l'époque archaïque. Deux nouvelles campagnes, en 1998 et 1999 , ont permis de préciser la situation. Elles ont livré de nombreux tessons de vases à boire (cratères, skyphoi, coupes), des figurines de déesse trônant (que les fouilleurs suggèrent d'identifier à Héra), ainsi que quelques statuettes de cavaliers. Dans les niveaux inférieurs, une rigole à libation associée à un tumulus et à une tombe de l'époque géométrique pourrait en outre indiquer l'existence d'un culte héroïque antérieur à la fondation du sanctuaire.

K. Barakari-Gleni et E. Peppa-Papaloannou, "A New Cult Place of the Archaic Period in Argos", in R.F. Docter, E.M. Moormann (éds), Proceedings of the XVth International Congress of Classical Archaeology, Amsterdam, 1999, p. 62-65; G. TouchaIs, BCH 124 (2000), Chron., p. 800 (avec informations complémentaires sur la fouille de 1999).

- Une fouille d'urgence à l'E de la ville antique (terrain des frères Apostolopoulos) a mis en évidence une aire dallẹe avec système d'égout, puits et fosses-dépotoirs, appartenant peut-être à un petit sanctuaire hypethre de quartier $\left(\mathrm{IV}^{\mathrm{e}}-\mathrm{III}{ }^{\mathrm{e}} \mathrm{s}\right.$. av. J.-C.).

ЕҮППО 3 (1999), р. 88.

02.08 - Tirynthe - Institut archéologique allemand, IV Éphorie des antiquités prébistoriques et classiques - En 1999, une fouille d'urgence dans la zone NE de la ville basse a révélé, outre de nombreux vestiges mycéniens, un dépôt votif (daté aux environs de 600 av. J.-C.) contenant des tessons de vases miniatures, de nombreux fragments de figurines zoomorphes ainsi que des éléments de parure en bronze. Par ailleurs, à la suite de nouvelles fouilles conduites en 1998, J. Maran démontrait que le bâtiment à antes construit dans la moitié $\mathrm{E}$ du Grand mégaron mycénien était en réalité un second mégaron, construit dans les ruines du précédent. L'édifice fut rapidement abandonné dans la dernière partie de l'HR IIIC. Face à l'absence totale de vestiges ultérieurs, il renonçait en outre à considérer la structure à antes comme un temple géométrique et 
archaïque, contrairement à l'hypothèse naguère formulée par Dörpfeld (et encore admise par Mazarakis-Ainian).

"Jahresbericht 1999", $A A$ (2000), p. 574; J. Maran, "Das Megaron im Megaron. Zur Datierung und Funktion des Antenbaus im Mykenischen Palast von Tiryns", $A A$ (2000), p. 1-16.

02.09 - Asiné - IVe Épborie des antiquités prébistoriques et classiques - Dans la nécropole mycénienne d'Asiné, la fouille de la tombe à chambre 19, en usage de l'HR IIIIIA1 à l'HR IIIC, a livré quelques tessons d'époque géométrique. Cette découverte pourrait dénoter une vénération momentanée et atteste, à tout le moins, l'accessibilité de la tombe à l'époque géométrique.

Z. Aslamatzidou, $A D 50$ (1995) [2000], B'1, p. 103-104.

02.10 - Epidaure - Société archéologique d'Athènes - En 2000, à côté des travaux d'anastylose de l'autel d'Apollon Maleatas, V. Lambrinoudakis a mis au jour de nouveaux vestiges du péribole hellénistique qui entourait la colline où furent découverts les années précédentes des bâtiments préhistoriques; la nature de ce temenos n'est toutefois pas encore connue.

V. Petrakos, Engon 47 (2000), p. 52.

02.11 - Dimaina - IV Éphorie des antiquités prébistoriques et classiques - En 1995, le Service archéologique a récupéré dans l'église Agios Georgios un perirrbanterion, dont la dédicace révèle l'existence d'un sanctuaire d'Artémis Choria dans les environs ( $\mathrm{IV}^{\mathrm{e}}-\mathrm{III}^{\mathrm{e}} \mathrm{s}$.).

Chr. Piteros, $A D 50$ (1995) [2000], B'1, p. 113.

\section{Laconie}

\subsection{2 - Généralités}

- Fr. Sirano dresse un bilan des découvertes archéologiques récentes effectuées en Laconie, qui ont permis ces dernières années la localisation de plusieurs lieux de culte et ont apporté un certain nombre de précisions quant aux sites déjà connus. La récurrence des offrandes athlétiques dans les sanctuaires du territoire laconien et les quelques indications de la tradition littéraire permettent de restituer un véritable parcours agonistique interne : les compétitions, tantôt réservées aux andres tantôt aux paides, paraissent en place au plus tard à la fin de l'époque archaïque. On notera en outre que les concours réservés aux paides concernaient premièrement des sanctuaires situés sur la frange orientale de l'État spartiate, répondant aux principes de l'agogè qui tend à confiner temporairement les futurs citoyens dans des marges sociales ét territoriales. L'A. conclut à un système d'intégration rituelle du territoire laconien dans l'État spartiate à travers une série de fêtes et de cultes qui impliquent des sanctuaires implantés dans des zones stratégiques.

Fr. Sirano, "Fuori da Sparta. Note di topografia lacone: recenti studi e nuovi dati dal territorio", ASAA 58-59 (1996-1997) [2000], p. 397-465.

02.13 - Tsakona - École anglaise d'Atbènes - En 1989, l'École anglaise d'Athènes procédait à une fouille de sauvetage sur le sanctuaire de Tsakona, dont des rapports préliminaires avaient été présentés dans $A B S A 85$ (1990), p. 15-35 et $\Lambda \alpha \kappa \omega v ı \kappa \alpha i ́ ~ \Sigma \pi o v \delta \alpha i ́ 10$ (1990), p. 276-295. Le matériel, déposé au musée de Sparte et dans l'apothèque d'Aphysou, a finalement pu être étudié en 1999. Les activités cultuelles présentent deux aspects, qui ne sont peut-être pas contemporains. D'une part, l'offrande d'armes (lances, pointes de flèche, boucliers) et d'objets liés aux activités gymniques (haltère et céramique) dénotent un culte rendu à une divinité masculine non-identifiée. D'autre part, une quantité importante de statuettes masculines ithyphalliques souvent grotesques (avec des traits 
simiesques), des figurines féminines nues écartant les jambes ainsi que des petits couteaux de bronze très effilés (scalpels ?) ont trait, selon le fouilleur, à des pratiques liées à la virilité et la fécondité. Toute activité semble cesser au début de l'époque hellénistique, si pas auparavant. Un article pour l'ABSA est en préparation, en attendant la publication complète du matériel.

H.W. Catling, $A R$ 1999-2000 (2000), p. 43.

02.14 - Geraki (ancienne Geronthrai) - Université d'Amsterdam, Institut néerlandais d'Athènes - Concernant la campagne de l'été 1999 , on signalera tout au plus, d'un point de vue cultuel, l'acquisition auprès des villageois d'une gargouille en terre cuite en forme de tête de lion, qui semble dater de la fin du $\mathrm{Iv}^{\mathrm{e}}$ ou du début du ${ }_{i I}{ }^{\mathrm{e}} \mathrm{s}$. et qui pourrait avoir appartenu au toit d'un temple.

J. Crouwer et al., "Geraki. An Acropolis Site in Lakonia. Preliminary Report on the Fifth Season (1999)", Pbaros 7 (1999), p. 21-50.

02.15 - Cythère - Service archéologique - Au lieu-dit Chorokambos, une caverne a livré de nombreux tessons du $\mathrm{v}^{\mathrm{e}}$ s., dont deux portaient le graffite 'A $\lambda \lambda^{\mathrm{e} \alpha} \varsigma_{\text {, }}$, attestant la diffusion du culte à la déesse arcadienne et laconienne Aléa, vraisemblablement importé dans l'île lors de l'occupation laconienne au $\mathrm{vI}^{\mathrm{e}}$ s. Par ailleurs, une intervention de sauvetage dans la grotte de Chousti, fréquentée du Néolithique Final à l'époque médiévale, a révélé une abondante céramique classique, dédiée à une divinité indéterminée. Enfin, sur l'îlot d'Antidragonara, les archéologues de la $\mathrm{II}^{\mathrm{e}}$ Éphorie des antiquités préhistoriques et classiques ont mis au jour les restes d'un petit sanctuaire en usage du début du $\mathrm{II}^{\mathrm{e}}$ à la fin du $\mathrm{I}^{\text {er }} \mathrm{s}$. av. J.-C, probablement consacré à Poséidon Gaieochos et fréquenté par des marins.

G. TOUChaIs, BCH 124 (2000), Chron., p. 818.

\section{Messénie}

02.16 - Messène - Société archéologique d'Atbènes - En 1997, les archéologues découvraient une base de statue dédiée par la cité à Dionysios, fils d'Aristoménès, dont l'inscription précise qu'il fut honoré comme héros après sa mort. En 1998, comme déjà annoncé l'an dernier (cf. CbronARG 2001, 02.11), la principale découverte cultuelle fut celle d'un dépôt votif dans l'angle NO du gymnase se rapportant vraisemblablement au berôon du Messénien Aristoménès, dont $\mathrm{P}$. Themelis livre à présent un rapport détaillé. Rassemblant les exemples, le fouilleur dresse du reste une synthèse des différents cultes

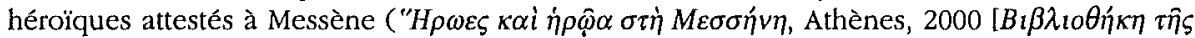

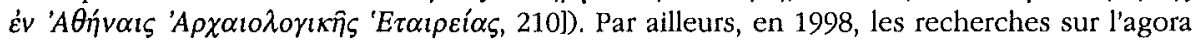
ont permis de mettre en évidence de nombreux éléments d'architecture appartenant vraisemblablement au grand temple dorique de Zeus Sôter et au temple de Poséidon. Les temples de Cybèle, d'Aphrodite et de Laphria, également signalés par Pausanias, n'ont eux pas encore été localisés avec certitude, quoique la découverte de deux statues d'Aphrodite au $\mathrm{N}$ du gymnase fournisse un indice.

\section{P. Themelis, PAAH 152 (1997), p. 79-113; PAAH 153 (1998), p. 89-126.}

- En 2000, les efforts de P. Themelis se sont une nouvelle fois concentrés sur le "berôon d'Aristomenès ». De nouvelles offrandes (statuettes, pinakes, restes osseux de sacrifices) sont apparues dans la fouille d'une fosse; à proximité de celle-ci, les archéologues ont mis en évidence une rigole probablement destinée à recevoir les offrandes liquides. On notera en outre la découverte dans une riche villa $d u u^{\mathrm{e}}$ ou du $\mathrm{IV}^{\mathrm{e}} \mathrm{s}$. d'une mosaïque représentant Dionysos, Ariane et un fidèle (le propriétaire de la maison ?) baisant la main de la divinité. Selon le fouilleur, ce jeu de main traduirait en image l'opposition idéologique des cultes païens à la diffusion du christianisme. 
V. Petrakos, Ergon 47 (2000), p. 58-70.

02.17 - Ano Melpeia - VII Éphorie des antiquités prébistoriques et classiques - En 1995, les archéologues ont repéré sur la colline de Pétroula (lieu-dit Agios Ilias) les fondations d'un temple qui pourrait dater de l'époque classique.

G. Hatzi-Spiliopoulou, $A D 50$ (1995) [2000], B'1, p. 186.

\section{Élide}

02.18 - Prassidaki - VII Éphorie des antiquités prébistoriques et classiques - En 1999, X. Arapoyanni a entamé la fouille du temple dorique d'Athéna repéré en 1971. La fouille de la cella a permis de mettre au jour quantité de terres cuites votives et d'objets en bronze des époques archaique et classique.

ЕҮППО 3 (1999), p. 99; G. Touchais, BCH 124 (2000), Chron, p. 830.

02.19 - Kombothékra - Institut archéologique allemand - Faisant suite aux publications de U. Sinn (MDAI(A) 93 [1978], p. 45-82 et 91 [1981], p. 25-71), H. Gregarek livre l'étude complète des figurines en terre cuite archäques et classiques du petit sanctuaire rural d'Artémis Limnatis. On notera qu'à la différence des statuettes géométriques, qui figurent le plus souvent des hommes et des animaux, les offrandes archaïques et classiques se composent essentiellement de figurines féminines. La plupart de ces objets apparaissent comme des productions locales, même si certaines importations (rhodiennes, béotiennes, athéniennes et argiennes) se laissent aisément identifier. On signalera par ailleurs la parution d'une étude synthétique sur les cultes d'Artémis Limnatis par Y. Morizot.

H. GregareK, "Das Heiligtum der Artemis Limnatis bei Kombothekra. IV. Die Terrakotten der archaischen und klassischen Zeit", MDAI(A) 113 (1998), p. 75-102; Y. Morizot, "Artémis Limnatis. Sanctuaires et fonctions", in R.F. Docter, E.M. MOORMANN (éds), Proceedings of the $X V^{t b}$ International Congress of Classical Arcbaeology, Amsterdam, 1999, p. 270-272.

02.20 - Olympie - Institut archéologique allemand - On signalera la parution d'un nouveau volume des Olympiscbe Forscbungen, consacré à la céramique archaïque découverte du $\mathrm{xIx}^{\mathrm{e}}$ s. à nos jours par les archéologues allemands. Sont désormais publiés les vases laconiens (E. Kunze-Götte), corinthiens (J. Heiden) et attiques à figures noires (J. Burow). Dans la mesure où l'essentiel de cette céramique provient - dans le meilleur des cas - de couches de remblais particulièrement hétérogènes, elle ne pouvait être présentée que par ordre chronologique; on n'y trouvera donc malheureusement guère de réflexions sur sa fonction ou sa signification dans l'enceinte sacrée d'Olympie.

E. Kunze-Götre, J. Heiden et J. Burow, Archaische Keramik aus Olympia, Berlin, 2000 (Olympische Forschungen, 28).

\section{Achaïe}

02.21 - Koumari Aigialeias - $V^{e}$ Éphorie des antiquités préhistoriques et classiques - En 1995 fut découvert au lieu-dit Trapéza un temple archaïque de la deuxième moitié du $\mathrm{vI}^{\mathrm{e}}$ s., dont le dégagement s'est poursuivi en 1999.

A.G. Vordos, $A D 50$ (1995) [2000], B'1, p. 238-239; EYППO 3 (1999), p. 96.

02.22 - Ano Mazaraki - VIe Éphorie des antiquités prébistoriques et classiques - En 1995, la septième campagne de fouille sur le sanctuaire d'Artémis a enfin permis de dégager l'ensemble de la structure, qui se présente désormais comme un hekatompedon périptère du Géométrique Récent $(34,40 \times 11 \mathrm{~m})$ doté d'une double abside, en arrière mais aussi en façade du bâtiment. La découverte la plus significative de cette campagne fut en 
effet la mise en évidence d'un prostôon en demi-cercle. L'édifice fut détruit dans la première moitié du $\mathrm{Iv}^{\mathrm{e}} \mathrm{s}$. av. J.-C. à la suite d'un tremblement de terre.

M. Petropoulos, $A D 50$ (1995) [2000], B'1, p. 220-225.

\section{Arcadie}

02.23 - Mantinée - Ve Éphorie des antiquités prébistoriques et classiques - Le sanctuaire archaïque de Poséidon Hippios, l'un des plus importants lieux de culte d'Arcadie, a une nouvelle fois retenu l'attention des archéologues grecs en 1999. Les fouilles de cette année ont livré des éléments d'architecture, des monnaies et quelques inscriptions.

ЕҮППО 3 (1999), р. 95.

02.24 - Pbigalie (Kourdoubouli) - Société archéologique d'Athènes - En 1997, $\mathrm{X}$. Arapogianni a poursuivi ses travaux sur le temple d'Athéna et de Zeus Sôter. La campagne a livré de nouvelles inscriptions (dédicaces et décrets) datant $\mathrm{du}_{\mathrm{rv}}{ }^{\mathrm{e}}$ au I $\mathrm{I}^{\mathrm{er}} \mathrm{s}$. av. J.C., qui confirment l'importance du sanctuaire pour la cité de Phigalie. Outre des vestiges de l'Âge du Bronze sous le sol du pronaos et un matériel votif approprié au culte d'une divinité féminine, la fouille a livré une épingle en bronze archaïque (désignée dans l'inscription par $\ddot{\alpha} \rho \delta 1 \varsigma$ ) dédiée à Athéna (lettres de la fin du ${ }^{\mathrm{e}}{ }^{\mathrm{e}}$ s.). En 1998, la fouille a permis de préciser la chronologie du culte. Il est à présent établi que le niveau de sol découvert à l'intérieur de la cella appartient à une phase archaïque du temple et est contemporain des murs les plus anciens de l'édifice, mis en évidence de part et d'autre du socle de la statue de culte.

X. Arapogianni, PAAH 152 (1997), p. 115-120; PAAH 153 (1998), p. 127-128.

02.25 - Lousoi - Institut autrichien d'Athènes - Les activités se sont poursuivies en 1999 sur le «bâtiment Est », dont la structure a été totalement dégagée, révélant un édifice

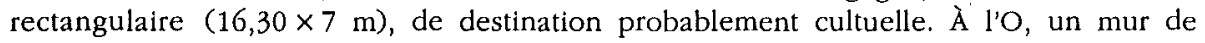
refend réservait un vestibule de $2,80 \mathrm{~m}$ de profondeur. Le mur $\mathrm{E}$ ne comportant manifestement aucune ouverture, l'entrée se faisait par l'O. Jusqu'à présent daté de l'époque archaïque, le bâtiment se voit désormais fermement situé au $\mathrm{IV}^{\mathrm{e}} \mathrm{s}$. La découverte d'un lécythe à cannelures du milieu du $\mathrm{Iv}^{\mathrm{e}} \mathrm{s}$. dans une couche d'argile contemporaine de la fondation offre un terminus post quem à la construction de l'édifice. Par ailleurs, la couche de destruction de la toiture a également livré des offrandes archaïques (une protomé féminine archaïque, un fragment de perirrbanterion corinthien tardo-archaïque) et un couvre-joint de type laconien de la fin du $v^{e}{ }^{e}$ ou du début du $v^{e} s$., qui attestent l'existence d'un édifice antérieur au temple d'Artémis (construit vers 300 av. J.-C.) et au "bâtiment Est », ainsi que l'utilisation cultuelle ancienne de l'ensemble du plateau.

V. Mitsopoulos-Leon, $A R$ 1999-2000 (2000), p. 38; ÖJb 69 (2000), p. 387-388.

02.26 - Stymphale - University of British Columbia - H. Williams signale la découverte d'un temple d'ordre dorique jusqu'alors inconnu situé à environ $2 \mathrm{~km}$ au $\mathrm{N}$ de la cité antique. En 1999, les recherches sur le sanctuaire d'Athéna se sont poursuivies; les découvertes - parmi lesquelles de nouvelles stèles aniconiques - témoignent d'une activite cultuelle importante vers la fin du $\mathrm{rv}^{\mathrm{e}} \mathrm{s}$., probablement juste avant la prise de la ville par les troupes de Cassandre en 311. Le sanctuaire paraît finalement abandonné vers le milieu du $\mathrm{II}^{\mathrm{e}}$ s., sans doute à l'époque de la destruction de Corinthe par Mummius.

H. Williams, "Excavations at Stymphalos, 1996-1999", AJA 104 (2000), p. 360; AR 19992000 (2000), p. 28-29; G. TouchaIs, BCH 124 (2000), Cbron., p. 796-797. 


\section{[03. Béotie, Eubée]}

\section{[04. Phocide, Locride, Étolie]}

\section{Acarnanie, Épire, Illyrie méridionale, îles ioniennes (François QuANTIN)}

\section{Acarnanie}

05.01 - Drymonas - VTe Éphorie des antiquités prébistoriques et classiques - Poursuite des recherches sur le sanctuaire rural d'Artémis découvert en 1993 au lieu-dit Drymonas Archontochôriou à l'E de Mytikas dans l'arrière-pays (ChronARG 2001, 05.02). À l'intérieur du petit temple les fouilleurs ont identifié une couche de destruction composée de tuiles plates. Un dépôt $(12 \times 15 \mathrm{~m})$, situé immédiatement en contrebas du sanctuaire au $\mathrm{S}$, contenait une très grande quantité de fragments de figurines en terre cuite et de statuettes en pierre, des bases de statuettes, des tuiles corinthiennes estampillées ( $A \Lambda$ YZEI $\Omega N$ ), des monnaies et de nombreux tessons de céramique, dont des vases à parfum. Le matériel est daté entre le Ive s. av. J.-C. et le $\mathrm{II}^{\mathrm{e}}$ ap. Il serait intéressant de savoir à l'avenir si ce "dépôt » correspond à une fosse votive, ou bien si le matériel, votif sans aucun doute, appartient à la couche de destruction du sanctuaire bien observée à l'intérieur du temple, ce que suggère le caractère tardif de certaines trouvailles et la présence de tuiles (pour ce type de distinctions, $c f$. T. Hackens, "Favisae", in Études étrusco-italiques. Mélanges pour le $25^{e}$ anniversaire de la chaire d'Étruscologie à l'Université de Louvain, Louvain, 1963, p. 71-99). L'US est-elle composée d'un matériel déposé, ou bien dispersé ? D'autre part, les timbres sur tuile indiquent que le sanctuaire est situé sur le territoire d'Alyzeia, dont

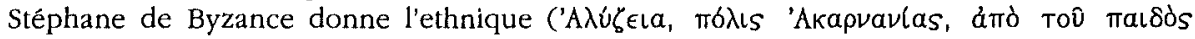

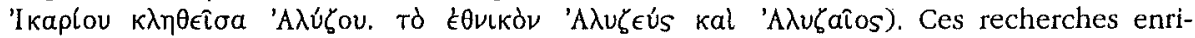
chissent donc notre connaissance du panthéon local d'Alyzeia, connu surtout par des bas-reliefs ( $c f$. W. Kovacsovics, "Zu drei Baudenkmälen aus Alyzia", MDAI(A) 97 [1982], p. 204-210, et T.D. Boyd, "The Reliefs at Kastri near Alyzia in Akarnania", MDAI(A) 100 [1985], p. 327-331).

G. Touchais, $B C H 123$ (1999) [2000], Chron., p. 723; L. Kolonas, AD 51 (1996) [2001], B'1, p. 241.

05.02 - Stratos - VIe Éphorie des antiquités prébistoriques et classiques, Institut finlandais - Pendant l'été 2000, dans le cadre des recherches menées sur Stratos et sa région, l'étude du temple périptère de Zeus a été reprise ( $c f$. F. Courby et Ch. Picard, Recherches archéologiques à Stratos d'Acamanie, Paris, 1924). Dans la perspective de la restauration - « reconstruction»- de ce grand temple dorique inachevé, il était nécessaire d'enregistrer tous les fragments d'architecture afin de fonder une réflexion métrologique et de restituer l'édifice. Ces recherches valident la restitution de l'ordre extérieur proposée par F. Courby et Ch. Picard. L'analyse des proportions des fûts pourrait établir un écart entre le projet, qui aurait prévu des colonnes plus hautes, et la mise en œuvre, peut-être victime d'une restriction financière.

J. Pakkanen, in D. Blackman, AR 2000-2001 (2001), p. 43.

\section{Épire}

05.03 - Ambracie - XII Éphorie des antiquités prébistoriques et classiques - Sanctuaires aux confins de la chôra des Ambraciotes : I. Andréou reprend l'étude des informations topographiques et toponymiques de trois règlements frontaliers fixant les limites du 
territoire d'Ambracie avec les terres des Charadrites, des Athamanes et des Acarnaniens. Ces trois inscriptions, qui ont donné lieu à de nombreux articles, sont immédiatement postérieures à 167 av. J.-C., et sont donc inspirées par le pouvoir romain. L'A. ajoute au débat sur l'identification des lieux mentionnés par ces inscriptions les riches données d'une prospection menée récemment dans la région d'Arta, afin de tracer la frontière de la cité antique, qui relie des points géographiquement remarquables qui servent de limites administratives actuelles. Le règlement frontalier entre les Ambraciotes et les Charadrites, découvert près du grand temple urbain d'Ambracie, mentionne un domaine consacré à Héraclès qui abrite un pbrourion ( $c f$. P. CABANES, I. ANDRÉou, "Le règlement frontalier entre les cités d'Ambracie et de Charadros", $B C H 109$ [1985], p. 499-544, et p. 753-757). Le sanctuaire est proche de la frontière mais appartient aux Ambraciotes. L'A. réfute la localisation du fort à Loutra Chanopoulou proposée en 1997 par V. KaratzénI

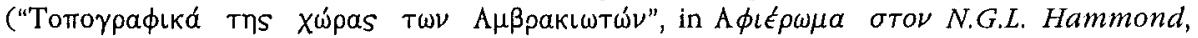
Thessalonique, 1997, p. 233-250), car le site n'a pas un caractère stratégique suffisant, et propose la colline du Prophète Élie, au $\mathrm{N}$ des sources chaudes de Loutra et à l'E de Kampi. Faut-il alors déplacer le sanctuaire? Le règlement frontalier entre les Ambraciotes et les Athamanes signale un sanctuaire de Poséidon ( $c f$. M. Holleaux, "Fragment de sénatus-consulte trouvé à Corfou", $B C H 48$ [1924], p. 381-398, et C. HADzIs, "L'arbitrage corcyréen pour le différend territorial entre Ambraciotes et Athamanes", in A $\phi \iota \epsilon \rho \mu \alpha$ otov N.G.L. Hammond, op. cit., p. 169-197). Le sanctuaire est associé dans le texte à un péribole de pierre, manifestement en montagne. Ce bieron est sûrement situé au NE d'Ambracie, dans la région des cours d'eau Kalendini et Sarandaporo. I. Andréou est séduite par le site du monastère Melatôn (p. 153, fig. 5); le lieu ou le village appelé Eủpúva dans la même inscription pourrait entretenir un rapport avec Poséidon. Cette localisation du sanctuaire en montagne et près d'un cours d'eau est très satisfaisante, car Poséidon est aussi familier de ce genre de paysage plus au $\mathrm{N}$, en Chaonie et en Illyrie méridionale.

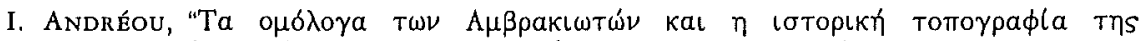

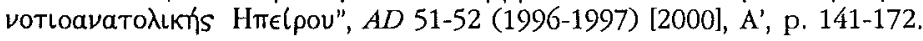

05.04 - Paramythia [région de] - VIII Éphorie des antiquités prébistoriques et classiques - À Photiki, on signale la découverte d'un autel en calcaire blanc sculpté d'un bucrane, d'une œnochoé et d'une patère. L'autel est peut-être datable de l'époque romaine. Rappelons qu'un temple de Diane est attesté à Liboni par une inscription - son épiclèse est probablement d'origine grecque : $c f$. A.E. KontoleoN, $B C H 16$ (1892), $\mathrm{n}^{\circ} 1$, p. 174-175 -, et qu'une importante quantité de statuettes en bronze de très bonne facture viendrait de la région de Paramythia (cf. H.B. Walters, Catalogue of the Bronzes, Greek, Roman and Etruscan, in the departement of Greek and Roman Antiquities, London, British Museum, 1899, p. 36-39 en particulier).

D. Blackman, AR 2000-2001 (2001), p. 55, fig. 98.

05.05 - Dodone - Université de Ioannina - La campagne 1998 a exploré plus particulièrement le $S$ et le $S O$ de la cour à péristyle $(O)$ de l'édifice situé au $S$ du bouleuterion du sanctuaire, interprété comme un prytanée (cf. ChronARG 2001, 05.08). La fouille s'est donc poursuivie dans l'aile $\mathrm{O} 2$ et devant la stoa.

La découverte d'une nouvelle couche dans l'aile $\mathrm{O} 2$ a permis de récupérer des tuiles, dont une porte le timbre $\Phi_{\circ} \mu(\sigma \kappa o v$, nom fréquemment attesté dans la région par les inscriptions et les légendes monétaires. Sous la couche de destruction de l'aile O2, les fouilleurs relèvent la découverte d'une empreinte de sceau épigraphe en terre cuite portant une tête d'Athéna casquée vers la droite. Les monnaies offrent de bons parallèles à cette représentation. La présence de la déesse en Épire est expliquée par son culte à Corinthe et une diffusion depuis l'attique à la fin du ve $s$. ( $c f$. Ch. Tzouvara-Soul, ' $H$

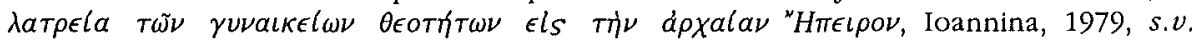


Athéna). Cette trouvaille pourrait montrer que la pièce contenait les archives du prytanée, peut-être aussi un atelier monétaire.

La fouille de la stoa à l'E de l'édifice a permis de retrouver la krepis à deux degrés et les bases en façade exhumées par $K$. Karapanos. Dans cette zone, on note la découverte de deux lamelles oraculaires en plomb - sur l'une d'elles est lisible le mot [I]EPA, superposé à une inscription plus ancienne - et d'une tuile estampillée $\Delta$ iòs Náov. Ce timbre fut aussi lu sur beaucoup de fragments en terre cuite provenant du bouleuterion et $\mathrm{du}$ bâtiment de scène du théâtre, mais aussi de l'aile O1 de l'édifice en cours de fouille. Les A. commentent l'épiclèse de Zeus Nálos ou Náos, l'associant à val et à vaós, pour insister sur le lien entre le dieu et sa maison sacrée.

Un des intérêts principaux de cette campagne est d'avoir confirmé le lien entre l'édifice fouillé et le portique découvert par K. Karapanos (Dodone et ses ruines, Paris, 1878, pl. 3); les archéologues devraient bientôt atteindre la porte méridionale de l'enceinte du sanctuaire. Notons que l'édifice de Dodone pourrait être comparé avec profit au grand bâtiment public (A) de Gitana en Thesprôtie, qui s'organise aussi autour d'une cour, et d'où proviennent des empreintes de sceaux en terre cuite ( $c f . \mathrm{K}$. Preka-Alexandri, "A First Presentation of three Recent Excavations in Thesprotia (Epirus)", in P. Cabanes, L'Illyrie méridionale et l'Épire dans l'Antiquité. Actes du II colloque international de Clermont-Ferrand (25-27 octobre 1990), Paris, 1993, p. 103-106, fig. 1).

Ch. Souli, A. Vlachopoulou, K. Gravani, PaAH (1998) [2000], p. 143-151; G. Touchais, $B C H 123$ (1999) [2000], p. 718, fig. 70-71; Ergon (1998) [1999], p. 59-65, et (1999) [2000], p. $67-68$.

\section{Illyrie méridionale}

05.06 - Apollonia - Mission épigraphique et archéologique française en Albanie, Institut archéologique albanais - Après une interruption des fouilles en 1997, les travaux reprennent en 1998. La campagne permet de mieux documenter l'édifice à mosaiqque, dont est publié un relevé ( $c f$. aussi $B C H 123$ [1999], p. 572, fig. 1). Un niveau de rue est fouillé au $S$ de l'édifice, contemporain de la mosaïque. Le bâtiment était probablement hypèthre; à l'intérieur, une base engagée dans le sol ne peut avoir une fonction architecturale, et pourrait être un cippe ou un autel consacré à une divinité. L'A. propose donc d'interpréter la structure comme un enclos à ciel ouvert délimité par un péribole de pierre. La probable présence de propylées, ajoutée à l'existence d'un sol mosaiqué, font penser à un sacellum construit aux $\mathrm{III}^{\mathrm{e}}-\mathrm{II}^{\mathrm{e}}$ s. av. J.-C. Notons aussi la découverte de matériel archaïque, qui pourrait montrer que la zone était occupée à cette époque.

Dans la grande rue E-O, les nombreux blocs en éboulis pris dans une couche noire - une fosse ? - sont évacués. Le long du mur au $\mathrm{N}$ de la rue, plusieurs niveaux de circulation en cailloutis ou en galets sont enregistrés. Certains correspondent à des sols de chantier datant de l'exploitation de la zone comme carrière. De ce secteur provient un fragment de chêneau à tête de lion, comparable à l'exemplaire déposé par L. Heuzey au Louvre. À noter la découverte d'un niveau de rue qui est la plus ancienne structure de la zone, et pourrait donc dater de l'époque archaïque. L'existence dans ce secteur d'Apollonia d'un grand temple corinthien d'époque impériale reste une hypothèse d'actualité.

J.-L. Lambolex, "Apollonia : résultats de la campagne 1998", in 50 Vjet arkeolog $i$ shqiptare, Actes du colloque international de Tirana (9-10 novembre 1998), Iliria 28 (1998) [2000], p. 231-242. 


\section{Îles ioniennes}

05.07 - Corcyre - VII Éphorie des antiquités prébistoriques et classiques - On relève la découverte en 1994 sur le terrain Mikalef d'une statue féminine en terre cuite assise sur une lionne, de fragments de figurines, et d'un moule de statuette féminine de style sévère. D'autres découvertes confirment l'existence d'un culte près de l'atelier, dont un fragment d'une statuette, sans doute d'Héraclès, et un trident en bronze.

Sur le terrain Pamphili, on signale la découverte d'un éventuel temple de l'époque archaïque, ainsi que des murs et de la céramique des $\mathrm{vII}^{e}$ et $\mathrm{vi}^{e} \mathrm{~s}$. av. J.-C. Des statuettes féminines en terre cuite, probablement des Artémis et des figurines animales confirment la présence d'un lieu de culte dans les environs.

K. Preka-Alexandri, $A D 49$ (1994) [1999], B'1, p. 420; G. Touchais, $B C H 123$ (1999) [2000], p. 712; D. BlaCKMAN, $A R$ 1999-2000 (2000), p. 55; id., AR 2000-2001 (2001), p. 51-52.

- Y. Morizot étudie un groupe de statuettes corcyréennes d'Artémis appartenant au lot découvert à Kanoni par H. LeChat ( $B C H 15$ [1891], p. 1-112; cf. CbronARG 2001, 05.16), afin de dégager la signification religieuse de ces figurines en terre cuite. La déesse conduit un char attelé à deux biches et deux panthères. Bien que le motif soit rare dans l'iconographie artémisiaque - qu'il soit interprété comme la représentation d'une épiphanie d'Artémis ou une évocation de son voyage vers l'Olympe -, l'A. montre bien qu'il est néanmoins lié à une dimension connue de la déesse, celle d'une potnia. L'Artémision de Kanoni est un sanctuaire dont la fréquentation est probablement féminine; idée qui oriente l'enquête de l'A. vers l'examen du rapport métaphorique entre femmes et bêtes sauvages. Deux événements de la vie féminine peuvent alors être proposés : l'accouchement, mais aussi et surtout le mariage, puisque le char a très souvent une connotation nuptiale, que d'autres figurines de Kanoni partagent. Grâce à cette étude et aux riches pistes de recherche proposées, un aspect de la vie religieuse des Corcyréennes au ve $s$. av. J.-C. est ainsi mieux connu.

Y. Morizot, "Autour d'un char d'Artémis", in Agatbos Daimon. Mythes et Cultes. Études d'iconographie en l'bonneur de L. Kabil, Paris, 2000 (BCH, suppl. 38), p. 383392.

05.08 - Leucade - XII Éphorie des antiquités prébistoriques et classiques - À Meganisi (promontoire oriental), on signale la découverte d'un dépôt de figurines dans les rochers littoraux. Le matériel est conservé au Musée de Ioannina.

A. Douzougli, $A D 48$ (1993) [1998], B'1, p. 304.

- La grotte de Voliatso à Kavallo, connue depuis 1992, a été explorée en 1994 par l'Éphorie de spéléologie. D'une superficie de $50 \mathrm{~m}^{2}$, les deux chambres qui composent la grotte ont été perturbées par des fouilles clandestines. Le matériel peut être daté entre le Néolithique et l'époque hellénistique; il est attribué à un atelier local ou corinthien. La céramique et les figurines en terre cuite ont un caractère votif, et suggèrent que nous avons affaire à un nouveau lieu de culte aux Nymphes, qui vient enrichir encore la liste des sanctuaires naturels consacrés à ces divinités à Leucade (Agia Kyriaki Nydriou, et Asvotrypa près de Phryni, cf. ChronARG 2001, 05.17), et plus largement dans les îles ioniennes ( $c f$. infra 05.09 et 10).

D. Blackman, AR 1999-2000 (2000), p. 68.

05.09 - Ithaque - VI Éphorie des antiquités prébistoriques et classiques - G. Touchais note les découvertes suivantes signalées par voie de presse : "Dans la Grotte des Nymphes [Marmarospilia], la fouille d'une couche de débris provenant du tremblement de terre de 374 av. J.-C. a livré sept figurines de Nymphes en terre cuite et une statuette de 
Pan, ainsi qu'une bague en bronze décorée d'un aigle (?), une autre en argent et en or d'une corne d'Amalthée. »

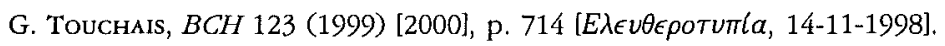

- Société archéologique - Les fouilles à Ithaque-Alalkomenai se sont poursuivies dans la région du temple attribué à Apollon, à l'O de la chapelle Saint-Georges, et ont permis de préciser les données chronologiques au centre de la ville antique. Un édifice a été découvert, contenant des vases interprétés comme des offrandes, des figurines en terre cuite et d'autres objets cultuels. Sous les fondations $O$ de l'édifice, les fouilleurs ont découvert un nombre important de tessons mycéniens, dont deux fragments de cratères. La céramique géométrique est aussi abondante, comme à l'extérieur de l'édifice. L'A. note aussi de la céramique du début du $\mathrm{IV}^{\mathrm{e}} \mathrm{s}$. av. J.-C. La couche de destruction de l'édifice doit sans doute être attribuée au séisme de 374 av. J.-C. Reconnaissant que la fonction du bâtiment n'est pas claire, et que son plan complet n'est pas encore connu, en particulier à l'E, S. Symeonoglou propose néanmoins l'hypothèse d'un temple, dont l'histoire serait alors longue, de l'époque mycénienne à la première moitié du $\mathrm{IV}^{\mathrm{e}} \mathrm{s}$. Deux sanctuaires seraient connus par l'archéologie : celui de la chapelle Saint-Georges, attribué à Apollon, et l'édifice fouillé cette année. L'A. propose avec prudence de l'identifier à l'Odysseion mentionné par l'inscription de Magnésie du Méandre (O. Kern, Die Inschriften von Magnesia am Meander, Berlin, 1903, 27, $\mathrm{n}^{\circ}$ 36). L'hypothèse repose sur le rapprochement suivant : le représentant d'Ithaque à Magnésie était un prêtre de l'Odysseion, fils de Praulos; or le nom Praulos apparaît sur une stèle funéraire découverte dans les environs de la chapelle Saint-Georges. L'hypothèse est donc fragile.

S. Symeonoglou, PAAH 1995 [1998], p. 211-215, pl. 92-93.

05.10 - Céphalonie - VIe Éphorie des antiquités prébistoriques et classiques - Sur le flanc O de l'acropole de Sami, on relève la découverte d'une stèle d'époque classique sculptée de deux divinités féminines et une femme devant l'autel. Perséphone et Déméter sont d'éventuelles candidates.

G. Touchais, BCH 123 (1999) [2000], p. 714.

- À Poros, l'Éphorie de paléoanthropologie et de spéléologie a continué la fouille en 1995 de la grotte de Drakaina. Une fosse votive associée au sanctuaire d'époque historique, mais installée dans des niveaux préhistoriques, a en particulier été explorée. La fosse contenait beaucoup de tessons de céramique, des protomés féminines et des figurines en terre cuite appartenant à des groupes de quatre personnages dansant autour d'un aulète au centre. Une inscription incisée sur le col d'un vase en West Slope montre qu'un culte est rendu aux Nymphes; une statuette de Pan illustre la présence du dieu nymphagète. L'hétérogénéité du matériel prouve que la fosse correspond à un nettoyage du sanctuaire dans la seconde moitié du $\min ^{\mathrm{e}}$ s. av. J.-C. au plus tard. Dans la tranchée B6, sous cinq niveaux stériles et au-dessus de l'argile qui scelle la couche préhistorique, on signale un bothros contenant du matériel du $\mathrm{vi}^{\mathrm{e}} \mathrm{s}$. av. J.-C. Des choeurs de jeunes filles dansant autour d'un aulète sont fréquemment découverts dans les sanctuaires naturels de la région; $c f$. aussi les disques en terre cuite ornés du même thème des grottes de Melissani à Céphalonie, et de Polis à Ithaque (voir Ch. Tzouvara-Soulı, $\Delta \omega \delta \omega \dot{\nu \eta}, 27-1$ (1998) [1999], p. 371-436).

D. BLACKMAN, AR 2000-2001 (2001), p. 45, fig. 82.

\section{[06. Phthiotide, Thessalie]}




\section{Macédoine (Kalliopi Chatzinikolaou et Emmanuel Voutiras)}

\subsection{0 - Généralités}

- Discussion sur le culte d'Isis en Macédoine. Analysant la diffusion du culte de la déesse dans la région, l'A. mentionne les sites de ses sanctuaires connus: Thessalonique, Dion, Philippes, Stobi et Herakleia Lynkestis.

M. Bommas, "Neue Heimat in der Fremde. Isis in Makedonien", Antike Welt 6 (2000), p. 617-624.

- L'A: publie trois nouveaux bekataia de Macédoine et fournit quelques éléments supplémentaires sur le culte d'Hécate. a) Hekataion de Pella, inv. ${ }^{\circ}$ Bח 1997/6 $\alpha$, de la fin du II $^{\mathrm{e}}$ ou du début du I ${ }^{\mathrm{er}} \mathrm{s}$. av. J.-C.; b) Hekatation du site de "Louloudies " près de Kitros en Piérie (catalogue des Antiquités de Pydna), inv. $\mathrm{n}^{\circ} 2462$, de la fin de la période hellénistique; c) Hekataion inscrit du site de «Kastania » en Piérie (Musée archéologique de Dion), inv. ${ }^{\circ}$ A.E. 7421 , de la fin du $\mathrm{II}^{\mathrm{e}}$ ou du début du $\mathrm{I}^{\mathrm{er}} \mathrm{s}$, av. J.-C. Ce dernier provient du site possible d'un sanctuaire d'Hécate (il s'agit d'un carrefour aujourd'hui).

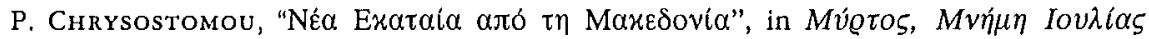
Bожотолоú

- L'A. publie trois reliefs votifs conservés au Musée archéologique national d'Athènes et deux fragments de statues considérées comme provenant de Grèce méridionale, et montre qu'ils ont une provenance macédonienne : a) relief votif, inv. $n^{\circ}$ EAM 2357: il représente Zeus (et non une déesse), provient de Thessalonique et peut être daté de la deuxième moitié du $\mathrm{Iv}^{\mathrm{e}} \mathrm{s}$. av. J.-C.; b) relief votif représentant Héraclès tenant une pomme, inv. $n^{\circ}$ EAM 2863, provenant de Kastoria; c) relief votif, inv. $n^{\circ}$ EAM 2352 : c'est la partie droite d'un relief de Cavalier provenant de Thessalonique; d) tête d'une statue jadis au Musée archéologique national d'Athènes (inv. $\mathrm{n}^{\circ} \mathrm{BE}$ 919/1955), représentant probablement Tyché ou Cybèle et maintenant au Musée de Philippes (inv. $n^{\circ} \Lambda 1964$ ); e) une tête d'Apollon provenant de Macédoine pourrait se trouver dans les magasins du Musée archéologique national d'Athènes.

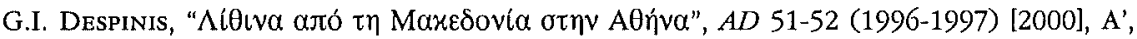
p. 119-124.

07.01 - Kastoria - Site de "Psalida " ou "Megalexandros" - XVII Éphorie des antiquités prébistoriques et classiques - Mention d'un certain nombre de trouvailles des fouilles du site d'un sanctuaire de sommet de Zeus Hypsistos : fragments de reliefs votifs, offrandes votives, statuettes.

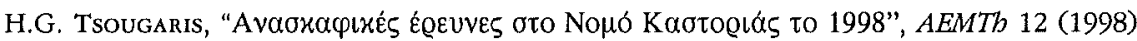
[2000], p. 573-575.

07.02 - Petres (préfecture de Florina) - XVII éphorie des antiquités prébistoriques et classiques - Un sanctuaire de Zeus a été mis au jour dans la partie $\mathrm{S}$ du quartier $\mathrm{E}$ de l'établissement de Petres. Le site a été identifié par une stèle inscrite mentionnant le nom du dieu, découverte en face d'un autel. L'A. pense que les magasins situés dans le quartier E de l'établissement pourraient être liés au sanctuaire.

P. ADAM-VelenI, $A D 50$ (1995) [2000], B' 2, p. 580.

07.03 - Xirolimni (préfecture de Kozani) - XVII Éphorie des antiquités prébistoriques et classiques - Un relief en marbre portant l'image d'Apollon Citharède, une statuette fragmentaire en marbre représentant le même dieu et une inscription votive à Apollon, le tout de la période romaine et provenant d'un champ sur le site de "Porta " ou "Por- 
tes », attestent l'existence d'un sanctuaire d'Apollon dans la zone. Les trouvailles ont été déposées au Musée archéologique de Kozani.

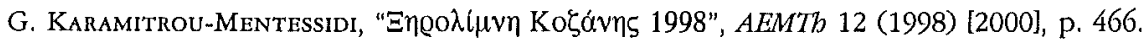

07.04 - Perdikkas (Eordaia - préfecture de Kozani) - XVII Éphorie des antiquités prébistoriques et classiques - Deux statuettes en bronze représentant Héraclès ont été trouvées dans un complexe de bâtiments de la période romaine mis au jour sur le site d'《 Aspri Poli », à l'E du village de Perdikkas dans l'ancienne Eordaia. Une statuette en bronze représentant Hermès a été déposée au Musée archéologique de Kozani.

E. Kephalidou, $A D 50$ (1995) [2000], B’2, p. 578, 584.

07.05 - Agios Christophoros (préfecture de Kozani) - XVII Éphorie des antiquités prébistoriques et classiques - Une stèle votive portant une inscription à Zeus Hypsistos a été déposée au Musée archéologique d'Aiani.

G. Karamitrou-Mentessidi, $A D 49$ (1994) [1999], B’2, p. 554.

07.06 - Kitrini Limni. (préfecture de Kozani) - XVII Éphorie des antiquités prébistoriques et classiques - Découverte d'un relief votif en marbre avec une représentation d'Artémis accompagnée d'un chien, datée du $\mathrm{II}^{\mathrm{e}} s$, ap. J.-C. Le relief a été remployé dans un bâtiment des $v^{e}-v_{1}^{e}$ s. ap. J.-C. sur le site de "Xeropigado » près du village moderne de Koilada dans la vallée de Kitrini Limni.

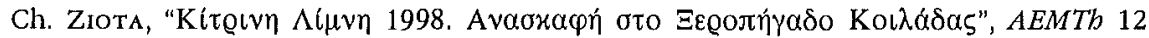
(1998) [2000], p. 511-512.

07.07 - Ryakio (préfecture de Kozani) - XVII Éphorie des antiquités prébistoriques et classiques - L'A. mentionne deux reliefs votifs non publiés représentant Héraclès Kynagidas et suggérant l'existence d'un sanctuaire du dieu dans la zone.

Ch. ZIOTA, $A D 50$ (1995) [2000], B'2, p. 584.

07.08 - Polymylos (préfecture de Kozani) - XVII Éphorie des antiquités prébistoriques et classiques - Mention de petites trouvailles des ${ }_{11} \mathrm{e}^{\mathrm{e}}-\mathrm{I}^{\mathrm{er}} \mathrm{s}$. av. J.-C. faites sur le site de Polymylos et dont la signification est peut-être cultuelle : terres cuites représentant Niké, deux moules d'un rhyton en forme de canard, partie d'une table d'offrande et quatre objets en forme de phallus en terre-cuite. Une stèle de marbre en relief a été déposée au Musée archéologique de Kozani.

G. Karamitrou-Mentessidi, M. Vatali, "Io

[2000], p. 486; G. Karamitrou-Mentessidi, $A D 50$ (1995) [2000], B'2, p. 583.

07.09 - Leukadia (préfecture d'Imathia) - XVII Éphorie des antiquités prébistoriques et classiques - Mention d'une statuette en ivoire représentant une Aphrodite nue provenant de l'antichambre d'une grande tombe macédonienne de Leukadia.

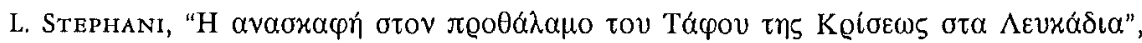
AEMTb 12 (1998) [2000], p. 419.

07.10 - Skydra (préfecture de Pella) - XVII Éphorie des antiquités prébistoriques et classiques - Les fondations d'un temple hellénistique ont été découvertes sur le terrain du complexe de logements pour ouvriers, au somment d'une colline dans la partie SO de la ville moderne. La structure mise au jour porte les traces d'interventions aux périodes romaine et paléochrétienne.

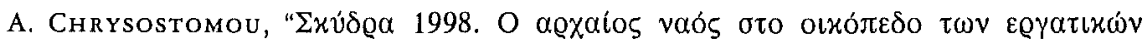

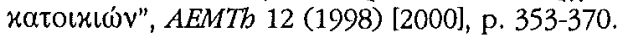

07.11 - Beroia - L'A. discute la stèle naguère publiée par elle-même, d'Adéa Kassandrou provenant de Beroia. Elle exprime des doutes sur l'interprétation qui fait de la jeune 
femme représentée sur le relief une prêtresse kleidouchos. L'interprétation de l'objet qu'elle tient est incertaine, ainsi que ses liens avec les cultes d'Isis ou d'Enodia.

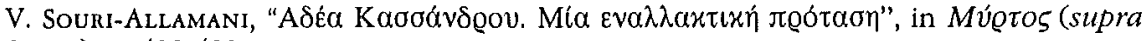
07.00), p. 489-493.

07.12 - Leukopetra (préfecture d'Imathia) - Publication des inscriptions du sanctuaire de la Mère des dieux Autochtone du site de «Leukopetra», près de la ville moderne de Beroia, mis au jour en 1965 par Ph. Petsas, alors éphore de la Macédoine occidentale. Les trouvailles les plus importantes furent les restes architecturaux d'un petit temple prostyle, ainsi que d'autres objets en marbre couverts d'inscriptions (actes d'affranchissement). Les A. commentent le culte de la déesse honorée à Leukopetra.

Ph.M. Petsas, M.B. Hatzopoulos, L. Gounaropoulou, P. Paschidis, Inscriptions d $u$ Sanctuaire de la Mère des Dieux Autochtone de Leukopetra, Athènes, 2000

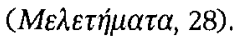

07.13 - Vergina - L'A. commente un relief votif inscrit hellénistique représentant Apollon jouant de la cithare, découvert en 1911 dans la zone de Vergina (partiellement conservé aujourd'hui au Musée archéologique de Beroia, inv. $n^{\circ} \Lambda 133$ ou 172). Le document atteste probablement l'existence d'un sanctuaire extra-muros du dieu dans la partie $S$ du village moderne de Vergina. Le dieu, représenté comme citharède vêtu de long, est identifié par l'inscription comme Lykios, ce qui est confirmé par la présence d'un loup à ses côtés.

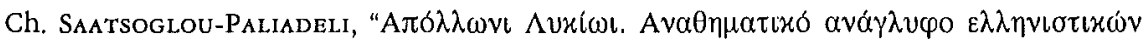

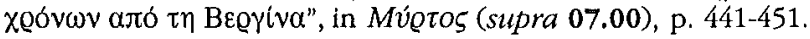

07.14 - Aigat -XVII Éphorie des antiquités prébistoriques et classiques - Mention d'un vase à parfum représentant Attis ou Adonis, provenant du cimetière hellénistique. Selon l'A., une construction en pierre et des restes de foyers découverts au NO du tumulus «Bella » suggèrent l'existence d'un lieu de culte à ciel ouvert à la fin de la période hellénistique.

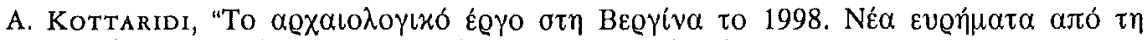

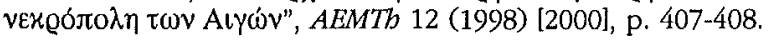

07.15 - Pella - M. Lilibaki-Akamati publie une étude exhaustive du sanctuaire de la Mère des dieux et d'Aphrodite situé à Pella (cf. déjà ChronARG 2001, 07.09). Le complexe de bâtiments constituant le sanctuaire est situé au centre de la cité, directement accessible par les trois routes $(\mathrm{E}, \mathrm{O}, \mathrm{S})$. Les vestiges architecturaux appartiennent à deux phases de construction différentes : a) fin du $I^{\mathrm{e}}$ s. av, J.-C., b) fin du $\mathrm{III}^{\mathrm{e}}$ s. av. J.-C. Un temple relativement petit orienté à l'O, entouré de stoa et reconstruit au moins deux fois, était le centre du culte au cours des deux phases. La plupart des trouvailles mises au jour par la fouille étaient des figurines de terre cuite produites dans les ateliers de Pella et représentant surtout Aphrodite nue et portant des sandales, à demi-nue debout, appuyée à un pilier, portant un Éros, assise. Il y a aussi des représentations traditionnelles de la Mère des dieux (assise sur un trône, tenant une phiale et un tambourin, avec un lion assis à ses côtés), des images d'Athéna comme «Protectrice des bovins", des paires de figurines de la Mère des dieux et Koré ou d'Éros et Psyché, quelques représentations dionysiaques et théâtrales, des autels miniatures et des représentations rappelant Attis, le compagnon de la Mère des dieux. Autres trouvailles : poterie, lampes, objets de métal, monnaies. Deux reliefs votifs en pierre, d'une humble facture, représentant ta Mère des dieux de manière traditionnelle ont été trouvés dans l'antichambre du temple dans un large espace à ciel ouvert. La base d'une offrande votive (en deux morceaux) portant une inscription mentionnant Aphrodite a été trouvée dans la partie NE du complexe. Un autel miniature portait quant à lui une inscription se référant à la Mère des dieux dans la stoa 
S. L'A. suggère la coexistence de deux cultes distincts, mais il n'est pas certain que les déesses aient été honorées dans des locaux séparés. Elle pense aussi que la Mère des dieux et Aphrodite Pandémos étaient de même nature et que la célébration commune de leur culte s'est donc justifiée. Les deux déesses dominaient le panthéon de Pella et leur sanctuaire était directement associé à l'agora. Elles étaient aussi honorées dans des sanctuaires domestiques et les trouvailles suggèrent que leur culte a pu être lié au héros guérisseur local Darron également.

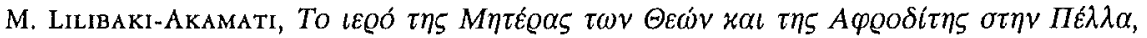
Thessalonique, 2000.

- XVII Éphorie des antiquités prébistoriques et classiques - Un bâtiment des $\mathrm{III}^{\mathrm{e}}{ }_{-} \mathrm{I}^{\mathrm{er}} \mathrm{S}$. av. J.C. découvert dans la zone du canal d'irrigation moderne, près du sanctuaire de Darron et en liaison avec lui, servait, selon l'A., de salle de banquets pour les fêtes, avant et après les cérémonies.

\section{AKamati, $A D 50$ (1995) [2000], B`2, p. 548-549.}

- Présentation des trouvailles faites dans le bâtiment $\mathrm{E}$ du sanctuaire du héros guérisseur local Darron, près du canal d'irrigation moderne de Pella, incluant des monnaies, des boucles d'oreille en or et des anneaux, le tout daté des débuts de la période hellénistique. La représentation de la Mère des dieux sur l'un des anneaux conduit l'A. à penser qu'il appartenait à un prêtre ou à une prêtresse de la déesse.

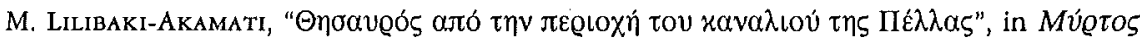
(supra 07.00), p. 377-391.

- L'A. publie deux objets miniatures, une phiale et un bouclier provenant du secteur central de la zone fouillée dans l'ancienne cité et conclut qu'il peuvent être liés à un culte des morts.

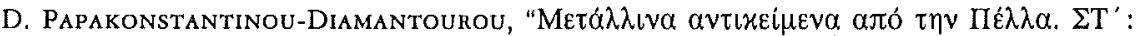

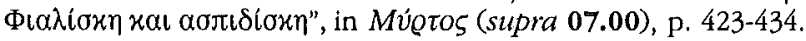

- XVIT Éphorie des antiquités prébistoriques et classiques - L'A. publie les résultats d'une recherche concernant une maison hellénistique fouillée sur le terrain de Georgios Pappas à Pella. Les trouvailles incluent des figurines de serpents en terre cuite, des grappes, des oufs par paire et un cavalier. Ces figurines peuvent être rapportées au culte de Dionysos, très répandu dans la région au ${ }_{\mathrm{II}}^{\mathrm{e}} \mathrm{s}$, av. J.-C.

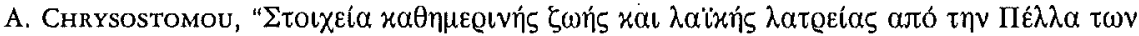

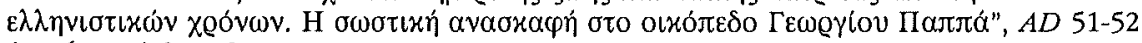
(1996-1997) [2000], A', p. 197-230.

07.16 - Apsalos, Almopia (Pella prefecture) - XVII Éphorie des antiquités prébistoriques et classiques - Une base portant une inscription votive à Hermès a été déposée au Musée archéologique d'Edessa (inv. ${ }^{\circ}$ AKE 1338). Selon l'A., elle appartient à un relief votif représentant le dieu, déjà mis au jour au même endroit (inv. $\mathrm{n}^{\circ} \mathrm{AK} 25$ - collection archéologique d'Edessa).

A. Chrysostomou, $A D 49$ (1994) [1999], B' 2, p. 553.

07.17 - Dion - Université Aristote de Thessalonique - Les fouilles dans la zone en face de l'autel de Zeus ont mis au jour une série de 36 bases en calcaire portant des. anneaux en bronze, probablement pour attacher les animaux à sacrifier. Sur la base de ces trouvailles, l'A. tente de reconstituer une hécatombe.

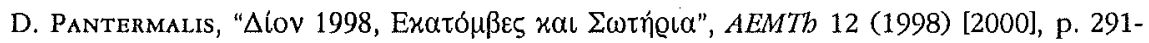
292. 
- Selon l'A., un bouclier macédonien partiellement conservé et trouvé dans le sanctuaire de Zeus Olympios à Dion pourrait être une offrande votive de Démétrios Poliorcète à Zeus.

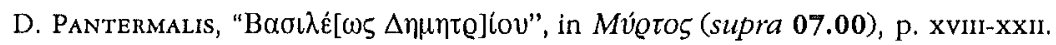

07.18 - Thessalonique, rue Melenikou-Chatziandreou - XVII Éphorie des antiquités prébistoriques et classiques - Des constructions rectangulaires ressemblant à des autels au-dessus de tombes à ciste et à fosse de la nécropole $\mathrm{E}$ de Thessalonique (période romaine) pourraient, selon les A., avoir une signification cultuelle. Des figurines de terre cuite représentant des Éros de différents types et Aphrodite font partie des trouvailles de la nécropole.

M. Tsibidou-Avloniti, A. Lioutas, $A D 49$ (1994) [1999], B'2, p. 434, 436.

- XVII Éphorie des antiquités préhistoriques et classiques - Présentation des trouvailles des bains de l'ancienne agora de Thessalonique. Parmi elles se trouve un grand nombre de terres cuites et de lampes portant des représentations en relation avec Dionysos, Aphrodite, Zeus, Athéna, Éros et Niké, ainsi que les dieux eux-mêmes. Les trouvailles vont de la fin de la période hellénistique jusqu'au règne de Vespasien.

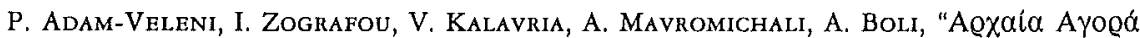

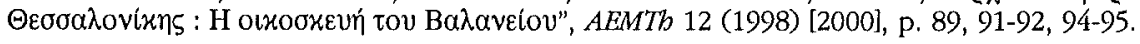

- Dioikitirio - XVII Éphorie des antiquités prébistoriques et classiques - Tête de statue d'Aphrodite en marbre ( $\mathrm{i}^{\mathrm{er}} s$. av. J.-C.) et terres cuites représentant Cybèle et Athéna ( $\mathrm{I}^{\mathrm{er}} \mathrm{s}$. av. $-\mathrm{I}^{\mathrm{er}}$ s. ap. J.-C.), provenant des fouilles d'un complexe de bâtiments situé place Dioikitiriou, où se trouvait probablement le centre administratif de l'ancienne cité.

A. TASIA, $A D 50$ (1995) [2000], B'2, p. 455.

07.19 - Oraiokastro (préfecture de Thessalonique) - XVII Éphorie des antiquités prébistoriques et classiques - Des figurines de terre cuite représentant Perséphone ou Aphrodite, des pommeaux en argile portant le buste d'Athéna Parthénos et une tablette de défixion en plomb proviennent d'une nécropole découverte dans le champ $n^{\circ} 528$ à Oraiokastro.

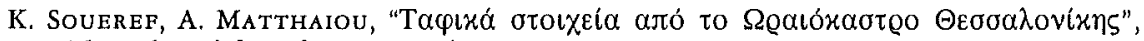
AEMTh 12 (1998) [2000], p. 233-234.

07.20 - Mendè (préfecture de Chalcidique) - Discussion du culte de Poséidon à Mendè, où un sanctuaire archaïque du dieu a été découvert. L'étude des sources littéraires et des inscriptions d'Érétrie conduit l'A. à suggérer que ce culte provient d'Érétrie, métropole de Mendè.

D. Knoepfler, "Poséidon à Mendè : un culte érétrien?", in Mv́@tos (supra 07.00), p. 335-349.

07.21 - Poseidi (sanctuaire de Poséidon) (préfecture de Chalcidique) - XVIII É Ephorie des antiquités prébistoriques et classiques - Rapport de fouille de la zone du bâtiment absidial principal (période protogéométrique $\mathrm{x}^{\mathrm{e}} \mathrm{s}$. av. J.-C.). Des restes de pyrai et d'actes rituels ont été mis au jour dans la partie $S$ de la zone fouillée. L'A. présume qu'un abandon ou une destruction du sanctuaire est intervenu au $1 \mathrm{x}^{\mathbf{e}} \mathrm{s}$. av. J.-C.

S. Moschonisioti, $A D 49$ (1994) [1999], B’ 2, p. 458.

07.22 - Aphytis (préfecture de Chalcidique) - Discussion des témoignages littéraires et archéologiques concernant le sanctuaire de Dionysos à Aphytis, dans la péninsule de Pallènè (Kassandra), près du village actuel de Kallithea. Le sanctuaire a été fouillé en 1968-1969 en urgence pendant la construction d'un hôtel moderne, en même temps 
qu'un sanctuaire de Zeus Ammon connu par les sources littéraires. Le sanctuaire de Dionysos mentionné par Xénophon (Hell. V, 3, 19) était à ciel ouvert et comprenait une grotte et un bois sacré. Le culte semble avoir commencé plus tôt (peut-être au vin ${ }^{\mathrm{e}} \mathrm{s}$, av. J.-C.). Une tête de Dionysos trouvée sur le site est conservée au Musée archéologique de Polygyros. Un fragment de relief votif inscrit transporté au Mont Athos au $\mathrm{xIx}^{\mathrm{e}} \mathrm{s}$. provient de ce sanctuaire, qui est d'origine eubéenne.

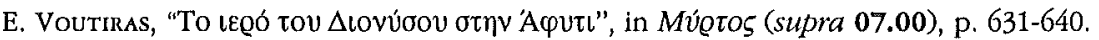

07.23 - Toronè (préfecture de Chalcidique) - La découverte, sur l'une des terrasses de l'ancienne cité de Toronè, d'une plaque en terre cuite représentant un héros cavalier de la période classique conduit l'A. à faire un certain nombre de remarques sur le culte des héros et des morts dans le monde grec. Il suggère que la plaque a été intentionnellement placée là où elle a été découverte, peut-être comme « offrande de fondation ». Il relie cette trouvaille à des choses similaires provenant de Troie, associées au culte des héros.

J.K. Papadopoulos, "A Toronaian Horseman-Hero and some of his Trojan mates", Mú $\varrho$ tos (supra 07.00), p. 411-421.

07.24 - Akanthos (préfecture de Chalcidique) - XVIe Éphorie des antiquités prébistoriques et classiques - Les fondations d'un temple ont été mises au jour sur le site d'«Alonia » (la colline au S de l'endroit). La date du bâtiment et l'identité de la divinité honorée restent inconnus.

E. Trakosopoulou, $A D 50$ (1995) [2000], B'2, p. 482-483.

07.25 - Ouranopolts (Nea Roda, préfecture de Chalcidique) - XVI Épborie des antiquités prébistoriques et classiques - Rapport préliminaire de la fouille du sanctuaire de Nea Roda. Un temple avec un pronaos à 5 ou 6 colonnes, une cella et une entrée monumentale ont été mises au jour. Un autre bâtiment situé au $S$ du temple pourrait lui être lié. Selon les A., ce complexe date de la fin du $\mathbf{I V}^{\mathrm{e}}$ s. av. J-C. ou du début du $\mathrm{III}^{\mathrm{e}} \mathrm{s}$. (pour une présentation plus détaillée, cf. CbronARG 2001, 07.15).

I. Vokotopoulou, E.M. Tsigarida, AD 49 (1994) [1999], B’ 2, p. 461.

07.26 - Melenikitsi (préfecture de Serrès) - XVIII Épborie des antiquités prébistoriques et classiques - Une petite stèle votive du site de « Leginitsko » représentant une oreille humaine, probablement une offrande à Isis ou à Sarapis, a été déposée au Musée archéologique de Serrès (inv, $\mathrm{n}^{\circ} \Lambda 194$ ).

M. VALLA, $A D 50$ (1995) [2000], B’2, p. 636.

07.27 - Mitriko (préfecture de Serrès) - XVIII Éphorie des antiquités prébistoriques et classiques - Une fosse près du tumulus de l'ancienne Strymè sur le site « Mitriko » pourrait être une fosse cultuelle ressemblant à des fosses similaires trouvées en Bulgarie, qui sont liées aux sanctuaires voisins.

D. Triantaphyllos, $A D 50$ (1995) [2000], B'2, p. 659.

\section{Thrace (partim) (Kalliopi Chatzinikolaou et Emmanuel Voutiras)}

08.01 - Rhodope [monts] (préfecture de Xanthi) - XIX Épborie des antiquités prébistoriques et classiques - Mention de lieux de culte possibles sur les hauteurs de la chaîne de montagnes Rhodope, liés aux nécropoles des débuts de l'âge du Fer mises au jour sur les rives du fleuve Kossinthos.

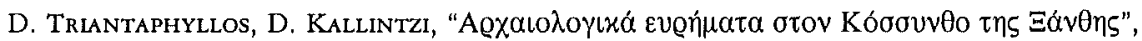
AEMTh 12 (1998) [2000], p. 9. 
08.02 - Maroneia - XVIII Éphorie des antiquités prébistoriques et classiques - L'A. postule l'existence d'un sanctuaire de Sarapis près du site de "Parathyra ", où ont été mises au jour des inscriptions votives se référant au culte des dieux égyptiens.

Ch. Karadima, $A D 50$ (1995) [2000], B'2, p. 660.

08.03 - Mesembria [région de] - XVIII Éphorie des antiquités prébistoriques et classiques - Une petite base de statue en marbre portant une dédicace à Aphrodite provient d'une maison dans l'établissement de la région de Mesembria (mur $\mathrm{O}$ ).

P. Tsatsopoulou, $A D 50$ (1995) [2000], B’2, p. 661.

08.04 - Iasmos (préfecture de Rhodopi) - XIX Éphorie des antiquités prébistoriques et classiques - La découverte d'amphores à fond pointu sur une colline du site de «Panagia » ou de «Tourla», au NE du village de Iasmos, conduit l'A. à supposer l'existence d'un sanctuaire du héros cavalier dans la région. Une même hypothèse est émise pour le site voisin de « Mega Pisto ».

D. Triantaphyllos, $A D 49$ (1994) [1999], B’2, p. 622.

08.05 - Gorna Krepost (préfecture de Kirdjali) - Mention du site d'un sanctuaire à ciel ouvert " thrace * près d'un complexe de bâtiments monumentaux de la période classique sur le Mont Perperek, dans la région du village moderne de Gorna Krepost en Bulgarie.

D. Ovtcharov, "Archaeological news", Archeologija (Sofia) 41, 3-4 (2000), p. 114.

08.06 - Boudinoi [région de] - Batkoun (Bulgarie) - Les A. rappellent que, selon Hérodote (IV, 108, 2), les Gelonoi, un peuple d'origine grecque vivant dans la région de Boudinoi, vénéraient les dieux grecs, notamment Dionysos. Ils soulignent aussi que, selon une inscription de Batkoun (IG Bulg. III 1, 1114), un sanctuaire d'Apollon se trouvait dans les parages.

B. Bravo, A.S. Chankowski, "Cités et emporia dans le commerce avec les barbares à la lumière du document dit à tort "inscription de Pistiros", $B C H 123$ (1999) [2000], p. 292, 297-298.

\section{9. îles de l'Égée (Kalliopi Chatzinikolaou, Alexis D'Hautcourt, Natacha Massar, Zozie Papadopoulou, Athéna Tsingarida, Emmanuel VOUTIRAS)}

09.01 - Thasos, cité ancienne - XIX Éphorie des antiquités préhistoriques et classiques - Une base ronde portant un Pan tenant une chèvre a été trouvée in situ dans le pavement d'une ancienne rue de la cité de Thasos. [K.Ch., E.V.]

Z. Bonias, $A D 49$ (1994) [1999], B' 2, p. 588.

- Fortification - École française d'Atbènes - Les A. établissent un lien entre le Pythion thasien situé près de la fortification et une inscription portant le nom d'Apollon sur le tondo d'une coupe datée du dernier quart du $\mathrm{vI}^{\mathrm{e}} \mathrm{s}$. av. J.-C. et mise au jour dans la fouille de la fortification. [K.Ch., E.V.]

Y. Grandjean, F. Salviat, $A D 49$ (1994) [1999], B' 2, p. 614.

- Limenaria - XVIII Éphorie des antiquités prébistoriques et classiques - Un torse masculin provient de la région de "Kalogeriko " près du village moderne de Limenaria. Il pourrait être hellénistique, et non archaïque, et représenter soit Apollon soit Dionysos. Il provient peut-être d'un sanctuaire. [K.Ch., E.V.]

S. Papadopoulos, $A D 50$ (1995) [2000], B’2, p. 619. 
09.02 - Samothrace, sanctuaire des Grands Dieux - American Scbool of Classical Studies - Progression des fouilles : a) «Building of the Dancers» (fondation S et E); b) au flanc $\mathrm{O}$ de la colline $\mathrm{E}$ du sanctuaire; c) terrasse $\mathrm{N}$ du temenos. [K.Ch., E.V.]

Ch. Karadima, $A D 50$ (1995) [2000], B' 2, p. 666; J.R. MCCredie, $A D 49$ (1994) [1999], B' 2, p. 626-627; $A D 50$ (1995) [2000], B'2, p. 669-670.

09.03 - Kos (Iraklis sto Psalidi) - XXII Éphorie des antiquités prébistoriques et classiques - En 1998, poursuite des recherches au sanctuaire archéo-classique découvert l'année précédente ( $c f$. CbronARG 2001, 09.05); dégagement de la façade occidentale du temple $(9 \times 24 \mathrm{~m})$. [A.DH., N.M.]

BCH 123 (1999), Chron., p. 805

- Poursuite des travaux dans la zone entre le grand mur archaïque et le temple archaïque. Mise au jour d'une couche de cendres qui contenait un lot de figurines zoomorphes (chevaux et bovins). Cette couche est associée à des vestiges architecturaux d'époque géométrique, ce qui suggère que l'espace avait une fonction cultuelle dès cette époque [A.DH., N.M.].

BCH 124 (2000), Chron. p. 983

09.04 - Kos (Marmaroto) - Différentes découvertes dans une nécropole en usage de l'époque archaïque à l'époque romaine. On a notamment trouvé, rue Asklipiou, une stèle funéraire "intacte avec une conduite en terre cuite pour l'accomplissement de libations ». [A.DH., N.M.]

BCH 123 (1999), Chron., p. 804-805

09.05 - Kos (sanctuaire d'Aphrodite Pandamos et Pontia) - À l'occasion de la publication d'une inscription inédite de Kos, les A. donnent un bref résumé de nos connaissances archéologiques sur ce sanctuaire. "With this textual evidence that of archaeology fits like the second half of an indenture. » Une seule prêtresse servait les deux cultes, qui bénéficiaient chacun d'un temple identique à l'intérieur du sanctuaire. [A.DH., N.M.]

R. Parker, D. Obbink, "Aus der Arbeit der ,Inscriptiones Graecae' VI. Sales of Priesthoods on Cos I", Chiron 30 (2000), p. 415-449, à la p. 430

09.06 - Kos (cultes égyptiens) - Synthèse sur les cultes égyptiens à Kos et à Rhodes aux époques hellénistique et romaine à partir des témoignages archéologiques, épigraphiques (en particulier, les attestations d'associations), numismatiques et surtout des types statuaires. L'A. propose notamment une analyse des types d'Isis attestés sur ces deux îles (photos). Enfin, il passe en revue les attestations de culte pour les Lagides et tente de déterminer leurs liens avec les cultes d'Isis et de Sarapis. [A.DH., N.M.]

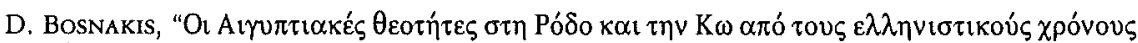

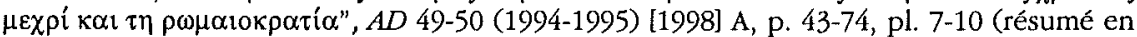
anglais p. 74 : "The Egyptian Gods on Rhodes and Kos from the Hellenistic Period to Roman Times")

09.07 - Rhodes - XXII É Éphorie des antiquités prébistoriques et classiques - Parmi les nombreuses découvertes faites dans les régions de nécropoles, notons, dans le quartier d'Epta Vagies, celle d'arêtes de poissons, "vestiges probables de banquets funèbres ", et, à la rue Kamirou, celle d'une fosse creusée dans le rocher $(2,70 \times 1,75 \mathrm{~m})$ qui servait sans doute à l'incinération des sépultures. [A.DH., N.M.]

BCH 123 (1999), Chron., p. 808; 124 (2000), Cbron., p. 984

09.08 - Rbodes (Secteur ouest, Rue Haghiou Ioannou, propriété du Genikis Technikis) - XXII Éphorie des antiquités prébistoriques et classiques - Poursuite des 
fouilles au sanctuaire mentionnées l'année passée (CbronARG 2001, 09.06; voir D. Blackmann, $A R$ 1999-2000, 2000, p. 125, fig. 182, pour une photo des structures aménagées dans la roche). On a découvert des fosses; celles-ci marqueraient l'emplacement d'arbres et témoigneraient de l'existence d'un bois sacré autour de l'autel. Des trous de poteaux ont également été identifiés; ils seraient les restes de structures légères destinées à apporter de l'ombre. La publication complète des fouilles permettra de juger de ces hypothèses. [A.DH., N.M.]

BCH 123 (1999), Chron., p. 807 (p. 808, fig. 173: photo de la statue d'hermaphrodite mentionnée dans ChronARG 2001).

09.09 - Rhodes (Secteur sud) - XXIIe Éphorie des antiquités prébistoriques et classiques - Poursuite de la fouille de l'Asclépieion. Mise au jour partielle des soubassements d'un édifice monumental, sans doute un portique, auquel appartiennent des tambours de colonne en poros. [A.DH., N.M.]

BCH 124 (2000), Chron. p. 984.

09.10 - Rbodes (Theologos) - XXII Éphorie des antiquités prébistoriques et classiques, Université de Ioannina - En 1993-1994, poursuite de l'exploration du sanctuaire d'Apollon Erethimios et découverte, notamment, de pavements de mosaïque. [A.DH., N.M.]

$B C H 123$ (1999), Cbron., p. 811

09.11 - Rbodes (Dionysion) - Étude de la fonction et de la localisation du «Dionysion » de Rhodes connu grâce à Diodore de Sicile, Strabon et au ps.-Lucien. Selon l'A., il ne s'agirait pas d'un temple, mais d'un enclos avec des portiques où étaient exposées des œuvres d'art, conformément à ce qu'en disent les auteurs anciens. L'A. associe à ce bâtiment des inscriptions avec des noms de prêtres de Dionysos et divers fragments de reliefs découverts lors de fouilles de sauvetage. Enfin, il pense que la statue d'un jeune orant du Musée de Berlin, étudiée récemment par R. Kabus-Preisshofen ( $A A$ [1988], p. 679-699), ne se trouvait pas dans le temple d'Hélios, mais également dans le Dionysion. [A.DH., N.M.]

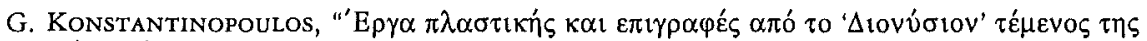

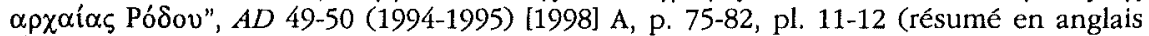
p. 82 : "Sculpture and Inscriptions from the 'Dionysion' of Ancient Rhodes")

09.12 - Rbodes (Nécropoles) - Catalogue et typologie des couronnes d'or découvertes dans les nécropoles de l'île de Rhodes. L'A. offre (p. 126-127) quelques considérations sur les significations religieuses, philosophiques et funéraires du placement d'une couronne d'or dans une tombe. [A.DH., N.M.]

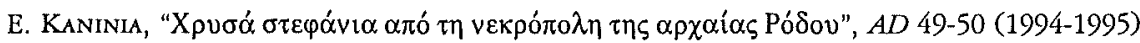
[1998], Mel. p. 97-132 (résumé anglais : "Gold Wreaths from the Necropolis of Ancient Rhodes", p. 131-132).

\section{Cyclades (Zozie Papadopoulou)}

\subsection{3 - Généralités}

- Dans un article examinant différents aspects du développement social dans les Cyclades protohistoriques, où l'élément religieux est prépondérant, l'A. (II Éphorie des antiquités prébistoriques et classiques) analyse les modèles de développement des agglomérations aux plans panhellénique, régional/cycladique, insulaire, en présentant chaque agglomération avec sa périphérie. Il essaie de décoder les modèles de distribution des agglomérations dans les Cyclades, accordant une attention particulière aux phénomènes liés à la naissance de la cité. L'A. dissocie la naissance de la cité dans les Cyclades de l'élément religieux, aussi bien au niveau local (voir p. 106, Kea, Paros, Naxos) qu'en ce qui con- 
cerne la signification panhellénique du sanctuaire de Délos. L'A. conclut que a) la variété des modèles de développement de l'habitat reflète les formes politiques qui se développent pendant les périodes PG et $G, b$ ) que la naissance de la cité dans les Cyclades est due aux exigences institutionnelles, créées par le besoin de communication avec les autres cités de la Grèce du continent.

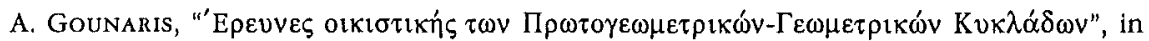
N. Stampolidis (éd.), $\Phi \Omega \Sigma K Y K \Lambda A \Delta I K O N, M v \eta ́ \mu \eta ~ N . Z \alpha \varphi \varepsilon t \rho o ́ \pi o v \lambda o v$, Athènes, 1999, p. 96113.

09.14 - Amorgos - Université de Ioannina, Société archéologique - Après avoir brièvement évoqué les fouilles des années récentes à Minoa, l'A. présente un sanctuaire local situé au sommet de l'Acropole, construit pendant la deuxième moitié du virl ${ }^{\mathrm{e}} \mathrm{s}$. av. J.-C. et resté en fonction jusqu'à l'époque romaine. Des couches des pyrai successives contenant des os d'animaux, de petits objets et des objets métalliques datant des périodes géométrique et archaïque témoignent du caractère cultuel du site. En soulignant les difficultés d'une identification à ce stade de la recherche, l'A. fait l'hypothèse que ce culte, apparemment de caractère chthonien, était probablement lié au ktistes, le fondateur mythique de Minoa, peut-être assimilé à la période archaique au culte de Dionysos. Le matériel archéologique des périodes hellénistique et romaine confirme la continuité du culte sur le site et permet de supposer que pendant la période romaine, les dieux égyptiens, et spécialement la triade alexandrine, étaient adorés au sanctuaire de Minoa.

L. Marangou, "The Acropolis Sanctuary of Minoa on Amorgos: cult practice from the 8th cent. B.C. to the 3rd cent. A.D.", in R. HäGg (éd.), Ancient Greek Cult Practice from the Archaeological Evidence, Stockholm, 1998, p. 9-26.

- L. Marangou, en étudiant l'histoire de la ville de Minoa à Amorgos, qui a vécu jusqu'au $I^{\mathfrak{e}}$ s. ap. J.-C., se réfère aux vestiges des périodes PG et $G$, parmi lesquels l'espace cultuel (au $S$ du Temple, le péribole avec le sacrifice de fondation, le dépôt de cendres, etc.). Une fortification de l'époque géométrique récente entoure l'Acropole avec le sanctuaire au sommet ainsi que la ville sur la pente de la colline. Une des découvertes les plus importantes de la "Ville Basse » est le péribole funéraire à l'E du Bastion du mur de fortification. Il s'agit de tombes de crémation, partiellement préservées, dans la plupart des cas dans des fosses peu profondes. L'A. présente en détail les pratiques funéraires ainsi que les trouvailles les plus importantes, parmi lesquelles l'enchytrismos d'un enfant. Il n'y a pas jusqu'à maintenant de données confirmant un culte des défunts, mais le soin que les habitants de Minoa portaient aux tombes témoigne de leur importance. Ce fait, en combinaison avec la position des tombes dans les murs de fortification, à côté de l'espace cultuel, ainsi que les trouvailles des tombes conduisent à l'hypothèse qu'il s'agit des tombes des $\gamma \varepsilon ́ v \eta$ aristocratiques de l'époque géométrique - peut-être des fondateurs de l'habitation. Il est très probable que cet endroit, caractérisé comme un lieu

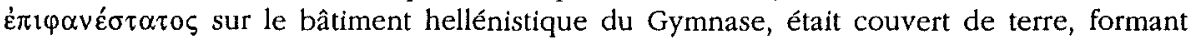
un tumulus, un sema; telephanes, peut-être un sanctuaire de défunts.

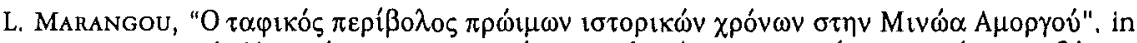

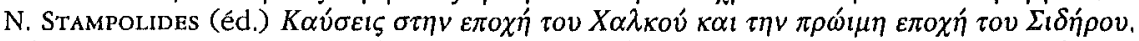
Athènes, 2001, p. 205-222. Cf. aussi la bibliographie récente, L. Marangou, PAAH (1997) [1999], p. 183-189.

- En 1998 ont éte effectués des travaux de conservation des éléments de construction du temple à Minoa. L'architecte G. Antoniou a commencé le rélevé topographique de tous les membres architecturaux; par ailleurs, des nouveaux éléments architecturaux ont été localisés dans des terrains et des constructions modernes avoisinants, et leur position initiale a été identifiée.

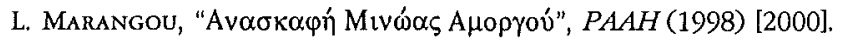


- L'A. a publié un guide des sculptures au Musée d'Amorgos dans lequel sont présentées des statues et des reliefs, par ex, une statue archaïque d'Artémis (p. 20, cf. Archaïsche und klassische griechische Plastik, Akten des Internationalen Kolloquiums vom 22-25 April 1985 in Atben I, 1986, p. 121-124), un relief peu connu de la fin de l'époque hellénistique représentant Déméter (p. 41), des offrandes à des sanctuaires, des statues liées aux rois et aux reines déifiés de l'époque hellénistique, des autels, etc.

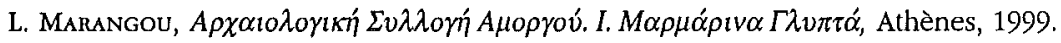

09.15 - Andros - XXI Éphorie des antiquités prébistoriques et classiques - Un nettoyage de la zone du temenos à l'habitation géométrique de Hypsilé a révelé une partie du péribole qui délimite la partie $\mathrm{N}$ du sanctuaire. Il y a aussi une réference à une tête d'une korè archaïque trouvée dans la région de Paliopyrgos; la tête pourrait provenir d'un bâtiment quadrilatéral de la région, probablement le même sanctuaire où a été trouvé le kouros $\mathrm{n}^{\circ} 14$ du Musée d'Andros. Une statuette d'Artémis a aussi été déposée au Musée d'Andros.

Chr. Televantou, $A D 49$ (1994) [1999], B'2, p. 678-687.

- Description d'un sanctuaire de l'époque géométrique récente, situé sur l'Acropole de Hypsilé, lequel, au $\mathrm{vl}^{\mathrm{e}} \mathrm{s}$. av. J.-C., est intégré dans un temple archaïque qui fonctionne jusqu'à l'époque classique. La nature des trouvailles de ce sanctuaire, comme par ex. des figurines de korai et de porcs, ainsi que le caractère chthonien et mystique du monument font penser à un Thesmophorion.

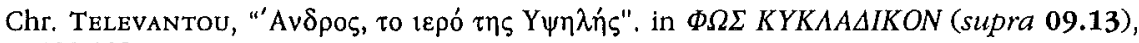
p. 132-139.

09.16 - Délos - École française d'Athènes - En étudiant la petite plastique chypriote (640-560 av. J.-C.), trouvée dans le sanctuaire délien, l'A. examine les relations du sanctuaire archaïque avec l'Orient ainsi que l'origine des offrandes et des pèlerins dans les différents lieux de culte de l'île. L'A. constate que la petite plastique chypriote de Délos, comme celle des autres sanctuaires, n'indique pas une présence chypriote en soi mais des relations étroites entre Délos et les Grecs de l'Est, où ce type de materiel est abondamment attesté pendant la période archaïque.

S. Fourrier, "Petite plastique chypriote de Délos", BCH 123 (1999), p. 373-388.

- L'A étudie les modes de présentation, de rangement et de conservation des ex-voto déposés dans les sanctuaires de Délos et répertoriés chaque année dans les inventaires déliens. La présentation du matériel votif visait à montrer la popularité du dieu. Les inventaires de la période de l'Indépendance privilégiaient le lien entre dieu et offrande, tandis que les inventaires plus tardifs mettent davantage l'accent sur la richesse du sanctuaire sous la deuxième domination athénienne.

Cl. Prêtre, "Le matériel votif de Délos. Exposition et conservation", BCH 123 (1999), p. 380-396.

09.17 - Délos - XXI Éphorie des antiquités préhistoriques et classiques - S'appuyant sur des sources littéraires, épigraphiques et iconographiques, l'A. examine le rôle de la musique et des chœurs dans les mythes 'et les rites déliens, notamment dans le culte d'Artémis et d'Apollon déliens.

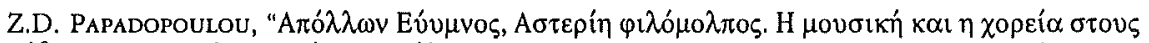

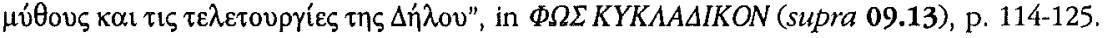

- L'A. pose le problème de l'identification de certains monuments déliens ('Autel des Cornes, la Théké et le Séma des Hyperboréens, le GD 42). Il fait l'hypothèse que l'unifica- 
tion de deux parties de l'Hymne bomérique à Apollon est liée à la fondation du monument GD 42, à identifier dans ce cas avec le temple d'Apollon Pythien.

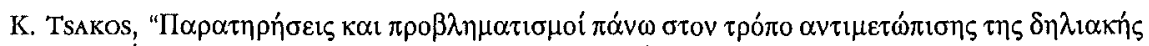

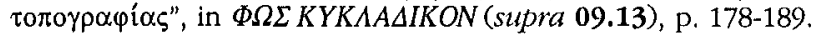

09.18 - Délos - Université d'Athènes, Musée Benaki - A. Delivorrias publie un relief inscrit, avec une représentation d'Apollon Délien, qui tient une bande et une branche de palmier, devant un autel, à coté d'un palmier. Ce relief pourrait provenir de Prasiai où le culte d'Apollon est établi et le contact avec Délos est ininterrompu.

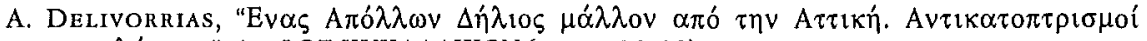

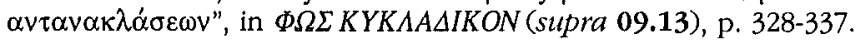

09.19 - Ios - XXIe Épborie des antiquités prébistoriques et classiques - L'A. publie un guide du Musée Archéologique de Ios. À partir des inscriptions exposées au Musée, elle se réfère aux dieux adorés sur l'île (Zeus Polieus, Athéna Polias, Apollon Pythien, Apollon Sôter, dieu chthonien Phytalmios). L'A. présente aussi des édifices à caractère cultuel, situés à l'extérieur des fortifications de l'ancienne ville, au NO de la colline de Kastro, ainsi que sur les sites côtiers Psathi et Ag. Théodoti, dans la partie E. de l'île.

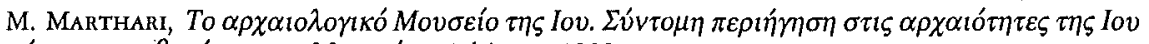

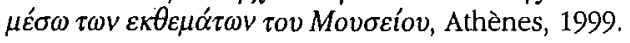

09.20 - Naxos - Dans le livret d'information du Musée souterrain du site de la Métropolis à Naxos, on trouve une brève description de l'aménagement d'une partie de la ville de Grotta qui était déjà florissante à l'époque mycénienne. Sur la partie côtière de la ville mycénienne, un tumulus a été aménagé où les habitants enterraient leurs morts dès l'aube du $\mathrm{I}^{\mathrm{er}}$ millénaire, dans des périboles familiaux, réaménagés pendant le $\mathrm{Ix}^{\mathrm{e}} \mathrm{s}$. en des unités plus grandes correspondant désormais à des genè (regroupant plusieurs familles) dont les ancêtres légendaires - censés remonter à l'époque mycénienne - reçoivent un culte qui va durer au moins pendant 800 ans. Voir aussi $P A A H$ (1982), p. 260-262; (1983), p. 299-304; (1984), p. 313-339; (1985); p. 163-167; (1994), p. 167-168; V.K. LambrinOUDaKIs, "Veneration of Ancestors in Geometric Naxos", in R. HäGG, N. Marinatos, G.C. Nordquist (éds), Early Greek Cult Practice, Stockholm, 1988, p. 235-246.

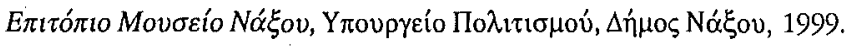

09.21 - Naxos - Université d'Athènes - L'A. publie la céramique provenant du cimetière situé dans la partie $S$ de la ville moderne de Naxos. Le matériel provient surtout des trouvailles de surface et des fouilles de sauvegarde effectuées par Ch. Karouzos, et surtout par N. Kontoleon. Malgré la pauvreté des données, l'A. aborde la question des rites funéraires; il semblerait que la crémation était la pratique la plus courante dans ce cimetière. L'A. aborde les questions des pratiques funéraires, des offrandes (notamment les «shoe models " et les oiseaux votifs), des semata et des croyances concernant la vie après la mort en rapport avec les éléments provenant d'autres cimetières, de Naxos et d'ailleurs.

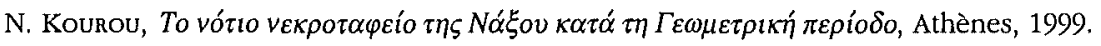

09.22 - Naxos et Paros - XXI Éphorie des antiquités prébistoriques et classiques - Ph. Zapheiropoulou examine les pratiques funéraires dans trois cimetières des Cyclades: d'abord le cimetière de Tsikalario (détruit en majeure partie par des fouilles clandestines), situé sur un plateau dans la campagne de Naxos. Le cimetière consiste en plusieurs constructions, surtout de périboles enfermant très probablement des tombes d'une famille (surtout des crémations). Avec la fin du viri ${ }^{\mathrm{e}}$ s., le cimetière devient un lieu de culte des défunts au moins jusqu'à la fin de l'époque archaïque. Dans le cimetière du site côtier Plithos à Chora de Naxos, en usage du début du $\mathrm{x}^{\mathrm{e}}$ jusqu'au virr ${ }^{\mathrm{c}} \mathrm{s}$., il n'y a pas de traces de culte des défunts; par contre, le culte des défunts héros ancêtres a lieu dans le voisinage du site de Metropolis, dans les ruines de la ville mycénienne (cf. 09.20). À 
Paroikia de Paros, au NO de la ville moderne près du port ancien, a été découvert un grand cimetière (les fouilles ont commencé en 1983 et continuent jusqu'à aujourd'hui). Il était en usage de la fin du viII ${ }^{\mathrm{e}} \mathrm{s}$. av. J.-C. jusqu' au $\mathrm{IV}^{\mathrm{e}} \mathrm{s}$. ap. J.-C. Dans ce cimetière ont été trouvées des traces de culte des défunts seulement sur deux fosses contenant un ensemble d'urnes cinéraires (à peu près 150 ).

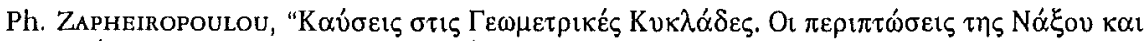

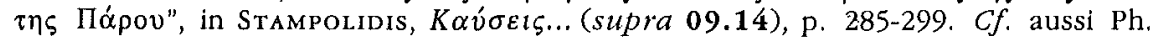
Zapheiropoulou, "I due "polyandria" dell'antica Necropoli di Paros", in Annali di Archeologia e storia antica, n.s. 6 (1999), p. 13-24.

09.23 - Paros - XXI Éphorie des antiquités prébistoriques et classiques - L'A. publie trois statues et une base d'ateliers pariens, trouvées à Paroikia de Paros, à côté d'une construction trapézoïdale, qui peut être identifiée soit à un sanctuaire hypèthre, soit à un péribole ou à un temenos (voir aussi $A D 48$ (1993), B'2, 434-436, $A D 49$ (1994) [1999], B'2, p. 665). Il est intéressant de constater que, dans des terrains avoisinants, ont été découvertes des constructions provisoires avec des traces de pyrai, des os et des tessons datant surtout de l'époque géométrique; à une distance de quelque $20 \mathrm{~m}$ de la construction trapézoïdale, dans un terrain avoisinant, a été aussi découvert un monument funéraire rond en gradins, contenant au centre une urne cinéraire; autour du monument, des traces de pyrai ont été localisées. Les gradins de ce monument portent des incisions de phalloi avec des traces de pieds qui identifient le monument comme berôon.

La première statue examinée dans l'article est une gorgone archaïque d'un type unique, trouvée au SE de la construction trapézoïdale. La statue était probablement un ex-voto, dressé dans un temenos hypèthre. Peut-être faisait-elle faisait partie d'un berôon, puisque, selon $\mathrm{N}$. Kontoleon qui a publié les plaques de Archilocheion, les berôa archaïques à Paros avaient une forme monumentale. Tout près de la statue de Gorgo, un kouros archaïque a été trouvé; les donnés de la fouille conduisent à l'hypothèse qu'il s'agit peutêtre d'un monument funéraire en l'honneur d'un défunt héroïsé qui était dressé, comme la statue de Gorgo et le monument funéraire rond en gradins, dans cet endroit qui était peut-être dédié au culte des défunts importants de la ville de Paros, héroïsés; il est aussi probable que la troisième statue de kouros, trouvée au même endroit, avait une fonction comparable.

Ph. Zapeiropoulou, "Parische Skulpturen", Antike Plastik 27 (2000), p. 7-35.

- L'A. présente un fragment de cratère attique à figures rouges, trouvé au cimetière de Vitzi, à Paroikia, daté de $c a 400$ av. J.-C., Athéna et Aphrodite sont représentées en tant que déesses courotrophes, dans une scène probablement liée à la fête de l'agrégation des enfants. Une partie d'une deuxième figure enfantine, membre de la même famille (?), avec des feuilles de lierre dessinées autour de sa tête, est probablement liée à la fête des Anthestéries.

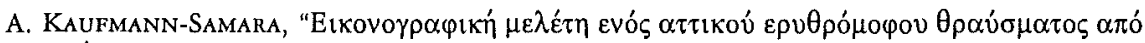

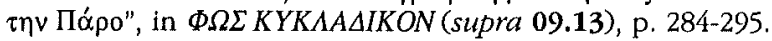

09.24 - Siphnos - N. Kourou (Université d'Athènes) réexamine en détail les deux figurines tournées trouvées dans un dépôt votif pendant les fouilles de Brock et Young (ABSA 44 [1949], p. 1-92) au Kastro de Siphnos, et provenant très probablement d'un sanctuaire non localisé. L'A. se refère à la tradition minoenne-mycénienne des statues féminines tournées et souligne la contribution de Chypre à la préservation du type. L'iconographie de la décoration de ces statuettes ainsi que leur provenance (sanctuaires de déesses féminines) suggèrent que le type était étroitement lié à une déesse de la nature, une Potnia therôn. Pour les statuettes de Kastro, elle observe que les éléments mis au jour par les fouilles permettent une identification soit avec Artémis, soit avec Athéna; en s'appuyant sur la tradition littéraire concernant les cultes de Siphnos, l'A. propose 
l'identification de la déesse adorée au sanctuaire de Kastro à une Potnia therôn, une préArtémis, qui fut peut-être identifiée ensuite à Artémis Ekvateria.

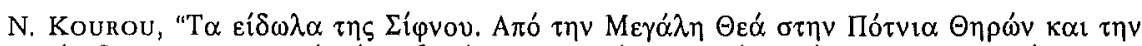

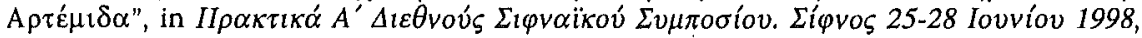
Athènes, 2000, p. 351-370.

09.25 - Siphnos - XXI Éphorie des antiquités prébistoriques et classiques - Dans un article concernant les artistes dionysiaques qui se sont produits à Siphnos, l'A. se réfère aux fêtes de l'île, connues par les inscriptions, et plus précisément aux Dionysies, pendant lesquelles un des artistes mentionnés dans les inscriptions siphniennes fut honoré. $\AA$ l'occasion d'un autre décret honorifique, l'A. se réfère aussi aux Euaggelia, les fêtes célébrées à l'occasion d'un événement joyeux (comme par ex. une victoire royale), et pendant lesquelles la propagande monarchique était pratiquée. Elle souligne aussi le rôle des technites dionysiaques, protégés souvent par les Épigones, dans le culte du roi qui, à l'époque hellénistique, était considéré comme l'incarnation de Dionysos.

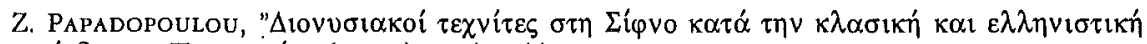

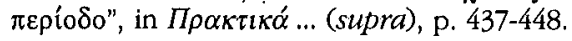

- En faisant un relevé des antiquités de Siphnos à travers les sources littéraires, les témoignages des voyageurs et les trouvailles archéologiques, l'A. se réfère, entre autres, aux cultes de Siphnos. Elle examine en détail les informations des voyageurs concernant le sanctuaire du dieu Pan et elle mentionne une inscription concernant la construction d'un temple à l'époque romaine.

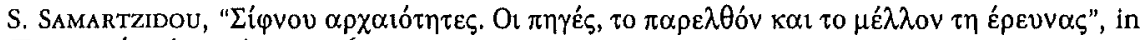

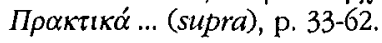

- L'A. (Université d'Athènes) s'interroge sur les raisons qui ont conduit les Siphniens à dédier leur Trésor à Delphes et non à Délos comme on l'attendrait d'un peuple insulaire d'origine ionienne. L'A. associe ce fait à l'oracle delphique donné aux Siphniens concernant leur destin; il pense que les sujets représentés sur les parties sculptées du Trésor étaient choisis non par les dédicants mais par les prêtres du sanctuaire qui voulaient, à travers ce monument ainsi qu'à travers l'oracle, mettre en avant l'idéologie delphique et l'attitude d'Apollon envers l'bybris.

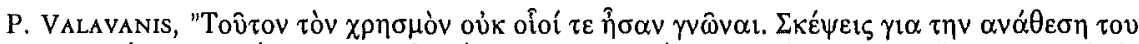

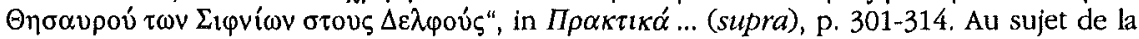
décoration du Trésor, $c f$. aussi la communication de K. SHEedY, dans le même volume, p. 219-226.

09.26 - Thera - XXI Éphorie des antiquités prébistoriques et classiques - Mise au jour d'un sanctuaire d'Aphrodite. Cf. Kernos 13 (2000), p. 241-245.

\section{Golfe Saronique (Athéna TsINGarida)}

09.27 - Egine - Deutscbes Archäologisches Institut - Après trois campagnes de fouilles dans le sanctuaire de Zeus Hellanios sur le Mont Oros, H.R. Goette livre ses conclusions concernant l'organisation de l'ensemble. Au centre d'une fortification remontant à l'HM et entourant le sommet de la montagne, on a construit, au plus tard à l'époque archaïque tardive, un temple en poros et un autel de type cycladique en marbre. C'est de cette époque que datent, par ailleurs, la majorité des restes architecturaux découverts sur le versant $\mathrm{N}$ de la montagne, à l'exception d'une cour à ciel ouvert, entourée de trois stoa érigées à l'époque où Égine était dominée par les rois de Pergame. Cette dernière construction devait être destinée aux banquets des pèlerins : le temple et l'autel étant reliés aux bâtiments du versant par une voie cérémoniale. Se référant à l'organisation de 
cet ensemble - une terasse comportant des bâtiments de cérémonies et une rampe imposante - le fouilleur y voit une sorte de Pompéion.

H.R. GoETTE, AR 2000-2001 [2001], p. 18-19.

09.28 - Poros (Kalaureia) - Institut archéologique suédois - Les recherches ont continué à l'intérieur et autour du bâtiment $\mathrm{D}$ du sanctuaire de Poséidon. Une tranchée, pratiquée au centre de la plus grande pièce du bâtiment, a révélé un mur mitoyen subdivisant l'espace en deux autres pièces de superficie égale. Des sondages profonds réalisés dans la partie occidentale du bâtiment ont également permis de changer la datation proposée par Wide en 1895. Ce dernier avait reconstitué deux phases d'occupation, une première remontant au $\mathrm{vi}^{\mathrm{e}} \mathrm{s}$. av. J.-C. pour la stoa, située au $\mathrm{N}$, et une deuxième, datée du $\mathrm{Iv}^{\mathrm{e}} \mathbf{s}$. av. J.-C., pour l'addition de la partie arrière de la construction. La fouille montre que l'ensemble, la stoa et le bâtiment, a été érigé au $\mathrm{Iv}^{\mathrm{e}} \mathrm{s}$. av. J.-C. sur un remblai comportant du matériel remontant au viII ${ }^{\mathrm{e}} \mathrm{s}$. av. J.-C. Les fouilles devront cependant être étendues pour vérifier ces conclusions.

B. Wells, $A R$ 2000-2001 [2001], p. 19.

\section{[10. Crète]}

\section{Chypre (Thierry Petrit)}

\subsection{0 - Généralités}

- Le propos de l'A. est de retracer l'histoire des recherches archéologiques à Chypre au cours du $\mathrm{xx}^{\mathrm{e}} s$. Il procède cependant à des retours en arrière au $\mathrm{xIx}^{\mathrm{e}} \mathrm{s}$. et, par là-même, rappelle dans quelles circonstances des personnages aussi hauts en couleurs que Luigi Palma di Cesnola et Max Ohnefalsch-Richter ont été amenés à fouiller nombre de sites cypriotes et notamment des sanctuaires, dont les objets furent souvent dispersés dans différents musées européens et d'Amérique du Nord. Les travaux de l'équipe suédoise sous la houlette d'Einar Gjerstad sont également évoqués.

P. Ásтӧм, A Century of International Cyprological Research (12 th Annual Lecture on the History and Archaeology of Cyprus), Nicosie, 2000.

- A. Hermary prend en compte les ex-voto dédiés dans les sanctuaires crétois, cypriotes et rhodiens. Il aboutit au constat d'une différence importante dans la nature des offrandes. Il est vrai que le nombre de sanctuaires connus varie considérablement d'une île à l'autre. A Chypre, l'A. distingue sanctuaires urbains, la plupart dédiés à une divinité féminine (la «Grande Déesse »), et sanctuaires ruraux, apanage, le plus souvent, d'un dieu masculin. Une des caractéristiques principales de Chypre est aussi la date relativement tardive de la fréquentation de ces sanctuaires : ils sont peu visités avant le $\mathrm{vIII}^{\mathrm{e}} \mathrm{s}$. av. J.-C. Une spécialité de Chypre est la statuaire en terre cuite de grandes dimensions, qui apparaît surtout dans les sanctuaires ruraux ou péri-urbains des dieux masculins, notamment Agia Irini, Idalion et Golgoi, alors qu'elle est presque totalement absente de Paphos, Tamassos, Amathonte et Kition. Parmi les sanctuaires féminins, on relève surtout Arsos, Idalion et SalamineAgios Barnabas. Les sanctuaires cypriotes présentent un visage très contrasté pour ce qui concerne les figurines de bronze. Elles sont nombreuses à Idalion, Tamassos, Agia Irini, Kourion, Lefkoniko, mais inconnues à Salamine et à Paphos (contrairement à ce qu'affirme l'A., elles ne sont pas totalement absentes d'Amathonte). Le chaudron en bronze, dont on connaît l'importance et le rôle dans les sanctuaires helléniques, est ignoré des sanctuaires cypriotes. Pour ce qui concerne les offrandes d'aegyptiaca, en 
particulier de petites faïences, seul le sanctuaire de Kition-Kathari en a livré une grande quantité.

A. Hermary, "Votive Offerings in the Sanctuaries of Cyprus, Rhodes, and Crete during the Late Geomatric and Archaic Periods", in V. Karageorghis, N. Chr. Stampolidis (éds), Eastern Mediterranean. Cyprus - Dodecanese - Crete. $16^{\text {th }}-6^{\text {th }}$ cent. B.C. Proceedings of the International Symposium beld at Retbymno-Crete in May 1997, Athènes, 1998, p. 265-275.

- En complément des travaux portant spécifiquement sur la Méditerranée occidentale, qui constituent l'objet même de ce volume, des études comparatives examinent la situation dans d'autres régions de la Méditerranée. L'A. présente les découvertes de céramiques attiques du $\mathrm{IV}^{\mathrm{e}} \mathrm{s}$. dans différents sites et surtout dans différents contextes cypriotes. Le contexte funéraire ne doit ici être mentionné que pour les trouvailles exceptionnellement abondantes de la nécropole de Marion, qui pourraient être associées à des rites funéraires spécifiquement grecs en usage dans la cité. Mais ce sont évidemment les découvertes de ce type de céramique dans un contexte religieux qui nous intéressent ici. On en trouve très peu à Paleapaphos-Kouklia ou à l'Aphrodision d'Amathonte, de même dans les sanctuaires de Tamassos et celui d'Apollon Hylatès à Kourion. Le seul sanctuaire cypriote qui ait livré beaucoup de céramique attique du $\mathrm{Iv}^{\mathrm{e}} \mathrm{s}$. est celui de Kition-Kathari. Comme ceux trouvés à Kition-Bamboula (Kition-Bamboula II), ces vases sont liés au monde dionysiaque et à la pratique du symposion. L'abondant matériel à vernis noir découvert près du rempart de Salamine semble également provenir d'un lieu de culte qui n'a pas encore été localisé (Salamine VIII). Le troisième contexte est celui de l'habitat qui ne nous intéresse que médiocrement ici. Il s'agit surtout de résidences princières (Vouni, Paleapahos). Signalons toutefois que la très abondante céramique du Palais d'Amathonte, que l'A. assigne à cette catégorie "habitat», pourrait fort bien provenir, pour partie au moins, de sanctuaires palatiaux dont la présence est attestée par de très nombreux exvoto ou fragments d'offrandes votives découverts dans le même contexte. Ainsi devraient être nuancées les conclusions de l'A. sur le contraste entre l'abondance de céramique importée dans les habitats et sa rareté relative dans les sanctuaires.

A. Hermary, "La céramique attique du ive siècle à Chypre", in B. Sabattini (éd.), La céramique attique du IV siècle en Méditerranée occidentale. Actes du colloque international organisé par le Centre Camille Jullian, Arles, 7-9 décembre 1995, Naples, Centre Jean Bérard, 2000, p. 277-281.

- À l'occasion de la publication d'un catalogue de quelque 500 pièces de la collection Cesnola du Metropolitan Museum of Art de New York (voir infra, V. Karageorghis et al.), un certain nombre d'entre elles ont fait l'objet d'un réexamen. Ainsi l'A. reconsidère-t-il la coupe en argent 4557 du catalogue de Myres (1914), datée avec vraisemblance du vil ${ }^{\mathrm{e}} s$., sur laquelle deux personnages, l'un masculin, l'autre féminin, banquettent couchés. Au vu de la nouvelle lecture que l'on a pu donner des inscriptions qui les surmontent, les personnages sont identifiés respectivement comme la déesse qui protège Chypre, Kypromedousa, et comme le roi de Paphos, dont la dynastie entretenait des liens privilégiés avec la Grande Déesse. Toutefois on ne peut totalement écarter l'idée que le personnage masculin serait son parèdre (Adonis ou Melqart).

A. Hermary, "Déesse plutôt que reine ? $\AA$ propos d'une coupe en argent de la collection Cesnola", CCEC, 30 (2000), p. 67-78.

- Avec l'étude d'Apollon, Héraclès et Athéna à Chypre, cet article peut servir de prélude à l'ouvrage du même auteur consacré à l'ensemble des dieux et héros grecs de l'île ( $c f$. infra, p. \$).

V. Karageorghis, "Greek Gods and Heroes in Cyprus: A Preview of the Problem", in O. Palagia (éd.), Greek Offerings. Essays on Greek Art in bonour of John Boardman (Oxbow Monograph 89), Oxford, 1997, p. 221-229. 
- Cet ouvrage de V. Karageorghis tant attendu comble un vide important dans la documentation archéologique cypriote, sans pour autant remplacer le catalogue de Myres ( $A$ Handbook of the Cesnola Collection of Antiquities from Cyprus, New York, 1914), plus exhaustif, mais infiniment moins bien illustré et d'ailleurs très ancien. Il s'agit de la plus riche collection d'objets cypriotes hors de l'île. Elle est due, comme l'on sait, à l'activité insatiable, quoique parfois brouillonne et peu scientifique, de Luigi Palma di Cesnola, consul des États-Unis à Chypre dans les années 1860 et 1870 . Nombre de ces objets proviennent de sanctuaires (Golgoi notamment) et constituent donc une collection remarquable d'ex-voto cypriotes, en particulier dans le domaine de la statuaire en calcaire. Mais d'autres ouvres provenant de nécropoles constituent également des témoignages intéressants sur les mythes répandus à Chypre, ou sur les divinités de l'île et les différents avatars sous lesquels elles étaient connues. Ainsi en est-il du sarcophage d'Amathonte, et de celui de Golgoi. Trois des quatre parties de l'ouvrage intéressent la présente chronique (parties II à IV, p. 77-293, qui vont de l'époque géométrique à la fin de la période romaine). Il est impossible d'énumérer les multiples apports de ce catalogue pour l'histoire de la religion cypriote. Nombreux sont les objets significatifs pour les cultes, le personnel et les destinataires du culte à Chypre : on trouve des prêtres $\left(n^{\circ} 172\right)$, des représentations d'Héraclès ( $\left.n^{\circ} 190-192,334\right)$, de Géryon $\left(n^{\circ} 193\right)$, de Bès $\left(n^{\circ} 354\right)$; et, à l'époque hellénistique ou romaine, des images d'Artémis ( $\left.n^{\circ} 421\right)$, d'Artémis-Bendis ( $n^{\circ} 422$ ) ou de Pan $\left(n^{\circ} 423\right)$, etc. Bien que la provenance de ces objets soit le plus souvent difficile à établir, il reste qu'ils constituent un ensemble extrêmement riche, qui éclaire les pratiques cultuelles et votives des Cypriotes.

V. Karageorghis (en collaboration avec J.R. Mertens et M.E. Rose), Ancient Art from Cyprus. The Cesnola Collection in the metropolitan Museum of Art, New York, 2000.

- Les Phéniciens ont créé une iconographie religieuse qui emprunte à l'Égypte et au Proche-Orient. Parmi les créations originales, on trouve différents types d'êtres ailés. H. Matthäus suit l'évolution du motif du "démon " à quatre ailes sur des gemmes de type phénicien. C'est au viı ${ }^{\mathrm{e}} \mathrm{s}$. que ce motif arrive du Levant à Chypre où il peut être suivi jusqu'au $v^{\mathrm{e}} \mathrm{s}$. De là, il passe dans le monde égéen et même en Méditerranée occidentale. Ces êtres ailés doivent représenter des divinités ou des démons. Visiblement les Cyprịotes et les Grecs ont déjà éprouvé des difficultés à indiquer clairement le sexe des représentations, qui prennent çà ou là le sexe qui convient à leur emprunt. Un sceau découvert dans la tombe 212 d'Amathonte, où cet être est associé à Athéna et à une divinité égyptienne, finit même par suggérer son identification à une déesse, tandis qu'à Sparte cette représentation peut avoir été associée à la potnia tberôn / Artémis Orthia.

H. Matthäus, "Beobachtungen zu Motivwanderungen und Motivwandlungen in der phönikischen, zyprischen und archaisch griechischen Glyptik. Paradigmata religiöser Ikonographie", in P. Åström, D. Sürenhagen (éds), Periplus. Festscbrift für HansGünther Bucbholz zu seinem acbtzigsten Geburtstag am 24. Dezember 1999, Jonsered, 2000 (SIMA, 27), p. 87-105, pl. 27-30.

- Les fumigations sont un rite assez universellement répandu dans le monde méditerranéen au début du $\mathrm{I}^{\mathrm{er}}$ millénaire av. J.-C. L'encens est acheminé par caravanes des régions sudarabiques et de Somalie, à travers la péninsule arabique, en direction de la Palestine, de la Phénicie et du Levant puis exporté vers l'ouest par le trafic maritime phénicien. Avec l'encens se diffusèrent des formes de brûle-parfum, thymiateria, de type oriental, jusque dans les régions les plus éloignées de la Méditerranée occidentale. L'A. décrit les différents types de brûle-parfum phénicisants connus en Méditerranée, et notamment à Chypre. L'île représente un centre de diffusion très important pour le type II (à feuilles déversées), que l'on a parfois appelé candélabre : on le rencontre à Salamine, Amathonte, Tamassos, Kourion, Idalion et Marion. On en trouve aussi sans provenance précise, mais d'origine cypriote, dans de nombreux musées. Ils sont le plus souvent liés à 
un genre particulier d'offrande funéraire, propre à l'île. Les Phéniciens ne paraissent pas avoir connu ce rite funéraire; mais ces objets sont connus plus à l'est (Arslan Tash, Nimrud, Samarie), de même qu'en Méditerranée centrale et orientale. En Grèce, on les trouve plutôt comme ex-voto dans les sanctuaires. Un type plus rare, sans fût et à feuilles tombantes, est aussi attesté à Chypre (Amathonte et Kourion) à l'époque archaïque. Une trouvaille de la nécropole de Paleapaphos, datée par l'A. des environs de 1000 av. J.-C., pourrait bien constituer le premier indice du développement de la civilisation phénicienne dans l'île. Il est certain cependant que le nombre des trouvailles ne s'explique pas seulement par des importations phéniciennes, mais aussi et surtout par une abondante production locale.

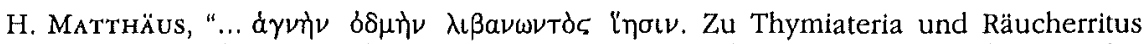
als Zeugnissen des Orientalisierungsprozesses im Mittelmeergebiet des frühen 1. Jahrtausends v. Chr.", Cabiers du Centre d'Études chypriotes 29 (1999), p. 10-31.

- En examinant les vestiges de sanctuaires, l'A. entend fournir des éléments déterminants dans la controverse sur la date de fondation des cités-royaumes cypriotes connues à l'époque historique. Son intention est, comme il l'admet lui-même d'emblée, « to gain some new perspectives on the historical process of the Achaean colonization of Cyprus through the study of the geographical background and the religion ». Ainsi il s'efforce de trouver dans le Péloponnèse pré-dorien les origines de certains cultes cypriotes. Pareilles prémisses devaient nécessairement conduire aux conclusions auxquelles aboutit l'A. En effet, conformément à pareille méthode, le prisme d'Asarhaddon de 673/2, qui ne mentionne pas Lapéthos, aurait moins de valeur, selon lui, que le témoignage de Lycophron (III ${ }^{\mathrm{e}}$ s. av. J.-C.), qui va dans le sens de la démonstration (p. 97).

Parce qu'il a des doutes (sic) sur la théorie selon laquelle les royaumes cypriotes n'auraient été fondés qu'au vir ${ }^{\mathrm{e}}$ s., l'A. imagine que le sanctuaire rural d'Agia Irini dépendait au début de l'Âge du Fer du royaume de Lapéthos. Il argue ensuite de la permanence des cultes dans le sanctuaire pour montrer la grande continuité entre Âge du Bronze et Âge du Fer, du $\mathrm{XI}^{\mathrm{e}}$ (puis, plus bas, du $\mathrm{xII}^{\mathrm{e}} \mathrm{s}$.!) au $\mathrm{vi}^{\mathrm{e}} \mathrm{s}$. Pareille démonstration pèche par plusieurs défauts rédhibitoires : pour n'en citer qu'un, l'A. omet de dire que le sanctuaire d'Agia Irini constitue une exception à Chypre, en ce qu'il offre la permanence d'un lieu de culte (sinon de culte) tout au long des époques géométrique et archaïque. De plus, dans les très rares sanctuaires qui présentent cette particularité, l'iconographie votive change totalement de faciès au Cypro-Géométrique III. L'A. minimise ces changements à Agia Irini (p. 100); ils sont au contraire radicaux (SCE II, 777-792; 817-822). Ainsi cette étude paraît essentiellement fondée, comme l'admet l'A., sur une "solid collective consciousness " et une "common oral tradition of the Achaean past " (p. 102), sentiment et source qui offrent peu de garantie au regard de la critique historique.

Th. Mavrogiannis, "Sanctuaries of the Cypro-Geometric Period: the cases of Marion and Agia Irini", in M. Incovou, D. Michaelides (éds), Cyprus. The Historicity of the Geometric Horizon (Proceedings of an Archaeological Workshop. University of Cyprus, Nicosia, $11^{\text {th }}$ October 1998), Nicosie, 1999, p. 95-107.

- Les collections du musée de Vienne comportent environ 700 objets cypriotes. La majeure partie des pièces provient des fouilles de Max Ohnefaslch-Richter et de John Myres entre 1869 et 1906. Une notable exception est constituée par le beau sarcophage des Amazones de la seconde moitié du Iv ${ }^{\mathrm{e}}$ s. av. J.-C. $\left(\mathrm{n}^{\circ} 1\right)$. Les objets ont été découverts dans le sanctuaire de Pyla, dans la nécropole d'Amathonte, à Agia Paraskevi, Idalion, Alambra, Tamassos ou Kition. On y voit un grand nombre de figurines et de statues d'époque archaïque et classique, ayant peu ou prou trait au culte ou aux rites funéraires : notamment des terres cuites modelées de la technique snow-man, des figurines moulées ou associant la technique du tour à celle du moulage, mais aussi des têtes masculines appartenant à des statues (votives ?) plus grandes. Dans la sculpture en pierre, on 
distingue des statues masculines et féminines, ainsi qu'une intéressante série de têtes de la fin de l'époque archaïque et de l'époque classique. Parmi les statues divines, on trouve une remarquable déesse assise, des courotrophes ou d'autres pièces plus rarement attestées du mobilier votif ou cultuel.

W. Seipel (éd.) (contrib. de A. Bernhard-Walcher, G. Dembski, K. Gschwantler, V. KARAGEORGHIS), Die Sammlung zyprischer Antiken im Kunsthistorischen Museum Wien, Vienne, 1999 (Sammlungskatalog des kunsthistorischen Museums, Band 2).

11.01 - Nicosie - À l'endroit où doit être édifiée la nouvelle Chambre des Représentants, un édifice a été fouillé qui montre des traces d'activités artisanales; en outre, un botbros a livré de la céramique du Cypro-Archaïque II et deux fragments de figurines en terre cuite; une autre fut découverte dans une fosse jouxtant le mur $S$ du bâtiment. Sur le sol du second état du bâtiment gisait une figurine de courotrophe. - Devant le Musée philatélique fut fouillée une série de fosses qui contenaient de la céramique cypro-archaïque et un petit fragment de figurine de cheval ou de centaure. Plus à l'E, près d'un édifice hellénistique, se trouvait un dépôt de cendres associées à du matériel céramique, une lampe, un brûle-parfum en calcaire peint et un fragment de scorie. - Au $\mathrm{N}$ du mur principal, on rencontra aussi un botbros du cypro-archaïque II, qui contenait, entre autres, des maxillaires de moutons et deux figurines fragmentaires en terre cuite représentant un personnage masculin avec une coiffe triangulaire et un bélier; des installations similaires s'étendaient aussi plus au S. - Des vestiges d'époque hellénistique ont aussi été exhumés sous l'aire de stationnement avec une grande quantité d'ocre et deux fragments de figurines en terre cuite.

\section{S. Hadjisavvas, BCH 123 (1999), p. 621-624.}

- En 1999, le Département des antiquités a continué ses fouilles sur la colline d'Agios Georgios, là où doit s'ériger le nouveau Parlement. Dans l'espace entre la chapelle et l'avenue Dimostheni Severi, dans les couches profondes, des tronçons de murs de la fin de l'époque romaine et de l'époque hellénistique ont été mis au jour avec des fragments de statuettes en calcaire et des figurines en terre cuite (p. 686). Dans le secteur VI, près de vestiges d'époque hellénistique qui constituaient une aire d'activités artisanales, deux stèles rectangulaires, qui servaient probablement d'autels, ont été révélées; et, non loin de là, des lacrymatoires, des lampes, deux autels votifs, des pesons de tissage, des outils de pierre et des tessons d'amphores, ce qui atteste de la double fonction de cette zone. Son utilisation va du $\operatorname{III}^{\mathrm{e}}$ au ${ }^{\mathrm{er}} \boldsymbol{s}$. av. J.-C. Dans le secteur IV, le sanctuaire hellénistique mentionné par Ohnefalsch-Richter au $\mathrm{xIx}^{\mathrm{e}} \mathrm{s}$., dont proviendraient des statues de belle facture, n'a pas été retrouvé, La présence de céramique hellénistique fait penser qu'il se trouvait bien à cet endroit, mais qu'il a été détruit par la construction de l'église anglicane voisine. Dans les couches inférieures, la fouille a révélé un grand nombre de fragments de figurines en terre cuite (des chevaux, des boucliers, etc.) appartenant à des groupes cheval-et-cavalier, ainsi qu'une figurine d'oiseau, une de singe et une figure féminine en cloche, peut-être plus ancienne.

\section{S. Hadjisavvas, $B C H 124$ (2000), p. 685-689.}

11.02 - Salamine-Enkomi - V. Karageorghis fait part de témoignages circonstanciés selon lesquels des fouilles illégales, sous l'égide de l'Université d'Ankara, ont repris sur le site de Salamine de Chypre, dans la partie $\mathrm{N}$ de l'île occupée par les troupes turques depuis l'été 1974. Des sondages auraient notamment été entrepris près du sanctuaire de Zeus, jadis fouillé par la mission française de l'Université de Lyon; des clichés pris sur place par des visiteurs montrent clairement que des fragments architecturaux et du mobilier ont été exhumés. 
V. Karageorghis, "Informations 1. Illegal Turkish excavations at Salamis", Cabiers du Centre d'Études chypriotes 29 (1999), p. 185-186.

- L'A. présente une série de sculptures en calcaire, des statues de grande taille en terre cuite et des figurines en terre cuite, qui proviendraient de tombes d'Enkomi, selon un carnet manuscrit de A.H. Smith et H.B. Walkers. Il s'agit de personnages féminins portant bijoux et/ou turbans. Pour expliquer la présence de ces objets à cet endroit, l'A. évoque des fouilles réalisées par Maria Hadjicosti dans la région d'Enkomi, et les trouvailles similaires qu'elle y a faites. Dès 1971, P. Dikaios avait suggéré qu'un petit établissement avait subsisté sur le site au début de l'Âge du Fer. M. Hadjicosti en avait conclu qu'un sanctuaire proche de la nécropole, où étaient dédiées des représentations féminines, était consacré à la Grande Déesse de Chypre, ce que semblent confirmer les statues et figurines du British Museum.

V. TAtron-Brown, "Sculptures and Terracottas from Enkomi in the British Museum", Cabiers du Centre d'Études chypriotes 30 (2000), p. 17-25.

11.03 - Achna (District de Famagouste) - Le vase étudié par l'A. provient de la région d'Achna, district de Famagouste, sans autre précision. Il appartient à la classe Bichrome IV, et date donc du Cypro-Archaïque (peut-être du $\mathrm{vII}^{\mathrm{e}} \mathrm{s}$.). Sa décoration est très originale, puisqu'il présente trois visages humains schématiques vus de face, reproduits de manière simplifiée. Il s'agit très probablement de représentations de masques, utilisés au cours de cérémonies rituelles. L'A. leur prête un caractère apotropaïque, et, grâce à des parallèles, en particulier les dinoi du cimetière à incinération d'Amathonte (infra 11.10), on pourrait leur assigner un usage funéraire.

E. LoukA, "Dinos du Musée de la Fondation Pierides à Larnaka", RDAC (1999), p. 203206.

11.04 - Kition - Après ses fouilles au sanctuaire de Kition-Kathari, V. Karageorghis avait proposé de voir dans le grand temple 1, édifié à la fin du $\mathrm{Ix}^{\mathrm{e}} \mathrm{s}$. sur. un temple du Bronze Récent, un sanctuaire d'Astarté, dont le culte aurait été instauré par les colons phéniciens. Cette attribution était essentiellement fondée sur une inscription gravée sur un bol de la fabrique Red Slip, découvert sur le premier sol du temple; elle fut contredite par plusieurs auteurs qui préfèrèrent voir dans le grand temple un sanctuaire d'Eshmoun-Melqart ou de Melqart, protecteur de la dynastie locale. Cette interprétation reléguait ainsi Astarté dans le petit temple 2. L'A. ne croit pas à la possibilité d'un culte de Melqart dans les premiers temps du temple (à la fin du $\mathrm{Ix}^{\mathrm{e}}$ s.). En effet, au Bronze Récent, le temple était dédié à une divinité protectrice de la métallurgie. En attendant la publication prochaine des niveaux phéniciens, l'A. présente plusieurs figurines féminines, découvertes sur le sol du $\mathrm{xI}^{\mathrm{e}}$ s., dont des "déesses aux bras levés », d'autres se teriant les seins et une dea gravida. Ces trouvailles laissent penser que la divinité tutélaire du temple était bien une déesse. Au $\mathrm{Ix}^{\mathrm{e}} \mathrm{s}$., Kition devint une des principales colonies de Tyr, ville dont le rol, Ethbaal, était aussi et avant tout prêtre d'Astarté. Quoi de plus normal, dans ces circonstances, de lui avoir dédié le grand temple de la colonie ? Sachant que des figurines masculines ont été trouvées au même endroit, doit-on alors supposer qu'au cours des temps, le dieu poliade, Melqart, remplaça Astarté dans le temple 1 ? L'A. pense plutôt que la déesse y était vénérée avec son parèdre masculin, un $\mathrm{Ba}^{c} \mathrm{al}$, phénomène assez fréquent dans l'Antiquité.

V. Karageorghis, "Astarte at Kition", in R. Role, K. Schmidt (éds), Archäologische Studien in Kontaktzonen der antiken Welt, Göttingen, 1998 (Veröffentlicbungen der Joachim Jungius - Gesellschaft der Wissenschaften. Hamburg, 87), p. 105-108.

- L'A. analyse les restes osseux découverts par V. Karageorghis dans les couches phéniciennes des temples 1 et 4 de Kition, soit dès après l'installation des Phéniciens à Kition, vers le milieu du $\mathrm{Ix}^{\mathrm{e}} \mathrm{s}$., et jusqu’à la haute époque hellénistique. Ces restes proviennent 
des rites sacrificiels opérés dans le sanctuaire et furent enfouis ensuite des botbroi qui se trouvaient à proximité des tables d'offrandes, dans le Saint des Saints ou dans les différentes cours ouvertes devant les temples. Sur 1328 échantillons identifiables, 97,5\% appartiennent à des espèces domestiques, bœufs, moutons, chèvres, porcs, chiens, ânes et chevaux; les $2,5 \%$ restants proviennent d'espèces sauvages, daims, lièvres, mais aussi quelques oiseaux, reptiles et poissons. La majorité des espèces domestiques était constituée de bœufs, moutons et chèvres. On trouve à cette époque, comme dans les couches préphéniciennes, des crânes de bovidés qui servaient manifestement de masques aux prêtres et aux fidèles. La plupart des crânes proviennent de jeunes boufs et un seul d'une vache, espèces dont on trouve de nombreuses représentations dans la coroplathie et la peinture de vase. La plupart des bovins furent sacrifiés entre deux ans et deux ans et demi. La tradition connue à l'Âge du Bronze de pratiquer des entailles sur les omoplates de bovins perdure aussi à l'époque phénicienne. On hésite encore à attribuer à ces objets une fonction oraculaire ou musicale. Dans l'avant-cour du temple 1, on avait déposé les squlettes en connexion de quatre moutons, ce que l'on peut interpréter comme des sacrifices de fondation associés à la reconstruction du grand temple d'Astartè, après sa destruction vers 800 av. J.-C.

G. Noвrs, "Tierreste aus dem phönizischen Kition", in 丸̊ströM - SürenHAGEN, Periplus (supra 11.00), p. 121-134, pl. 32-34.

- Cette rencontre fut l'occasion pour l'A. de comparer les développements de Salamine et de Kition avant l'installation des Phéniciens sur le site de cette dernière, notamment du point de vue culturel. À Salamine, la fouille a révélé, près du rempart de la ville, un sanctuaire dédié à un dieu masculin, révéré sous la forme taurine, qui fut en activité pendant toute l'époque géométrique et archaïque. Les minces vestiges architecturaux qui furent découverts ne montrent aucune rupture avec les usages illustrés à Enkomi à la fin de l'Âge du Bronze. Sur le site de Kition, occupé dès le xir ${ }^{\mathrm{e}}$ s., le sanctuaire de Kathari perdura jusqu'au $\mathrm{xi}^{\mathrm{e}}$ s., mais fut abandonné vers $1000 \mathrm{av}$. J.-C., ainsi que les ateliers métallurgiques qui en dépendaient. Le quartier des temples fut réoccupé dès l'arrivée des Phéniciens au $\mathrm{IX}^{\mathrm{e}} \mathrm{s}$. Il connut alors une renaissance autour des grands temples phéniciens. $\mathrm{Au}$ lieu-dit Bamboula, un temple fut élevé pour la première fois au $\mathrm{Ix}^{\mathrm{e}} \mathrm{s}$.

M. YoN, "Salamis and Kition in the 11th-9th Century B.C.: Cultural Homogeneity or 'Divergence?", in IAcovou, - Michazlides Cyprus (supra 11.00), p. 17-33.

11.05 - Athienou-Malloura - Dans la partie orientale du sanctuaire rural d'AthiénouMalloura, dont la période d'activité va de l'époque archaïque à l'époque romaine, la fouille sous le sol du $\mathrm{IV}^{\mathrm{e}} \mathrm{s}$., menée jusqu'au rocher vierge, a livré des omoplates de moutons ou de chèvres portant des syllabogrammes cypriotes qui évoquent la "bonne fortune... ", ainsi qu'une figurine en terre cuite du type Astarté/Aphrodite, les mains sur la poitrine (plaquette d'Astarté ?). Le sanctuaire avait jusqu'alors livré des statues en pierre et des figurines divines ou votives masculines, notamment une statue du $v^{e} s$., presque grandeur nature (musée de Larnaka), mais très peu de figurines féminines. Dans la partie occidentale du sanctuaire, on a découvert les fondations d'un péribole, associé à une grande quantité d'objets : notamment une statue en calcaire intacte d'un tiers de la taille normale, qui montre un personnage masculin vêtu, avec une coiffure conique; l'œuvre est datée du milieu du $\mathrm{vI}^{\mathrm{e}} \mathrm{s}$. ou peu après. De nouveaux sondages ont été pratiqués, qui avaient pour but de localiser les limites occidentales du sanctuaire. Des trouvailles permettent de dater son installation de l'époque hellénistique (monnaies d'Alexandre et lampes). Un autre mur témoigne de remaniements à l'époque archaiqque.

S. Hadjisavvas, $B C H 123$ (1999), p. 610.

- En 1999, dans ce même sanctuaire, des murs appartenant peut-être à un édifice couvert ont été révélés; et, parmi les trouvailles mobilières, des figurines en terre cuite, de la 
céramique et des lampes avec des monogrammes de potier, et six monnaies. Comme lors de précédentes campagnes, on a exhumé des statues en calcaire plus ou moins fragmentaires, dont les dimensions vont de quelques centimètres à une taille plus grande que nature. Parmi elles, on note quatre statues de personnages masculins grandeur nature, trois d'époque archaïque et une d'époque classique.

S. Hadjisavvas, BCH 124 (2000), p. 678.

11.06 - Pyrga - En 1960 et 1968, la découverte d'un abondant matériel votif a révélé l'importance du site de Pyrga, à la limite $\mathrm{N}$ du district de Larnaka (ancienne Kition). Les scarabées et les sceaux ont été publiés, mais ne constituent qu'une infime partie du matériel. Dans cet article, l'A. tente de replacer la glyptique dans un contexte historique. Le sanctuaire est situé aux confins de trois royaumes: Amathonte, Kition et Idalion. Son emplacement exact n'a pas été localisé, mais les objets découverts en surface constituent un échantillon assez représentatif pour mesurer l'importance du site. Les scarabées et les sceaux sont de différents types et ont avant tout une fonction magique. Des perles de verre, une bague à deux châtons en argent et un pendentif en forme de croissant de lune ou de cornes complètent les trouvailles de joaillerie. Les figurines sont au nombre d'une quarantaine. Elles sont pour la plupart d'un type attribué à une fabrique idalienne. On trouve un aigle, représentation exceptionnelle, des femmes portant des vases, un cheval provenant peut-être d'un attelage. Les statues en calcaire sont souvent très fragmentaires, mais certaines devaient être de grande taille. On peut distinguer deux groupes. Le premier (35 fragments) est constitué essentiellement de personnages féminins, dont deux musiciennes (lyre et tambourin). Il est antérieur à ca 550. Le second groupe est postérieur à $c a 530$ et se réduit à quatre fragments. Trois appartiennent à des personnages féminins vêtus à la grecque. Les inventaires du Cyprus Survey conservés à Nicosie signalent un sanctuaire en usage de l'époque géométrique à l'époque romaine. Mais les objets datant de cette dernière période sont très rares et proviennent d'un autre contexte que celui des pièces décrites. L'essentiel des trouvailles est d'époque archäque, entre le viI ${ }^{\mathrm{e}} \mathrm{s}$. et $c a 470$. C'est à ce moment que se multiplient dans l'île les sanctuaires ruraux (Agia Irini, par exemple). L'A. associe ce phénomène à la volonté des royaumes de s'affirmer politiquement par une meilleure maîtrise, et donc un "marquage ", du territoire. Or le sanctuaire de Pyrga montre une forte empreinte culturelle idalienne et une totale absence d'éléments caractéristiques de la production kitienne. En outre, S. Fourrier signale que la statue fragmentaire d'un Géryon de type idalien du British Museum fut découverte à Pyrga. Si cette interprétation d'un sanctuaire de frontière de l'État idalien devait être avérée, elle confirmerait l'étroitesse particulière du royaume de Kition, sans véritable chôra.

S. Fourrier, "Un sanctuaire de frontière à Pyrga", CCEC 30 (2000), p. 45-66.

11.07 - Idalion - Sont ici présentés quelque 44 fragments de statues en calcaire provenant d'une étable détruite dans le village de Dhali (près des ruines de l'ancienne Idalion). Dans la mesure où le grand père de l'actuel propriétaire avait été très actif dans l'entourage de Max Ohnefalsch-Richter, l'A. suppose qu'il s'agit de statues et de figurines fragmentaires provenant de la fouille du sanctuaire alors appelé " temple d'Aphrodite » et dissimulées ensuite. Ce serait donc des statues votives. Il s'agit de têtes masculines, parfois couronnées, parfois coiffées d'un bonnet pointu, d'un torse féminin, de mains, d'un quadrige grossièrement rendu, de figurines et d'un trône en terre cuite, de perles en verre, etc. L'ensemble des trouvailles va du Cypro-Archaïque II à l'époque hellénistique.

P. Flourentzos, "A Group of Sculptures from Idalion", in Åström - Sürenhagen, Periplus (supra 11.00), p. 59-62, pl. 19-22. 
- Malgré l'absence de vestiges architecturaux de l'Âge du Bronze, l'A. émet l'hypothèse d'une continuité cultuelle entre cețe époque et le Cypro-Géométrique III, à travers les Cypro-Géométriques I et II.

M. Hadjicosti, "Idalion before the Phoenicians: the Archaeological Evidence and its Topographical Distribution", in Iacovou - Michaelides, Cyprus (supra 11.00), p. 3554.

- La mission américaine de l'Université d'Arizona a poursuivi l'exploration du sanctuaire d'Adonis, sur l'acropole orientale, où un culte fut rendu au dieu depuis le viII ${ }^{\mathrm{e}} s$. jusqu'à l'époque romaine. Sous l'autel tardif a été dégagée une construction cypro-archaïque qui présente des similitudes avec des structures cultuelles de Yahweh ou d'Adonaï à Tell Dan et à Arad. Dans la ville basse, une fosse circulaire a été fouillée près d'un pressoir à huile; elle a livré de la céramique décorée et des fragments de figurines, qui attestent l'utilisation de cette fosse comme dépôt votif. Le plus ancien matériel remonte au viI ${ }^{\mathrm{e}}$ s., mais des tessons hellénistiques suggèrent que les dépôts n'ont peut-être pas été enfouis avant cette époque.

S. Hadjisavvas, $B C H 123$ (1999), p. 613-614.

11.08 - Agia Varvara-Almyras - Le site cuprifère de Agia Varvara-Almyras, repéré dès 1982 par l'A. dans la vallée de Sia, est l'objet d'investigations archéologiques depuis exactement douze ans et a fourni de nombreux renseignements sur les activités extractives et métallurgiques à Chypre. L'intérêt du site réside aussi dans sa chronologie. Alors que les activités métallurgiques de l'Âge du Bronze ont fait l'objet de nombre d'explorations archéologiques ou d'analyses historiques (A.B. Knapp), la totalité des activités domestiques, religieuses et métallurgiques d'Almyras ont été datées entre le vir et le $\mathrm{II}^{\mathrm{e}} \mathrm{s}$. av. J.-C. Outre les installations liées à l'extraction et à la transformation du minerai, d'autres sont plutôt liées à des activités domestiques, pour la plupart, mais aussi cultuelles. Certains types particuliers de céramiques, deux figurines en terre cuite et une statuette en calcaire montrent que le site était le cadre de certaines pratiques religieuses.

W. PASTNACHT, "Excavations at Agia-Varvara-Almyras: A review of twelve years of research", RDAC (1999), p. 179-184.

11.09-Tamassos - Le sanctuaire d'Aphrodite à Tamassos se compose d'un temple avec une avant-cour et d'un autel. Dans ce secteur, deux couches archéologiques constituées de deux importants dépôts votifs ont été fouillées par la mission archéologique allemande. Le plus ancien correspond au temple des $\mathrm{vII}^{\mathrm{e}}$ et $\mathrm{vl}^{\mathrm{e}} \mathrm{s}$., le plus récent au temple d'époque classique. En septembre 1975, plusieurs morceaux d'un petit groupe fragmentaire en calcaire furent découverts près de l'autel. Le fragment conservé a une largeur de $15,1 \mathrm{~cm}$, pour une hauteur restituée d'au moins $22 \mathrm{~cm}$. Manquent les têtes des deux personnages et les jambes du personnage masculin. La manière empressée dont l'homme saisit la femme de son bras droit évoque une scène de rapt. Un élément vertical avec des rainures obliques pourrait appartenir à une autre représentation de plus grande taille, peut-être une divinité, de laquelle le personnage masculin tenterait d'éloigner la femme. L'A. évoque plusieurs mythes dont le groupe pourrait être la représentation: quoique l'enlèvement de Perséphone par Hadès ne soit pas exclu, l'A. penche poủr le rapt des Leucippides. Le groupe doit être daté de la première moitié du $\mathbf{~ v}^{\mathrm{e}} \mathrm{s}$.

W. Wamser-Krasznai, "Frauenraubszene. Eine Kalksteingruppe aus Tamassos", in ÅströM - SÜrenhaGen, Periplus (supra 11.00), p. 183-188, pl. 58.

11.10 - Amatbonte-Limassol - La communication de D. Christou au colloque de Rethymno fut l'occasion de faire connaître la découverte en 1992, lors d'opérations illégales de terrassement, d'une nécropole à incinération de type phénicien, trouvaille pour l'heure unique à Chypre, que d'aucuns, sans doute hâtivement, ont identifiée à un 
tophet. Lors de la construction, dans cette zone très touristique, d'un hôtel de grande taille, les excavatrices mirent au jour, à quelques dizaines de mètres de la plage de la cité antique d'Amathonte, quelque 340 urnes cinéraires, dont 159 du type dinos. Les vases contenaient des restes de squelettes brûlés, ainsi que le matériel qui leur était associé, savoir plus d'un millier d'objets : des cruchettes, des bols, des plats, des mors de chevaux, des astragales, des anneaux d'argent, etc. Les urnes elles-mêmes appartiennent aux classes III et IV de Gjerstad, ce qui nous place au Cypro-Géométrique III et au Cypro-Archaïque IA $\left(\mathrm{V}_{\mathrm{III}} \mathrm{e}^{\mathrm{V}}-\mathrm{VII}^{\mathrm{e}} \mathrm{s}\right.$ ); mais on trouve aussi des formes céramiques proprement phéniciennes. Des analyses ont montré que la plupart des ossements appartenaient à des enfants, des oiseaux, des agneaux et des chevreaux, Selon D. Christou, il existerait un lien fonctionnel entre cette découverte et des structures révélées en 1982, distantes d'une centaine de mètres de la nécropole à incinération. Elles se composent de deux parties distinctes. La première consiste en une substructure circulaire de moellons et de pierres brutes de $c a$ $3,70 \mathrm{~m}$ de diamètre, associée à une construction rectangulaire de $2,90 \times 1,80 \mathrm{~m}$. Le tout était entouré d'un épais mur de blocs. La seconde partie du complexe est un bûcher rectangulaire $(5,10 \times 3,30 \mathrm{~m})$ constitué de briques crues dans sa partie interne et de moellons de calcaire pour son parement. Trois couches de cendres successives couvraient le sol de ce bûcher. L'A. propose donc d'interpréter ces vestiges comme un temple miniature (sic) et son autel, associés à un bûcher où étaient pratiqués des rites qui précédaient l'ensevelissement. L'association se trouverait confirmée par la similitude des trouvailles céramiques du bûcher et des offrandes funéraires de la nécropole.

D. Christou, "Cremations in the Western Necropolis of Amathus", in Karageorghis -

Stampolidis, Eastern Mediterranean. Cyprus-Dodecanese-Crete (supra 11.00), p. 207-215.

- Une figurine fragmentaire d'un camélidé fut découverte en 1979 au cours des fouilles du sanctuaire d'Aphrodite à Amathonte et identifiée comme telle dès son invention. Elle provient d'un bothros du Cypro-Archaïque I (ca 750-600). Il s'agit de la seule représentation d'un dromadaire à Chypre, si l'on excepte la coupe en argent d'Idalion (motif reproduit fig. 3), dont on a souvent souligné le caractère phénico-cypriote. L'A. rappelle la rareté des représentations de dromadaires avant l'époque ptolémaïque; selon elle, ce type d'ex-voto serait lié à des considérations qui ne relèvent pas de la sphère aristocratique, et serait plutôt associé aux risques et profit du commerce.

B. Fischer, "Un dromadaire égaré ? À propos d'une figurine archaïque en terre cuite de l'acropole d'Amathonte à Chypre", CCEC 30 (2000), p. 27-43.

- Il s'agit là d'un des deux importants dépôts de céramique archaïque découverts dans le sanctuaire d'Aphrodite. Le matériel de cette grotte, située au cour de l'espace sacrificiel du temenos, est donc essentiel pour appréhender le culte voué à Aphrodite, à cette époque encore mal documentée. Le matériel est surtout constitué de céramique cypriote décorée, bien que l'on trouve quelques tessons de céramique importée et des fragments de figurines. Il ne s'agit cependant pas d'un botbros en place, mais plutôt d'un remblai pris ailleurs afin de combler la grotte. Il faut noter que ce matériel était mélangé à d'importantes quantités d'ossements carbonisés qui ont fait l'objet d'une analyse détaillée : la majorité des ossements provient d'ovi-capridés, mais le bœuf est également représenté, En revanche, l'absence de porc est remarquable (Columeau, BCH 120 [1996], p. 779-797). En outre, on a observé un net déficit des côtes et des vertèbres de ces animaux, ce qui signifie que les rachis et les côtes étaient emportés pour être consommés ailleurs. Ainsi les ossements, et donc les fragments de céramique qui leur sont associés, proviennent de la zone de sacrifice près de l'autel et non d'un lieu où se déroulaient les banquets sacrés. S. Fourrier suggère même que l'autel a pu être déplacé entre l'époque archä̈que, moment où il se trouvait à proximité de la grotte, et l'époque classique. C'est sans doute à l'occasion d'une destruction que la grotte fut abandonnée puis comblée. 
"La majeure partie des couches, qui ont servi à remblayer la grotte, date du CA II » soit ca $600-c a 480$ (p. 143), et sauf exceptions, les céramiques de la grotte ne peuvent en tout cas remonter au-delà du milieu du vir ${ }^{\mathrm{e}} \mathrm{s}$. Avant son comblement, la grotte elle-même devait avoir une utilisation cultuelle, sur laquelle on ne possède aucune indication. Son existence paraît même avoir été oubliée jusqu'à l'époque paléochrétienne. La totalité des céramiques cypriotes de la grotte appartient aux classes IV et V de Gjerstad, et date donc des Cypro-Archaïques I et II $(c a 750-c a$ 480). On dénombre 131 fragments de figurines différentes pour environ 32000 tessons. Certaines sont intéressantes, comme celle d'un personnage portant la main gauche sur le ventre et la droite contre la bouche, sans doute en signe d'adoration; ou encore ces personnages aux masques taurins ou anthropomorphes. On trouve aussi des masques miniatures en terre cuite, quelques représentations de cavaliers et seulement deux figurines féminines (une plaquette d'Astarté et une korè) - rareté qui étonne dans un Aphrodision -, des chevaux, des chèvres ou béliers, et peut-être un taureau, des fragments de char, un tambourin, peut-être un fragment de modèle de bateau. Comme la céramique, cette production coroplathique couvre l'ensemble de la période archaïque. On y voit aussi quelques objets en métal, dont une scorie qui atteste l'existence d'activités métallurgiques dans le sanctuaire, phénomène bien connu à Chypre (références à compléter par PETIT, Trans 12 [1996], p. 101-103). Un fragment de vase en cristal de roche, deux alabastres fragmentaires, quatre lentilles en cristal de roche, des éclats de calcédoine laiteuse, peut-être des loupes d'orfèvre, des perles en pierres semi-précieuses, qui attestent l'offrande de colliers, complètent l'inventaire. La céramique d'importation est extrêmement rare. La céramique locale, c'est-à-dire cypriote en général, mais plus proprement amathousienne, constitue donc l'écrasante majorité du matériel. Dans un chapitre conclusif (p. 141 sq.), l'A. tente de tirer les enseignements de ces trouvailles pour l'histoire du sanctuaire et son culte. Le terminus ante quem de la céramique de la grotte ne peut guère aller au-delà des premières années du ve s. Ainsi on peut associer la destruction du sanctuaire et le complet réaménagement dont il fut l'objet à cette époque avec les événements politiques et militaires dramatiques que connut l'île lors de la révolte contre les Perses. D'autres indices sont convoqués à l'appui de cette interprétation, notamment le dépôt de céramique de la terrasse $O$ et les trouvailles du palais ( $c f . B C H 112$ [1988], p. 873; BCH 113 [1989], p. 909). En outre, S. Fourrier serait tentée de voir dans cette grotte un lieu de culte dédié au dieu masculin associé à Aphrodite, fréquemment attesté à ses côtés dans des sanctuaires rupestres, qu'on le nomme Adonis, Adonis-Osiris, etc. De tels lieux de culte paraissent jouer un grand rôle dans l'« ensevelissement du dieu » ou de la divinité considérée comme bisexuée. Le caractère strictement local des offrandes céramiques semble attester que le sanctuaire d'Aphrodite, au moins pour les périodes concernées, était fréquenté essentiellement par des locaux. On peut ainsi le classer dans la catégorie des sanctuaires urbains consacrés à la divinité principale du royaume, comme à Salamine ou Idalion. Ils sont donc intimement liés au pouvoir royal. À ce titre, il est possible qu'un tel culte ait été réservé aux Amathousiens.

S. Fourrier, Le dépôt de la grotte à Amatbonte. Contribution à l'bistoire archaïque du sanctuaire d'Apbrodite (Mémoire de troisième année présenté par S. Fourrier, membre de l'École française d'Athènes, à l'Académie des Inscriptions et Belles Lettres), avril 2000 [inédit] $^{1}$

- Lors du dégagement du cimetière à incinération d'Amathonte (voir Christou, supra), un grand nombre d'urnes contenant des cendres humaines et animales ont été mises au

1 Je tiens à remercier tout particulièrement S. Fourrier d'avoir autorisé la consultation de son mémoire et la diffusion de ses principaux enseignements, en attendant la publication de son importante étude. 
jour. L'une d'entre elles est une amphore de la classe Bicbrome IV, qui présente, sous chaque anse, un décor peint montrant un visage humain. Provenant de la partie occidentale de la nécropole, elle contenait des os calcinés d'adulte, des tessons d'un vase à libation (cruchon), une épingle en bronze, un scarabée et une plaquette en os. Les visages peints sont barbus et reproduisent manifestement des masques, comme c'est le cas pour un autre vase de la nécropole $O$. Ainsi leur contexte funéraire suggère que ce motif comporte un symbolisme apotropaïque, à l'instar de simples masques en terre cuite trouvés dans les tombes. Il s'agit là d'une coutume funéraire phénicienne; les représentations peintes sur des vases constituent cependant une variante proprement cypriote de cette pratique. Signalons cependant que l'on trouve aussi de tels masques dans un contexte cultuel, comme au Palais d'Amathonte, parmi les nombreux ex-voto qui y ont été découverts $(B C H, 113,1989$, p. 907, fig. 75; $B C H, 118,1994$, p. 493, fig. 28).

E. LouKA, "La grande amphore LM 1441-47", RDAC (2000), p. 163-168.

- Les vases zoomorphes apparaissent à Chypre dès l'Âge du Bronze. Mais, dès le Cypriote Récent II, le taureau devient le thème principal de ce type de céramique. Puis ils disparaissent pour réapparaître à nouveau au Cypro-Archaíque II, quoique en quantité limitée. On en connaît actuellement 18 exemplaires. Ils sont de fabrique Plain Wbite, c'est-à-dire non décorés, non peints. Cette production paraît confinée à la région de Limassol-Amathonte, puisque 15 d'entre eux ont été découverts à Limassol même (au sanctuaire de Komissariato), à Agia Phyla, au N de Limassol, et à Agios Tychonas, au N d'Amathonte. Les trois autres sont de provenance inconnue. Tous ces vases sont réalisés sur le même principe : un vase tourné auquel on a ajouté les attributs taurins modelés. $K$. Nys distingue dans cette petite production quatre ateliers différents, désignés par les lettres A-D. On peut même réduire la production à deux ateliers seulement $(A+B, C+D)$. Plusieurs potiers sont identifiables dans le groupe A (atelier dit « de LimassolKomissariato "). On peut ainsi en déduire un certain nombre d'observations utiles pour la nature des cultes et la fréquentation des sanctuaires. On constate notamment qu'un atelier ne destinait pas sa production à un sanctuaire particulier.

K. NYs, "Detecting workshops of bull-shaped vases in the Cypro-Archaic period", RDAC (1999), p. 185-195.

- En 1992, le Département des antiquités de Chypre a réalisé des sondages sur la colline du Kastro près du village de Phasoula, dans le district de Limassol. C'est là que L. Palma de Cesnola avait identifié un sanctuaire de Zeus Labranios. Certains indices permettent d'avancer l'hypothèse qu'il s'agit là d'une zone d'ateliers plutôt que d'un sanctuaire: on ne trouve ainsi aucune trace de vestiges architecturaux en place ou même erratiques, malgré les caractéristiques de la pierre locale, propice à la taille; à quoi s'ajoute la découverte concomitante de statues inachevées et d'un grand nombre de déchets de taille. Cette hypothèse n'exclut pas cependant, selon l'A., la présence d'un culte à Zeus Labranios sis à proximité. La chronologie des trouvailles est désormais bien établie grâce à la découverte de deux monnaies datées du règne de Dioclétien et de Julien l'Apostat.

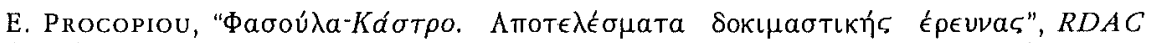
(1999), p. 315-323, avec un appendice de A. Destrooper-Georghiades, "The coins found at Phasoula-Kastro", p. 324-325.

- L'A. analyse une scène champêtre représentée sur une amphore du style d'Amathonte de la seconde moitié du $\mathrm{vi}^{\mathfrak{c}} \mathrm{s}$. av. J.-C. Le vase provient d'un contexte funéraire, mais éclaire sans aucun doute un rituel en relation avec la Grande Déesse de l'île. On y voit deux banquetteurs couchés à même le sol, allongés sous un arbre où se tiennent des oiseaux, tenant des coupes à boire; ils sont accompagnés de deux serviteurs, l'un avec une cruche, l'autre avec une couronne, et d'un joueur d'aulos. Le décor est agrémenté de fleurs, de plantes, d'arbustes et de palmiers-dattiers. On a souligné le lien entre les vases 
de cette fabrique et le culte d'Aphrodite dans la ville d'Amathonte. On ne peut donc y voir une scène purement profane. Les vases avec des scènes de banquets sont souvent découvertes dans des contextes funéraires. C'est aussi le cas ici, mais rien ne permet de situer la cérémonic elle-même dans un tel contexte. L'A. y voit un certain nombre de détails qui associent la scène à la déesse, notamment le palmier-dattier, symbole de fécondité, et les oiseaux. L'usage et la présence des jardins dans les cultes de divinités de la fécondité sont connus à Chypre et ailleurs. Une scène similaire attribuée à un atelier samien sur un vase de Fikellura aurait servi de modèle à la fête amathousienne. Certains textes décrivent la cérémonie tenue en l'honneur de l'Héra samienne et qui avait lieu en dehors de la ville. Ainsi l'A. considère que les analogies que l'on relève entre les deux scènes ne peuvent être dues au hasard et estime que la scène d'Amathonte s'inspire de l'iconographie de l'Héra de Samos.

E. Raptou, "Une "fête champêtre" à Amathonte et le culte d'Héra à Chypre", $R D A C$ (1999), p. 207-222.

- La mission de l'École française d'Athènes à Amathonte a découvert, près de la muraille $\mathrm{N}$ de la ville, une tête de statue en marbre, de grandeur nature, qui pourrait représenter Aphrodite, mais tout aussi bien Artémis ou Hygie. Les inventeurs rapprochent cette trouvaille de la découverte d'une inscription mentionnant un sanctuaire de Titus et Aphrodite à quelque quarante mètres de là. Un édifice contigu à cette même muraille a livré des fragments de décor en stuc, où alternent des losanges et des éléments figurés (coq, dauphin et buste d'Hélios), datês du $\mathrm{I}^{\mathrm{er}} \mathrm{s}$. de l'ère chrétienne. La couche de destruction d'une pièce de cet édifice, interprété comme un cantonnement, a livré trois autels portatifs, dont l'un en forme de cippe cylindrique et un autre en forme de table d'offrande, ainsi que des lampes qui pourraient avoir été disposées dans des niches (fig. 20-22)

P. Aupert et al., "Rapport sur les travaux de l'École française à Amathonte", $B C H 124$ (2000), p. 527-546.

11.11 - Kourion - L'A. fait le point sur les rapports entre les récits mythologiques ou légendaires attachés à la fondation de la ville et les vestiges archéologiques du site. Elle évoque notamment le culte d'Apollon Hylates dans le sanctuaire suburbain qui lui est dédié (p. 73-74). Quoique le nom du dieu n'apparaisse qu'au v $v^{\mathrm{e}}$ s. et son épiclèse à l'époque hellénistique, il est vraisemblable que son caractère silvestre doit être plus ancien de quelques siècles, ce que confirmeraient les trouvailles de terres cuites archaïques. Comme chacun sait, le sanctuaire répond au type habituel à cette époque : un temenos hypèthre avec plusieurs autels de cendres. Sa disposition rappelle celle des sanctuaires de l'Âge du Bronze, ce qui pourrait indiquer une volonté de continuité de la part de ses fondateurs, affirmation dont on laissera la totale responsabilité à l'A. Elle voit une confirmation de cette volonté dans la découverte d'une jarre du Bronze Ancien dans les niveaux les plus anciens de l'autel. Mais les trouvailles céramiques des niveaux de fondation ont permis de situer celle-ci à la fin du Cypro-Géométrique ou au début du Cypro-Archäque. L'A. rappelle aussi la découverte exceptionnelle de deux figurines de taureaux, l'une en or, l'autre en argent. Elle conclut ainsi que la disposition des lieux et les trouvailles mobilières ne présentent pas le caractère d'un culte «importé », mais, au contraire, une parenté avec l'Âge du Bronze local.

D. Buitron-Oliver, "Kourion: the Elusive Argive Settlement and its Burial Grounds from the 11th to the 8th Century B.C.", in Iacovou - Michaelides, Cyprus (supra 11.00), p. 69-77.

11.12 - Kouklia-Paleapaphos - Parmi les objets nouvellement entrés dans les musées de l'île, signalons, au musée de Paphos, une " tête de femme » reproduite sur une plaque rectangulaire en or appartenant à un diadème et provenant d'une tombe de la nécropole 
de Plakes; il pourrait s'agir d'une image d'Hathor d'un type déjà connu dans l'île sur de tels supports.

S. Hadjisavvas, $B C H 124$ (2000), p. 675, fig. 36.

11.13 - Rantidi - La mission américaine a nettoyé une favissa sur la colline Lingrin tou Diyeni. Les classes de céramique d'époque hellénistique permettent de montrer que le sanctuaire fut utilisé bien après le $\mathrm{vI}^{\mathrm{e}} \mathrm{s}$., époque à laquelle appartiennent la plupart des trouvailles naguère faites à cet endroit : ce sont des figurines en terre cuite de production locale du type snow-man, quelques fragments de statues en terre cuite grandeur nature, ainsi qu'une tête de démon grimaçant.

S. Hadjisavvas, BCH 123 (1999), p. 630-631.

11.14 - Prastio-Agios Savvas tis Karonis - Le West Cypris Project (soutenu par la Brock University, Canada) a pour but de mieux comprendre l'époque du Chalcolithique Moyen dans la zone d'investigation déjà choisie pour le Canadian Palaipaphos Survey Project (voir RDAC [1993], p. 381), à savoir le district de Paphos. Les environs du monastère d'Agios Savvas furent choisis comme site témoin pour préciser la chronologie de la zone. Des vestiges d'autres époques furent cependant découverts. Une tranchée de sondage stratigraphique semble avoir coupé une favissa d'époque archaïque (p. 210-212). Les fragments de figurines qui en proviennent sont au nombre de 25 . Elles sont toutes modelées (technique dite snow-man), et, à une exception près, elles paraissent toutes appartenir au type de la déesse aux bras levés. Certaines sont remarquables en ceci qu'elles sont peintes selon la technique Bichrome et portent le polos. Le $\mathrm{n}^{\circ} 4$ pourrait être un «charmeur de serpents », si les A. interprètent bien une sorte de boudin de terre cuite passé sur son épaule.

D.W. Rupp, L.-W. Sørensen et J. Lund, "Prastio-Agios Savvas tis Karonis monastery (Pafos District, Cyprus): 1992-1995 Cypro-Archaic ceramics and figurines and CyproClassical through Roman ceramics", RDAC (2000), p. 197-215.

11.15 - Nea-Paphos - Université de Catane - La sixième campagne de fouille de la mission italienne a permis de mieux comprendre l'édifice à abside construit à l'ouest du sanctuaire à hypogée d'époque hellénistique et romaine. Cette zone atteste du passage des cultes païens au christianisme vers le milieu du $\mathrm{Iv}^{\mathrm{e}} \mathrm{s}$. ap. J.-C.

F. et G. Giudice et al., "Pafos, Garrison's Camp. VIa Campagna", RDAC (1999), p. 279314.

- Les fouilles de la mission se sont poursuivies dans la zone du dromos. Elles ont mis en évidence une série de fosses. Il est difficile de déterminer si elles sont associées au sanctuaire chrétien ou au sanctuaire païen. Le matériel est essentiellement constitué de céramique qui va de l'époque hellénistique à l'époque romaine tardive.

F., G. et E. Giudice (et al.), "Pafos, Garrison's Camp. VII a campagna", RDAC (2000), p. $259-298$

- En 1998 et 1999, la mission italienne de Paphos-Garrison Camp (Toumballos) a poursuivi ses fouilles dans la zone du sanctuaire d'Apollon. On savait déjà que le quartier chrétien s'était installé dans la zone du dromos d'accès, au moment de l'abolition des cultes païens. Dans les niveaux anciens, une grande fosse, creusée dans le rocher, devait avoir une destination votive. De la céramique attique de la fin $d u v^{e}$ ou du début $d r^{c} s$. semble prouver que le site était occupé avant la fondation de Nea-Paphos.

S. Hadjisavvas, BCH 123 (1999), p. 624-625; S. HadjISAVVAS, BCH 124 (2000), p. 689.

- Université de Sydney - Un tronçon de rue d'époque romaine avec une séquence stratigraphique intéressante, notamment du point de vue de la céramique Cypriot Red Slip 
Ware, a été mis au jour par la mission australienne. Parmi divers objets, mais hors contexte, on relève une figurine en bronze d'Athéna du $\mathrm{Iv}^{\mathrm{e}} \mathrm{s}$. ap. J.-C. (p. 275 et fig. 4:4).

A. Rowe, "A Late Roman streetscape in Nea Pafos", RDAC (1999), p. 269-278.

11.16 - Marion - Université de Princeton - Les fouilles ont commencé en 1983 afin de révéler les deux cités que l'on suppose enfouies sous la bourgade actuelle de Polis tis Chrysochou: Marion et Arsinoé. Plusieurs secteurs ont déjà été explorés, parmi lesquels le plus clair et le plus complètement fouillé est celui d'un sanctuaire d'époque archaïque (B.D.7 : cf. BASOR, 308 [1997], p. 77-98). Un mur de péribole, renforcé aux angles par des blocs taillés, entourait un petit édicule avec un porche tourné vers le $S$; en face, se trouvait un autel. Le sanctuaire est sans doute déjà occupé dès le vin ${ }^{\mathrm{e}} s_{\text {, }}$, mais les premères constructions apparaissent à la fin du $v_{I^{e}}{ }^{2}$ ou au début du vir $\mathrm{s}$, av. J.-C. Ce premier édifice fut suivi, dans le courant du $\mathrm{vI}^{\mathbf{e}}$ s., par une série de pièces irrégulières disposées le long d'un axe NS. Elles donnaient sur un double porche au seuil de pierre taillée, sur lequel reposaient des colonnes, sans doute en bois, tandis qu'une seconde série de blocs, qui n'étaient pas en connection, marquent sans doute une seconde rangée de colonnes également en bois. L'édifice connut une fin brutale vers 500 av. J.-C. À l'intérieur du sanctuaire lui-même on exhuma des statuettes et des statues, ainsi que des thymiateria d'un type commun en Méditerranée orientale, des bols en bronze et des obeloi en fer. En 1991, une tranchée de sondage fut ouverte dans la partie orientale du sanctuaire et révéla une large cavité circulaire de cinq mètres de diamètre et trois mètres de profondeur, creusée dans le rocher, entièrement comblée de céramiques et de fragments de très belles terres cuites. Cette cavité servit de bothros pour la phase du sanctuaire qui prit fin vers 500. Un étrange dispositif trouvé à proximité pourrait, sous toute réserve, constituer une zone d'atelier où se fabriquaient les figurines dédiées dans le sanctuaire. Après ca 500 , une pièce fut établie sur la zone du bothros faisant face au $\mathrm{S}$. La date de cette construction peut être déduite d'un petit dépôt de trois figurines, dont une korè drapée à la grecque de la fin du Cypro-Archaïque. Cette dernière phase est modeste et de courte durée. On a évidemment mis en rapport la destruction de ca 500 av. J.-C. avec le siège dont les différentes cités cypriotes furent l'objet de la part des forces perses, lors de la répression de la révolte de l'île (Hérodote, V, 104-116). En outre, la brève période d'activité du dernier sanctuaire peut s'expliquer par les conséquences de l'intervention de Cimon à Marịon et à Kition vers 450 (Diodore, XII, 3, 3).

Plus près du village, le chantier A.H9 révéla une portion de la muraille urbaine; contre celle-ci, juste à l'intérieur de la ville, un petit sanctuaire d'époque classique, assez bien conservé, a livré des figurines de terre cuite, des statuettes et des fragments de statues colossales (voir infra, N. Serwin). Ils s'agit de personnages masculins et féminins. Des traces d'un important incendie ainsi que la chronologie des offrandes laissent penser que le sanctuaire fut détruit au moment où Ptolémée Sôter fit piller Marion (312 av. J.-C.). Seul un terminus ante quem pour la date de son établissement a pu être obtenu : la fin du $\mathrm{v}^{\mathrm{e}}$ s.; mais il se pourrait qu'il soit bien plus ancien. En outre, dans le mur d'un naïskos situé à proximité, furent trouvées une statue féminine drapée d'époque archaïque et une belle statuette drapée (p. 231, fig. 5:1) de la fin du $v^{\mathrm{e}}$ ou du début du $\mathrm{IV}^{\mathrm{e}} \mathrm{s}$. D'autres fragments statuaires et coroplathiques du $\mathrm{Iv}^{\mathrm{e}} \mathrm{s}$. furent aussi découverts dans les parages.

Dans le secteur E.G0, au $\mathrm{N}$ de la ville, à proximité des ruines d'un important édifice romain, des indices d'un sanctuaire d'époque classique ont été aussi révélés : un grand nombre de fragments de statuettes en calcaire représentant des hydrophores et au moins deux terres cuites montrant des truies avec des porcelets.

W.A.P. Childs, "Princeton excavations at Polis Chrysochous, 1994-1997: Interim Report", RDAC (1999), p. 223-236. 
- La statue fragmentaire étudiée par N. Serwin a été trouvée dans un contexte cultuel sur le site de Marion, sur la côte NO de l'île. Il s'agit sans aucun doute d'un matériel votif lié à un sanctuaire dont la fouille américaine a retrouvé les structures architecturales (voir supra, W.A.P. Childs); l'édifice fut détruit violemment vers la fin du $\mathrm{IV}^{\mathrm{e}} \mathrm{s}$. av. J.-C., sans doute lors des représailles menées contre la ville par Ptolémée Ier en 312. Selon l'hypothèse de l'A., la statue se dressait contre le mur arrière de la pièce SE de la cella du temple, face aux fidèles. La statue devait avoir une taille de quelque trois mètres de hauteur, ce qui en ferait la plus grande statue cypriote connue. Comme toutes ses congénères de grande taille, elle est composée de plusieurs parties assemblées. Subsistent les épaules, le torse et le haut des cuisses d'une statue masculine. Les épaules sont très larges, comme il est de coutume dans la statuaire cypriote. Les vestiges des cuisses indiquent que le personnage était vêtu d'un shenti assez stylisé. Elle est donc du style égyptianisant bien connu dans l'île. Elle porte des traces de peinture rouge et jaune. $N$. Serwin la date du $v^{e}{ }^{e}$ s, sans qu'une plus grande précision soit possible. Bien que les dominant par sa taille, l'œuvre était entourée d'autres statues et figurines par milliers.

N. Serwin, "A Colossal Terracotta Statue from Ancient Marion", in Åström - Sürenhagen, Periplus (supra 11.00), p. 173-181, pl. 48-57.

\section{Asie Mineure (Patrick Constancio, Isabelle Tassignon)}

\section{Lycie}

12.01 - Oinoanda - Université de Londres et Musée d'Isparta - Une étude consacrée à deux inscriptions repérées au cours de prospections des dernières années à Oinoanda met en évidence le rôle de cette localité comme oracle d'Apollon. Outre le fait qu'elle fasse aussi mention des Nymphes et de Dionysos, la plus récente des deux inscriptions, d'époque impériale, semble avoir appartenu à un petit berôon destiné à un prêtre d'Apollon, vraisemblablement un prophetes exprimant les oracles par les mots. L'autre inscription, datée de la fin de l'époque hellénistique, serait un oracle rendu par l'Apollon d'Oinoanda et constituerait le plus ancien témoignage du culte local.

N.P. Milner, "Notes and Inscriptions on the cult of Apollo at Oinoanda", AS 50 (2000), p. 139-149.

\section{Carie}

12.02 - Herakleia Salbakè [environs de] - DAI, Berlin - Reprenant les descriptions et les dessins des voyageurs et confrontant ces données aux blocs visibles sur place, $R$. Fleischer identifie les vestiges d'un grand sanctuaire d'Apollon. Les blocs de frise conservés montrent principalement divers épisodes du mythe d'Apollon ainsi que d'autres divinités : Héraclès, Aphrodite et Éros, Perséphone et Hadès, Zeus et Héra. Le monnayage d'Herakleia Salbakè frappé au type d'Apollon seul ou d'Apollon entouré de deux déesses - vraisemblablement Léto et Artémis - évoquerait le rôle prédominant d'Apollon dans cette localité. Par comparaison iconographique des types apolliniens représentés sur ces monnaies, l'A. date le sanctuaire et ses reliefs de la période julioclaudienne.

R. Fleischer, " Ein Heiligtum bei Herakleia Salbake in Karien ", $A A(2000)$, p. 405-453.

\section{Ionie}

12.03 - Milet (Sanctuaire d'Athéna) - Institut archéologique allemand - W. Held propose une publication d'ensemble de l'Athénaion de Milet depuis l'époque géométrique jusqu'« à l'époque classique » ( $c f$. infra). Le matériel découvert atteste l'impor- 
tance des importations orientales. Ce sont d'ailleurs des bronzes nord-syriens datés du $\mathbf{I x}^{\mathrm{e}}$ s. qui constituent les offrandes les plus anciennes. Cependant, on ne saurait exclure qu'il s'agisse là d'artefacts dédiés au vin ${ }^{\mathrm{e}}$ s., époque à laquelle le sanctuaire est certainement en activité. L'A. met aussi en évidence le caractère très « masculin » des offrandes - armes offensives et défensives - ainsi que l'absence d'offrandes en terre cuite. L'importance de l'Athénaion (structures et matériel) croît durant toute l'époque archaïque ce qui le distingue des autres sanctuaires de Milet au point que W. Held y verrait le sanctuaire principal de la cité ( $c f$. importance d'Athéna Poliouchos en Ionie), Malgré des aménagements importants à la fin du vir ${ }^{\mathrm{e}}$ s., le sanctuaire ne connaît aucun développement majeur dans la seconde moitié du vi $\mathrm{e}$., lors de la domination perse. L'A. suppose ainsi que le sanctuaire aurait été supplanté par ceux d'Apollon à Milet (Delphinion) et à Didymes. Il aurait été rasé en 494 par les Perses et reconstruit de manière monumentale au cours $d u v^{e} s$. On notera toutefois que cette présentation ne fait pas l'unanimité : depuis le dépôt du manuscrit (mai 1998) les résultats des fouilles effectuées dans le secteur du sanctuaire et publiées peu après ( $A A$ [1999], p. 373-413 et 415-438) ont mis en lumière que le temple « classique » constituerait, en réalité, le dernier état archaïque de l'Athénaion. De même, sur la question des origines du sanctuaire, W. Held rejette tout rapport avec les structures de l'Âge du Bronze découvertes dans ce secteur : celles-ci sont considérées comme un habitat présentant les traces d'un culte domestique. Les travaux menés dans ce secteur tendent à réduire l'hiatus chronologique évoqué par W. Held tout en soulignant l'importance cultuelle du secteur à l'Âge du Bronze : dans le cadre du «Projekt Minoisch-mykenisches bis protogeometrisches Milet», les fouilles dirigées par B. et W.-D. Niemeier ont permis de mettre au jour plusieurs autels en argile, des traces de sacrifices et du matériel à caractère cultuel (e.a. un rhyton à relief et les restes d'un trône carbonisé). Les structures se succèdent du BA au BR; le matériel renvoie aux dernières phases.

W. Held, "Das Heiligtum der Athena in Milet, Mayence, 2000; Jahresbericht 1999 des Deutschen archäologischen Instituts - Milet", $A A(2001)$, p. 599-600.

12.04 - Milet / Didymes (voie sacrée - sanctuaire des Nymphes) - Institut archéologique allemand - Les archéologues du DAI poursuivent leurs recherches sur la voie sacrée qui reliait le Delphinion de Milet au sanctuaire d'Apollon à Didymes. Les travaux ont porté sur l'emplacement supposé du sanctuaire des Nymphes, mentionné par la célèbre inscription des Molpes. Une prospection intensive et des sondages ont été effectués en 1994 à environ $4 \mathrm{~km}$ au $\mathrm{S}$ de la cité, aux alentours d'une source. Celle-ci provenait d'une faille rocheuse aménagée, accessible depuis la voie sacrée par une rampe d'environ 50 mètres et orientée vers le NE. L'occupation de ce secteur s'étend de l'époque archaïque à l'époque byzantine. Des thermes d'époque impériale furent aménagés à proximité. Au $\mathrm{S}$ de la rampe d'accès, plusieurs découvertes de surface peuvent être mises en rapport avec le caractère cultuel du secteur : un fragment de kymation archaïque (vers 530) pouvant appartenir à un autel ou à un édifice cultuel ainsi que deux fragments d'une korè. De même, une tuile en marbre découverte dans cette zone atteste la grande qualité de l'édifice qui avait été construit là.

H. Bumke, A. Herda, E. Röver, Th, Schattner, "Bericht über die Ausgrabungen 1994 an der heilige Strasse von Milet nach Didyma. Das Heiligtum der Nymphen?", $A A$ (2000), 1, p. 57-97.

12.05 - Epbèse (Artémision) - Institut arcbéologique autrichien - U. Muss passe brièvement en revue les « rapports » qui unissent l'Artémision d'Éphèse à d'autres régions du monde grec ou oriental. Si les importations ou la diffusion de certaines offrandes sont évoquées, ce sont essentiellement les parallèles formels qui suggèrent ces 
contacts qui sont mis en évidence. L'A. souligne ainsi les rapports avec la Crète (architecture et petite plastique géométriques et archaïques) et l'Étrurie (fibules et petite plastique, représentations figurées). Il en est de même pour Délos (e.a. autel aux cornes) et Syracuse (temple d'Artémis) où, comme à Éphèse, on trouve le toponyme d'Ortygie associé à la naissance des enfants de Léto.

U. Muss, "Das Artemision von Ephesos - Wege von und nach Westen", in Fr. Krinzinger (éd.), Die Ägais und das Mittelmeer. Beziebungen und Wechselwirkungen 8. bis 5. Jhs. V. Chr. (Akten des Symposions Wien 1999), Vienne, 2000, p. 149-155.

12.06 - Claros - Les terres cuites anthropomorphes archaiques, mises au jour dans deux dépôts votifs, sont brièvement analysées par $M$. Dewailly. Les figures masculines, identifiées à Apollon (attribut significatif) constituent des séries.peu variées et furent retrouvées en grande quantité. Elles seraient des productions locales destinées aux pèlerins soucieux d'honorer le dieu principal du sanctuaire. Par contre, les statuettes féminines constituent des séries variées et ne possèdent aucun attribut significatif. Elles doivent être attribuées à Artémis dont la présence est clairement attestée dans le sanctuaire. Ces statuettes féminines dédiées à Claros seraient des productions éoliennes destinées à l'exportation.

M. Dewailly, "Les statuettes en terre cuite du sanctuaire d'Apollon à Claros : production et consommation (fin $\mathrm{vI}^{\mathrm{e}}-$ fin $\mathrm{v}^{e}$ siècle)", in KRINZINGER, Die Ägaïs und das Mittelmeer (supra 12.05), p. 343-347.

12.07 - Pbocée - Ö. Özyigit et A. Erdogan publient un article de synthèse sur les découvertes cultuelles qui eurent lieu lors des fouilles de Phocée entre 1988 et 1999. Trois aspects sont mis en lumière (1) Le temple d'Athéna. Le sanctuaire poliade de la cité avait fait l'objet de fouilles anciennes remblayées par la suite. Les travaux entrepris dans ce secteur visaient à retrouver les dégagements antérieurs et à étendre la zone de fouilles. Outre certains éléments architecturaux (tambours, chapiteaux), les murs $\mathrm{N}$ et $\mathrm{O}$ (avec un retour au S) de la terrasse sur laquelle a été édifié le temple ont ainsi été identifiés. Ils définissaient un espace presque régulier d'environ $50 \times 35 \mathrm{~m}$. Le matériel retrouvé dans le remplissage de ce podium indiquerait qu'il fut édifié vers 590-580. (2) Les autels archaïques. Hors-les-murs, à l'endroit qui, au $S$ de la ville, abritait le deuxième port de la cité (act. "La Grande Mer ») deux autels contigus ont été exhumés (env. $6 \times 5 \mathrm{~m}$ et 5,8 $\times$ $4,6 \mathrm{~m}$ ). Constitués de blocs de calcaire soigneusement appareillés, ils forment chacun un $p i$ ouvert vers le $\mathrm{N}$ (côté cité). Le matériel découvert en association avec ces structures exclut une date postérieure au deuxième quart $\mathrm{du}_{\mathrm{vI}} \mathrm{I}^{\mathrm{e}} \mathrm{s}$. Ces structures ne semblent pas devoir être rattachées à un temple et les auteurs suggèrent qu'il s'agit là d'autels indépendants en relation avec le port. On ignore dans l'état actuel de la recherche, qui étai(en)t honoré(s) là. De même, le rapport avec les inhumations (archaïques - romaines pour la plupart ) qui sont effectuées à un mètre à l'E. de l'autel oriental reste à établir. (3) un inventaire commenté des lieux de cultes dédiés à la Grande Mère (Cybèle). Ces lieux de culte se répartissent entre les îles (Incir d'une part, Orak de l'autre) et le continent : (a) le sanctuaire dit «du port » qui jouxte au $\mathrm{N}$ la terrasse du temple d'Athéna et lui serait contemporain. Ce dernier aurait été accessible par la mer. Plusieurs niches, une piscine, des bassins et divers canaux ont été taillés dans le rocher. (b) Altin Magarasi Tepesi "Colline de la Grotte de l'Or » (c) Degirmenli Tepe, "La colline des Moulins " Dans ce dernier cas, 9 lieux de culte aménagés ont été distingués, chacun pouvant comprendre de nombreuses niches (avec trous de fixation pour statuettes) et des reliefs (très érodés). Ces ensembles pourraient correspondre à des familles; dans ce cas, les niches seraient liées aux individus. Cybèle aurait à Phocée un double aspect : déesse de la fertilité mais aussi déesse de la mer. 
Ö. ÖZyigit, A. ERDogAN, "Les sanctuaires de Phocée à la lumière des dernières fouilles", in A. Hermary, H. 'Treziny (éds), Les cultes des cités pbocéennes (Coll. Aixen-Provence / Marseille 1999), Aix-en-Provence, 2000, p. 11-23.

- Ce bref article propose d'identifier Artémis dans le profil féminin coiffé d'un bonnet qui apparaît sur certains monnayages archaïques de Phocée (argent et électrum). L'identification est acceptable. L'A. souligne, en outre, l'importance de la déesse dans cette cité et le parallèle avec certaines émissions massaliètes. Le transfert du culte d'Artémis à Marseille constitue un élément important du récit de fondation de cette cité (voir Strabon IV, 1, 4). On relèvera toutefois la forme particulière du transfert d'apbidruma puisqu'il ne s'effectue pas au départ de la métropole mais depuis le sanctuaire d'Artémis à Éphèse, justifiant la présence d'un Éphésion dans la colonie (IV, 1, 4 et 8). Si le culte de la déesse, comme le souligne l'A., est attesté à Phocée, le lien entre le récit de fondation et les types monétaires gagnerait à être plus explicite : s'agit-il, dans les deux cités, de l'Ephesia?

H. Cahin, "Artémis à Phocée", in Agathos Daimon. Mytbes et Cultes. Études d'Iconograpbie en l'bonneur de L. Kabil, Paris/Athènes, 2000 (BCH suppl. 38), p. 73-75.

\section{Éolide}

12.08 - Kymè - Mission arcbéologique italienne - S. Lagona présente une synthèse des découvertes (anciennes et récentes) relatives au culte de Cybèle et d'Isis à Kymè. Statuettes et reliefs de la Grande Mère (assise, tenant dans les bras un lion - ou un tympanon et une phiale - et coiffée d'un polos) découverts dans la cité éolienne sont brièvement décrits. Ils s'étendent de l'époque archaïque au début de l'époque hellénistique. C'est au cours de l'époque archaïque que le culte - d'origine phrygienne ou plutôt lydienne - se serait superposé à celui de la « déesse de la nature » préhistorique dans cette région ainsi qu'à Phocée. L'expansion phocéenne aurait ainsi assuré la diffusion en Occident de son culte et de son iconographie. À l'époque hellénistique, Isis pourrait avoir pris la relève de la déesse dans son sanctuaire situé sur le sommet de la colline $\mathrm{N}$ et refouillé depuis 1991. Un dépôt votif hellénistique composé, pour l'essentiel, de lampes, de monnaies et de statuettes en terre cuite dont une courotrophe y a été mis au jour.

S. Lagona, "Cibele e Iside a Kyme Eolica", in Krinzinger, Die Agais und das Mittelmeer (supra 12.05), p. 143-148.

\section{Bithynie}

12.09 - Daskyleion - Parution d'une étude de la céramique mise au jour dans la zone dite du mur de temenos à Daskyleion. Le bothros contenant les offrandes typiques du culte de Cybèle, il pourrait s'agir d'un temple dédié à cette divinité. Le temple pourrait être daté des viII $^{\mathrm{e}}-\mathrm{vII}^{\mathrm{e}} \mathrm{s}$, Ultérieurement, sous le règne des satrapes, on aurait érigé un temenos pour Cybèle et d'autres divinités. Les plus anciens documents datent de 575-565. Ce type de matériel présente des points de comparaison avec le matériel trouvé à l'Héraion de Samos et à l'Artémision d'Éphèse.

Y. Tuna-Nörling, Daskyleion I. Die attiscbe Keramik, Izmir, 1999, 92 p., 45 pl. (Arkeoloji Dergisi, 6). 


\section{Grande Grèce (Massimo Osanna)}

13.01 - Paestum - Dans le volume Paestum. Scavi, studi, ricerche, qui présente les résultats de la recherche archéologique à Paestum entre 1988 et 1998; la première partie concerne la présentation et les discussions de quelques publications récentes sur la cité, que ce soit la peinture paestane (A. Pontrandolfo, A. Rouveret, Le tombe dipinte di Paestum, Modena, 1992) ou l'architecture sacrée urbaine (D. Mertens, Der alte Heratempel in Paestum und die archaische Baukunst in Unteritalien, Mayence, 1993) ou le sanctuaire de Santa Venera (J.G. PedLey, M. Torelli, The Sanctuary of Santa Venera at Paestum, Rome, 1993). A propos de Santa Venera, M. Barra présente et discute les problèmes de la structure et du culte de cet important sanctuaire. Il avance des propositions d'interprétation de la structure complexe (oikos et édifice rectangulaire), au travers desquelles se dessine l'histoire du sanctuaire entre le $\mathrm{v}^{\mathrm{e}} \mathrm{s}$. av. et le $\mathrm{e}^{\mathrm{er}} \mathrm{s}$. ap. J.-C. Suivent alors des considérations sur les caractéristiques du culte, mises en parallèle avec les sanctuaires de Locres. Il propose de voir dans l'oikos une salle de banquets alors que l'édifice rectangulaire, lui aussi destiné à des repas rituels dans une première phase, aurait connu, dans la phase des $\mathrm{II}^{\mathrm{e}}-\mathrm{I}^{\mathrm{er}} \mathrm{S}$. av. J.-C., des pratiques liées au bain rituel dans le cadre de rites de passage.

M. Barra Bagnasco, "Considerazioni sul santuario di Santa Venera: le strutture e il culto", in E. Greco, F. Longo (éds), Paestum. Scavi, studi, ricerche. Bilancio di un decennio (1988-1998), Paestum, 2000, p. 67-72.

- Istituto Orientale di Napoli - Dans ce même volume, la seconde partie présente les résultats des fouilles conduites à l'intérieur de la cité et dans son territoire (le long du côté N-E de l'enceinte fortifiée, dans la zone de la Porta Giustizia et celle de la Porta Marina, dans les nécropoles du Gaudo et à l'Héraion du Sele). Pour les espaces sacrés, il faut mentionner la contribution d'I. D'Ambrosio et $R$. De Bonis concernant un nouveau sanctuaire mis au jour dans la partie orientale de l'agora occupée au moins à partir du ve s. jusqu'au ${ }_{1}{ }^{\mathrm{e}}-\mathrm{I}^{\mathrm{er}} \mathrm{s}$. av. J.-C. (E du Musée) : particulièrement significative est la présence, dans le rocher qui affleure, d'une profonde cavité artificielle (ca $20,3 \times 12 \mathrm{~m}$ ) colmatée entre le $\mathrm{I}^{\mathrm{er}} \mathrm{s}$. av, et le $\mathrm{I}^{\mathrm{er}} \mathrm{s}$. ap. J.-C., de nombreux petits puits de dimensions variées, et d'une petite cavité contenant la moitié supérieure d'une amphore retournée. À l'intérieur des petits puits, outre de la céramique, se trouvaient des ossements d'animaux : dans un des puits plus grands, circulaire, creusé à la limite d'une rampe qui conduit à la grande cavité dans la roche, se trouvaient des tortues. On a en outre conservé les traces d'une structure difficile à interpréter, caractérisée par la présence d'une «eschara » constituée d'un puits rectangulaire $(0,9 \times 0,8 \mathrm{~m})$ délimité par des blocs, couvert d'une plaque de travertin trouée en son centre et d'une profondeur d'environ $2 \mathrm{~m}$. À l'intérieur se trouvaient associés à de nombreux ossements d'animaux, du bois carbonisé et des cendres, des fragments céramiques appartenant à de la vaisselle (assiettes et coupes, gobelets) et de la céramique commune destinée à la cuisson et au service à table; on y trouve en outre de nombreuses lampes et des vases à onguent, le tout datable entre le $\pi^{\mathrm{c}}$ et le ${ }^{\mathrm{er}} \mathrm{s}$. av. J.-C. Parmi les animaux, outre les ovins et les porcins, et dans une moindre mesure les bovins, il faut signaler la présence d'un chien. Le sacrifice d'un chien et les carapaces de tortue permettent de faire l'hypothèse que le culte était peut-être adressé à Aphrodite, dans sa dimension particulière d'Ourania, peut-être associée au culte d'Adonis.

I. D'Ambrosio, R. De Bonis, "Il santuario sul lato orientale dell'agora", in Paestum, p. 109-116.

- Soprintendenza archeologica per le provincie di Salerno, Avellino e Benevento - Présentation des nouvelles recherches entreprises à l'Héraion extra-urbain du Sele depuis 1987 (sur ces recherches, $c f$. aussi J. DE LA Genlère, G. Greco, "Beaucoup de questions et quelques réponses au sanctuaire de Héra à Foce Sele", in I culti della Campania antica. 
Atti del convegno internazionale di studi in onore di N. Valenza Mele (Napoli 1995), Napoli, 1998, p. 37-45). Les fouilles menées près du petit autel ont permis de fixer une chronologie de la structure à la fin du vi ${ }^{e} s$. av. J.-C. et de découvrir l'existence d'un autel de cendres originel déjà monumentalisé dans la première moitié du $\mathrm{vI}^{\mathrm{e}} \mathrm{s}$. av. J.-C. Un sondage réalisé à l'intérieur de la cella du « grand temple » a conduit à confirmer la chronologie tardo-archaïque de la structure mais n'a pas permis d'identifier de traces sûres d'un édifice plus ancien dont on avait fait l'hypothèse. Dans la zone du "Thesauros", les nouvelles fouilles ont permis d'assurer que les dimensions du petit temple ne dépassaient pas la longueur conservée : il s'agit donc d'une structure beaucoup plus petite que celle reconstituée par Krauss. La chronologie est plus basse que celle précédemment avancée, ne remontant pas assurément au-delà du Ive s. av. J.-C. Il n'est donc plus possible d'attribuer à cet édifice les fameuses métopes archaïques.

G. Tocco, "Nuove ricerche nel santuario di Hera al Sele", in Paestum, p. 213-218.

- Nouvelle interprétation de l'important édifice paestan construit à la fin du vi ${ }^{\mathrm{e}} \mathrm{s}$. sur le côté O de l'agora, connu sous le nom d'“ hypogée " (P.C. SESTieri, Il Sacello-Heroon, in Boll. d'Arte, 40 [1955], p. 53-64) et généralement interprété comme lieu de culte de l'œciste de la colonie. Le matériel mis au jour dans le contexte paestan, qui s'inscrit tant dans la célébration typique du culte hérö̈que (hydries avec du miel, amphore pour les libations de vin) que dans celle du culte olympien (broches pour le rôtissage des restes de la victime sacrificielle), est confronté aux pratiques rituelles documentées dans la loi sacrée de Sélinonte (M.H. JAMESON, D.R. JORDAN, R.D. KotANSKY, A lex sacra from Selinous, Durham, 1993). Le parallèle effectué entre les deux réalités documentaires, l'une de la phénoménologie archéologique, l'autre du texte épigraphique, conduit l'A à proposer d'identifier le petit sanctuaire comme lieu de culte des Tritopatores. La substitution du culte des Tritopatores à celui de l'œciste accueilli sur l'agora s'expliquerait par la nécessité de vénérer sur la place publique de la colonie des entités représentatives de la collectivité tout entière, caractérisée selon la tradition par le mélange d'Achéens et de Trézéniens. L'hypothèse, déjà avancée par Jameson, Jordan et Kotansky (sur laquelle $c f$. les critiques de E. Greco, in Paestum..., p. 154), ne semble pas fondée sur des arguments solides. Du reste, la présence d'une composante trézénienne à Poseidonia est le fruit d'une théorie moderne ( $c f$. E. Greco, Arcbeologia della Magna Grecia, Roma/Bari, 1992, p. 70).

M. RausCh, "Das Hypogäum auf der Agora von Poseidonia: ein Kultort der Tritopatores?", Kernos 13 (2000), p. 107-116.

13.02 - Métaponte - Soprintendenza archeologica della Basilicata - Dans la commune de San Biagio alla Vinella (Bernalda), des travaux de nettoyage ont eu lieu sur les structures dégagées dans les années ' 60 par $\mathrm{D}$. Adamesteanu et relatives à un sanctuaire extraurbain dédié à Artémis. Les interventions se sont surtout concentrées sur l'espace sacré monumental en liaison avec une source. Un édifice rectangulaire avec un toit de tuiles en terre cuite a été dégagé. Il est orienté $\mathrm{E}-\mathrm{O}$ et la première assise du côté $\mathrm{S}$ est entièrement conservée. Les autres côtés sont perceptibles au travers de cavités de pillage et de traces de fondation. La structure pourrait avoir appartenu à un temple périptère d'au moins $16 \times 19 \mathrm{~m}$ (en considérant que le côté $\mathrm{E}$ a complètement disparu). L'état extrêmement fragmentaire des restes rend toute reconstruction précise très problématique. La chronologie de l'édifice tourne autour du $\mathrm{IV}^{\mathrm{e}} s$. av. J.-C, à en juger par les signes de taille présents sur deux blocs et par les fragments de céramique récupérés sous un coin intact de l'écroulement de la toiture. L'édifice s'élève dans un lieu déjà fréquenté à la période archaïque - comme du reste tout l'espace sacré - ainsi que l'atteste un matériel varié, entre autres le manche anthropomorphe d'une patère en bronze. Au-dessous de ces 
structures sont apparus des pavements appartenant à un établissement préhistorique dont les limites chronologiques inférieures se placent au Bronze Moyen.

- Dans la zone du sanctuaire extra-urbain de Métaponte connu sous le nom de "Tavole Palatine " se trouve un périptère monumental de la période archä̈que. Deux sondages effectués dans l'espace en face du temple, au point le plus élevé du terrain, ont permis de constater avec certitude l'absence de structure appartenant au sanctuaire. Aux niveaux inférieurs s'est confirmée la présence d'importantes traces d'un établissement préhistorique.

M.L. NAvA, "Attività archeologica in Basilicata", in Atti del XXXIX Convegno di studi sulla Magna Grecia (Taranto, ottobre 1999), Napoli, 2000, p. 672 sq.

13.03 - Herakleia - Soprintendenza arcbeologica della Basilicata - Dans le rapport annuel de l'activité archéologique en Calabre en 1999 et 2000, présenté dans le cadre du colloque annuel de Tarente sur la Grande Grèce, le surintendant a livré les résultats de la fouille de l'Institut archeologique de l'Université d'Innsbruck au sanctuaire de Déméter à Herakleia, situé dans la vallée centrale de l'établissement urbain. Il s'agit notamment d'une synthèse des phases de construction de l'espace sacré. Dans le sanctuaire, qui a déjà fait l'objet des investigations de l'Université de Pérouse, les prospections se sont poursuivies dans le secteur NO: un sondage a mis au jour un niveau déjà fréquenté à la période archäque, caractérisé par la présence d'ex-voto mêlés à de la céramique rituelle (une coupe, une cruche, un poids de métier à tisser et une statuette en terre cuite). On a notamment trouvé un lieu d'activité sacrificielle avec des traces de combustion, des restes ostéologiques et du matériel varié (une coupe à ombilique, des kylikes, un poids de métier à tisser, une hydrie), datable des débuts du $v^{e} s$. av. J.-C. Dans cette partie du sanctuaire apparaissent des traces d'activité cultuelle appartenant à la phase d'Herakleia. À l'E de l'espace sacré, il a en outre été possible de vérifier l'extension du sanctuaire audelà des limites du temenos archaïque, comme l'attestent les dépôts de vases miniatures et de terres cuites votives qui suivent le cours de la source souterraine bien au-delà des limites précédemment assignées à la zone. Au cours de la campagne 2000 dans cette partie du sanctuaire est venu au jour un puits en terre cuite de la période hellénistique, situé au centre d'un espace caractérisé par de petits noyaux de dépôts votifs. En ce qui concerne les édifices voisins, une première phase suit immédiatement la fondation de la colonie en $433 / 2$ av. J.-C. et se caractérise par la présence de deux petits sanctuaires orientés au $\mathrm{N}$ : le mégaron A situé dans la partie la plus haute du terrassement du sanctuaire et le mégaron $B$ en bas, près de la source qui occupe le fond de la vallée. Une seconde phase, située autour de 370 , quand Herakleia est devenue le siège de la Ligue italiote, voit la monumentalisation de l'espace sacré : en haut est érigé un mur décoré de niches et sur le devant, à côté du mégaron A, une terrasse entourée de deux clôtures, l'une des deux intégrant un botbros semi-circulaire et d'une petite échelle permettant de descendre vers la source. Le long des pentes du contrefort du mégaron B, alors transformé (oikos B), est érigé un nouvel oikos (C). Deux édifices à portique viennent en outre délimiter le côté $\mathrm{E}$ de l'espace central du sanctuaire.

M.L. NAvA, "Attività archeologica in Basilicata", in Atti del XXXIX Convegno di studi sulla Magna Grecia (supra 13.02).

- Université d'Innsbruck - Un bref article sur les fouilles du sanctuaire de Déméter publie le pied d'une kylix à vernis noir datée de 500 av. J.-C. et portant un graffite lu $\Delta$ tou (?) interprété comme le datif d'une épiclèse de Zeus. La présence d'une divinité masculine dans le sanctuaire archaïque semble confirmée par la mise au jour d'une terre cuite masculine barbue. L'éditeur du volume, dans une note additionnelle, propose la lecture $\Delta$ tor[évous sur la base de la forme de la dernière lettre. 
B. OTro, "Ein achäisch-ionischer Graffito aus dem Quellheiligtum von Policoro am Golf von Tarent", in Steine und Wege. Festscbrift fïr Dieter Knibbe zum 65. Geburtstag, Vienne, 1999, p. 239-240.

- Un dépôt votif mis au jour entre 1968 et 1971 à l'entour d'une petite porte qui s'ouvre à l'angle SO de la muraille de Métaponte, dans la propriété Favale, est en cours de publication par Maria Grazia Liseno (Il deposito votivo Favale di Metaponto, Corpus delle stipi votive, in c.d.s.) qui a livré une présentation préliminaire au congrès de Pérouse : le dépôt semble appartenir à un espace sacré situé à l'abri de la muraille, en relation avec une déviation du tracé du fossé qui, à ce point, s'éloignait du mur, manifestement pour respecter le petit sanctuaire. Au même espace sacré semble appartenir le riche dépôt votif (céramique, terres cuites et bronzes datables entre le début du vre et le milieu du ve $\mathrm{s}$. av. J.-C.) mis au jour à peu de distance au lieu-dit Crucinia, dont l'exploration intervenue en 1957 (F.G. Lo Porto, Metaponto. Nuovi scavi nella città e nella sua necropoli, in NSA [1981], p. 289-334) est reprise dans l'état de 2000 (restitution d'un abondant matériel en terre cuite provenant des dépôts perturbés). Le dépôt Favale, en ce qui concerne la céramique, comprenait des vases miniatures (surtout des cratérisques), ayant probablement servi à l'offrande de prémices, de la céramique de cuisson et de table (entre autres des vases à boire, kylix et skypboi) provenant de repas rituels : il s'agit essentiellement d'une production locale, comprise entre les $\mathrm{VI}^{\mathrm{e}}$ et $\mathrm{IV}^{\mathrm{e}} \mathrm{s}$. av. J.-C. Les terres cuites comprennent des types féminins d'époque archaique, où se détache la figure au polos, vêtue du péplos dorien, soit debout soit assise, et d'époque classique, où se signalent les figures avec polos et/ou voile, ou privées de couvre-chef, aux attributs variés, dont fréquemment l'œnochoé associée à un ovin ou à la coupe de fruits. Un groupe revient de manière récurrente : il s'agit d'une figure féminine avec polos tenant une phiale et une oinochoe, précédée d'une enfant portant une couronne de fruits sur la tête et une brebis. Le culte est rendu à une divinité féminine qui préside au passage entre l'espace urbain et celui de la chôra. L'A. ne se prononce pas sur l'identité de la divinité. La localisation de l'espace sacré et le matériel mis au jour pourrait faire penser à Artémis ( $c f . \mathrm{M}$. Osanna, Cborai coloniali da Taranto a Locri, Rome, 1992, p. 50, 77).

M.G. Liseno, "Il deposito votivo Favale di Metaponto", in Depositi votivi e culti dell'età antica dall'età antica dall'età arcaica a quello tardo-repubblicana (Perugia, 1-4 giugno 2000), in c.d.s.

13.04 - Sybaris - Soprintendenza archeologica della Calabria - Dans le rapport annuel de l'activité archéologique en Calabre en 1999, présenté dans le cadre du colloque annuel de Tarente sur la Grande Grèce, le surintendant a signalé la découverte d'un espace sacré dans la grotte Campanella, une petite cavité karstique à environ $800 \mathrm{~m}$ d'altitude. La fréquentation cultuelle est attestée par la découverte de matériel votif, aussi miniature (dont de la céramique corinthienne) datable dans le courant du $\mathrm{vI}^{\mathrm{e}} \mathrm{s}, \mathrm{av}, \mathrm{J}, \mathrm{-C}$.

E. LATTANZI, "L'attività della soprintendenza archeologica della Calabria nel 1999", in Atti del XXXIX Convegno di studi sulla Magna Grecia (supra 13.02), p. 732.

13.05 - Crotone - Soprintendenza arcbeologica della Calabria - Dans le rapport annuel de l'activité archéologique en Calabre en 1999, présenté dans le cadre du colloque annuel de Tarente sur la Grande Grèce, le surintendant a signalé la mise au jour, dans la région du stade, d'un petit édifice $(c a 6,8 \times 3,4 \mathrm{~m})$ en blocs quadrangulaires, qu'il faut probablement identifier comme un petit sanctuaire. La fouille d'un ensemble voisin de matériel hétérogène a permis de récupérer des restes architecturaux de l'édifice, entre autres des antéfixes à tête de lion datables du $\mathrm{Iv}^{\mathrm{e}} \mathrm{s}$. av. J.-C.

- Dans ce même cadre, mention de la mise au jour, au lieu-dit « Acqua di Friso », à environ deux $\mathrm{km}$ au $\mathrm{N}$ du centre de Cropani Marina, de traces significatives d'activité cultuelle : une fosse ( $\mathrm{L}$ ca $4 \mathrm{~m}$, prof, $1 \mathrm{~m}$ ) avec des restes sacrificiels (grande quantité de 
cendres, ossements consumés) et un dépôt votif de céramique, allant de la fin du viI ${ }^{\mathrm{e}}$ au $\mathrm{v}^{\mathrm{e}} \mathrm{s}$. av. J.-C. Il y a aussi de la céramique miniature (hydries, olpai, kotyles et cratérisques), de la vaisselle (non peinte, destinée à la cuisson, à vernis noir) et des vases de stockage (amphores et grands contenants). Dans le dépôt apparaissent aussi des objets d'ornement personnels, des outils de travail, des armes miniatures et 24 pièces de monnaie en argent. L'espace sacré situé à une certaine distance du centre urbain de Crotone pourrait avoir été fréquenté par les Crotoniates, même si la zone était probablement, à la période archaïque, extérieure à la chôra coloniale (sur les limites du territoire, M. Osanna, Chorai coloniali da Taranto a Locri, Roma, 1992, p. 167-189).

E. LatTanzi, "L'attività della soprintendenza archeologica della Calabria nel 1999", in Atti del XXXIX Convegno di studi sulla Magna Grecia (Taranto, ottobre 1999), Napoli, 2000, p. 735, 739.

13.06 - Cumes - Un riche dépôt votif, découvert à Cumes en 1911, près de la limite $\mathrm{N}$ de la terrasse inférieure de l'acropole, à quelque $45 \mathrm{~m}$ du temple d'Apollon, et resté inédit, est en cours de publication par M. Catucci, L. IANnell et I. Sanesi Mastrocinque (Il deposito votivo dell'acropoli di Cuma, Corpus delle stipi votive, in c.d.s.). Un rapport préliminaire a été présenté au congrès de Pérouse : dans le dépôt, 221 terres cuites sont identifiées, comprenant des têtes, de la petite plastique et des ex-voto anatomiques, mais beaucoup d'objets, entre autres la céramique, sont désormais dispersés. Le matériel, datable entre les $\mathrm{IV}^{\mathrm{e}}$ et $\mathrm{II}^{\mathrm{e}}$ s. av. J.-C., appartient à la catégorie des ensembles votifs étruscolatio-campaniens et peut être rattaché au processus de romanisation de la cité (laquelle obtint en 334 av. J.-C. la civitas sine suffragio). L'iconographie des terres cuites figurées (généralement des fidèles, répartis selon leurs rôles sociaux et les classes d'âge : enfants et femmes, mères, enfants couverts d'un manteau, adultes en toge, guerriers) ne permet pas d'identifier la divinité. Les ex-voto anatomiques qui relève de la sphère de la santé font penser à un culte d'Apollon dont la fonction guérisseuse semble avoir été valorisée à la fin $d u r v^{e} s$.

M. Catucci, L. Ianneldi, "Il deposito votivo dell'acropoli di Cuma", in Depositi votivi (supra 13.03).

13.07 - Hipponion - Soprintendenza archeologica della Calabria - Présentation des données relatives aux explorations, anciennes et nouvelles, de l'espace sacré identifié en 1916 par P. Orsi (Monteleone Calabro, Nuove scoperte, in NSA [1921], p. 481) près de la Cava Cordopatri, au SE de la ville moderne de Vibo Valentina, le long du côteau qui descend vers le Castello, près de l'ancien tracé du mur d'enceinte de la cité grecque. Si le matériel récupéré au moment de la première fouille est aujourd'hui dispersé, et le petit oikos trouvé par Orsi n'est plus localisé avec certitude, les recherches récentes (M.T. Iannelli, G. Givigliano, "Hipponion-Vibo Valentia: la topografia (carta archeologica)", ASNP, 19 [1989], p. 665-666), en particulier celles de 1997 et celles en cours, ont permis de récupérer une très riche documentation en rapport avec le culte pratiqué dans le sanctuaire. Le sondage préliminaire effectué grâce à une série de carottages a permis de faire l'hypothèse d'un vaste espace de "favisse, periodicamente sigillate con strati sabbiosi ». La fouille a permis de vérifier la présence d'importantes canalisations fonctionnant initialement grâce à l'écoulement des eaux de pluie provenant de la terrasse supérieure où devait se situer le petit sanctuaire trouvé par Orsi. Vers la fin du $\mathrm{IV}^{\mathrm{e}} \mathrm{s}$. av. J.C., les canaux ont été remplis d'un colmatage contenant du matériel votif et rituel associé à des ossements d'animaux. Le déroulement des actions rituelles à l'intérieur de l'espace est documenté par la présence de strates révélant de larges traces de combustion. Les artefacts provenant des différents dépôts identifiés comprennent de nombreuses amphores de type corinthien ou locrien au rebord en bourrelet datables entre les $\mathrm{v}^{\mathrm{e}}$ et $\mathrm{Iv}^{\mathrm{e}}$ s. av. J.-C., un abondant matériel céramique soit non peint soit vernis (parmi lequel des formes à boire, skyphoi et coupes-skyphoi, coupes et petites coupes à vernis noir qui vont 
de la fin du $\mathrm{vi}^{\mathrm{e}}$ au $i v^{\mathrm{e}}$ s. av. J.-C.), et enfin de la coroplastique, où se signalent des exemplaires de recumbenti datés du $\mathrm{v}^{e}$ et du $\mathrm{rv}^{\mathrm{e}} \mathrm{s}$. av. J.-C., une statuette féminine avec un oiseau et quelques reliefs avec des figures à cheval. La découverte de petites flèches en bronze est particulièrement significative. Il faut également signaler la présence de terres cuites architecturales autres que des tuiles, qui semblent attester la présence d'édifices sacrés dans l'espace. À titre d'hypothèse, le culte est attribué à Dionysos, une divinité encore peu attestée dans le panthéon des colonies locriennes (sur les cultes d'Hipponion, voir en dernier lieu M.C. PARrA, "Le divinità dei campi ed i segreti di Orfeo", in M.T. IANNElli, V. Ammendolia (éds), I volti di Hipponion, Soveria Mannelli, 2000, p. 61-67).

M.T. Iannelli, M. Cerzoso, "Stipi votive nella subcolonia di Hipponion: l'area sacra alla "Cava Cordopatri', in Depositi votivi (supra 13.03).

13.08 - Medma - Soprintendenza archeologica della Calabria - Un important espace sacré, découvert à Rosarno près de l'abattoir municipal en 1988 et fouillé entre 1994 et 1996 (M.T. IANnelli, "Medma: le recenti acquisizioni. L'area sacra al Mattatoio", in I Greci in Occidente. Santuari della Magna Grecia in Calabria (Catalogo della Mostra), Napoli, 1996, p. 120-121), est en cours de publication par M.T. IANNELli et M. Cerzoso dans le Corpus delle stipi votive. Une présentation préliminaire est faite au congrès de Pérouse. Le sanctuaire semble s'être élevé dans une partie non périphérique de la cité antique, en relation avec l'axe routier principal de l'implantation urbaine d'époque classique. La fréquentation du lieu est déjà attestée par la phase archaïque des traces de sol en terre battue et de matériel céramique datable du vi ${ }^{\mathrm{e}} \mathrm{s}$. av. J.-C. (amphores de type corinthien A, «ps.-ionique », «type locrien», de coupes ioniques, de céramique miniature et de kotyles d'imitation corinthienne, phiales mesonpbaloi non peintes), à l'exception d'un fragment d'amphore SOS, datable déjà à la fin du vir ${ }^{e} s$. qui constitue une des trouvailles les plus anciennes de Medma. La monumentalisation de l'espace semble intervenir au milieu du $v^{c}$ s. av. J.-C., époque où se place l'érection d'un édifice cultuel structuré ( $c a 15$ $\times 13 \mathrm{~m}$ ), - d'une lecture difficile en raison du pauvre état de conservation, - apparemment caractérisé entre autre par une vaste pièce rectangulaire précédée d'une sorte d'atrium. La destruction de la structure semble dater de la fin du $\mathrm{Iv}^{\mathrm{e}} \mathrm{s}$. et du début du siècle suivant, à une époque où le sanctuaire continue d'être fréquenté, comme l'atteste le matériel retrouvé lors d'un sondage réalisé au SE et qui a livré du matériel de la fin du $\mathrm{II}^{\mathrm{e}}$ s. av. J.-C. Le matériel récupéré à l'intérieur de l'édifice relève du domaine du banquet: la céramique, associée à de petits ossements animaux, comprend des formes à boire, de grands contenants et de la vaisselle non peinte. Parmi le matériel mis au jour dans la zone fouillée, on signale surtout l'abondant matériel coroplastique (plus de 600 fragments): outre de petites têtes masculines et féminines (dont deux sont attribuables à Athéna), une figure masculine à cheval et quelques représentations de satyres et de silènes, la présence de statuettes de recumbenti est significative. Ceux-ci, vu leur rapport au banquet dionysiaque, sont liés à l'organisation de repas rituels à l'intérieur du sanctuaire, bien attestés par la vaisselle de table et de cuisine, associée aux trouvailles ostéologiques. En ce qui concerne l'iconographie des terres cuites, on pourrait identifier dans le type du recumbente la représentation de Dionysos dans l'hypostase d'Hadès, avec son épouse Perséphone. En ce qui concerne la divinité qui recevait un culte dans cet espace sacré, l'analyse du matériel laisse entendre que Dionysos jouait un rôle significatif.

M.T. Innnelli, M. Cerzoso, "Stipi votive nella subcolonia locrese di Medma: l'area sacra al Mattatoio", in Depositi votivi (supra 13.03).

13.09 - Tarente - Un riche dépôt votif découvert à Tarente en 1929, via Duca degli Abruzzi, et resté inédit (une description sommaire de E. L.ippolis, in I culti greci in Occidente. I. Taranto, Tarante, 1995, p. 111-112) est présenté par B.M. Buccoliero au congrès de Pérouse : elle traite de quelque 400 fragments coroplastiques allant de la 
période archaïque tardive à l'époque hellénistique et retrouvés dans un puits. Il s'agit essentiellement de figures de recumbenti et de statuettes de Hyakinthos et Polyboia, et dans une moindre mesure de figures féminines debout ou assises, de guerriers, de cavaliers, de silènes, d'Artémis Bendis, des pinakes avec les Dioscures. Le contexte de la découverte, à la limite de l'espace urbain et de la nécropole, de même que la composition du dépôt rappellent, comme dans le cas de nombreux autres dépôts tarentins, des pratiques de culte en relation avec l'espace funéraire et destinées à concrétiser, par la dédicace d'ex-voto en terre cuite, le changement de statut du défunt.

B.M. Buccoliero, "Il deposito votivo in via Duca degli Abruzzi a Taranto", in Depositi votivi (supra 13.03).

\section{Sicile (Nicola CucuzzA)}

14.01 - Lipari - Soprintendenza ai Beni Culturali e Ambientali di Messina - Compte rendu détaillé du résultat des fouilles conduites, tant dans la zone urbaine que suburbaine de Lipari. D'un intérêt tout particulier est la découverte, datée de 1955-56, d'un sanctuaire situé près du domaine Maggiore, un peu à l'O de la muraille du $\mathrm{vi}^{\mathrm{e}} \mathrm{s}$, av. J.-C. et déjà reconnu à l'époque (Bernabò BREA, BTCGI 9, p. 145-146, 158-162). Dans cette zone, fréquentée à l'époque préhistorique, ont été retrouvées les fondations d'un édifice tripartite (pièces E, F, G), datable du ve $s$. av. J.-C. et accessible par le S, interprété comme un Koreion. Les restes de deux autres pièces (dont une seule certaine) appartiennent au même niveau, à quelques mètres plus à l'O. Le complexe entier a peut-être été détruit au moment de la construction du mur voisin, dans la première moitié du $\mathrm{Iv}^{\mathrm{e}} \mathrm{s}$. av. J.-C. : le niveau de sol fut alors notablement surélevé et à l'angle NO de l'édifice E-G fut érigée une structure de plan probablement carré $(4,70 \mathrm{~m}$ de large), interprétée comme un autel. Autour de cette construction, trois fosses étaient remplies de matériel céramique et de nombreuses statues en terre cuite, d'un type plus sacral que théâtral (ces dernières déjà publiées par Bernabò BreA, Menandro e il teatro greco nelle terrecotte liparesi, 1981). Des tombes ont été creusées dans la zone après la destruction de Lipari en $252 / 1$ av. J.-C., tandis qu'à l'époque romaine un mur circulaire (appartenant peut-être à une arène) et une citerne furent construites. Du ve s. ap. J.-C. est daté le prélèvement de blocs, peut-être pour construire des fortifications contre les incursions wisigothes ou vandales. L'interprétation religieuse de la structure des $v^{e}$ et $v^{e} s$. av. J.-C. mise au jour repose principalement sur la présence de pinakes (plus de 3000 , portant presque exclusivement des figures féminines) et de statuettes en terre cuite (la majeure partie, - environ 2300 , - avec flambeau et porcelet), ainsi que de tables de libation et d'une arula inscrite. On trouve aussi des statuettes représentant des divinités déterminées comme Artémis, Aphrodite, Athéna, Hermès, Léda; un seul fragment représente une courotrophe. L'importance attribuée au culte d'Artémis dans le sanctuaire est certainement à revoir : elle se fonde en fait sur une mauvaise lecture de l'inscription sur l'arula (Manganaro, PP 20 [1965], p. 176), qui doit plus probablement être interprétée comme une dédicace à Isis (Cbiron 22 [1992], p. 388; SEG XLII 852). On dispose également de la publication définitive des tombes (en majeure partie de simples inhumations dans le sable) des $v^{e}$, Iv et $\mathrm{II}^{\mathrm{e}} \mathrm{s}$. av. J. C. mises au jour dans les fouilles de 1993-96 à la via Franza, en 1986 et en 1993-95 dans la localité de Portinenti. Notons que l'une d'entre elles ( $\mathrm{n}^{\circ} 2546$ ) était une petite fosse remplie de statuettes et de masques de théâtre en terre cuite.

L. Bernabò Brea, M. Cavalier (éds), Meligunis lipára X. Scoperte e scavi archeologici nell'area urbana e suburbana di Lipari, Rome, 2000, p. 21-180, 230-232, 255-261, 377403. 
14.02 - Messina - Soprintendenza ai Beni Culturali e Ambientali di Messina - À la via Torino, près du quartier $Z$, les fouilles conduites entre 1989 et 1993 ont mis au jour une partie d'un quartier antique qui semble délimité à l'E par une route. Les espaces fouillés appartiennent à deux habitations différentes (maison A et B). Dans l'espace A1, de forme carrée (4,5 $\mathrm{m}$ de large), une structure construite en tuiles et en chaux, et couronnée d'une corniche dentelée, située au centre, a été interprétée comme un autel domestique. La dernière époque d'utilisation de la pièce se situe entre la fin $\mathrm{du}_{\mathrm{I}} \mathrm{v}^{\mathrm{e}}$ et le début du $\mathrm{mI}^{\mathrm{e}} \mathrm{s}$. av. J.-C.

G.M. Bacci, G. Tigano (éds), Da Zancle a Messina I, Palerme, 1999, p. 105-106.

14.03 - Naxos - Soprintendenza ai Beni Culturali e Ambientali di Messina - Présentation des pointes de lance mises au jour dans les fouilles du temenos près du torrent Santa Venera, dont on a déjà partiellement rendu compte (P. PelaGatti, BdA [1964], p. 154 fig. 15).. Le matériel qui leur est associé permet de dater les 20 pointes de lance à la fin du vil ${ }^{\mathrm{e}}$ s. av. J.-C. : le dépôt des armes provient du sanctuaire en relation avec le Sacello A, de l'intérieur de petites fosses avec des restes de combustion, d'ossement d'animaux brûlés et de petites coupes, interprétées comme des thusiai. De telles thusiai, certaines sans armes, sont situées le long des côtés $\mathrm{O}$ et $\mathrm{N}$ du Sacello A et ne caractérisent pas, par contre, le Sacello B plus récent. Rappelant qu'Héra était certainement honorée dans le temenos, l'A. s'interroge sur le rite à l'origine de ces dépôts, faisant l'hypothèse de l'existence de pratiques sacrificielles (sur l'autel voisin) liées aux banquets et en relation avec l'initiation des éphèbes.

M.C. Lentini, "Armi a Naxos dalle mura e dal santuario", in I. Berlingò, H. Blank, F. Cordano, P.G. Guzzo, M.C. Lentini (éds), Damarato. Studi di antichità classica offerti a Paola Pelagatti, Milan, 2000, p. 155-166.

14.04 - Francavilla - Soprintendenza ai Beni Culturali e Ambientali di Messina - Dans deux publications d'ensemble, U. Spigo étudie les pinakes en terre cuite découverts dans le sanctuaire partiellement fouillé en 1979/81 à la via don Nino Russotti, dont il récapitule brièvement les données disponibles. Le sanctuaire compte deux phases distinctes, qui suivent une période d'occupation de la fin de l'âge du Bronze.

a) À la première phase, datable entre $560 / 550$ av. J.-C. et la fin du $\mathrm{vI}^{\mathrm{e}}$ siècle av. J.-C., appartiennent des dépôts de céramique pour libations (cratérisques, kylikes, olpai) et d'offrandes coroplastiques (protomés, statuettes féminines assises) avec des restes d'ossements animaux (pas encore analysés) et deux fragments de kouroi; les dépôts étaient quelquefois superposés et séparés les uns des autres par de minces couches de sable et de cendre; à ce stade, le sanctuaire était privé de structure architecturale. Un bassin en bronze et deux anneaux en or font partie du peu de matériel en métal retrouvé dans le sanctuaire. Les éléments assurés manquent pour affirmer la tenue de repas rituels.

b) La seconde phase est datée entre la fin du vi ${ }^{\mathrm{e}}$ s. av. J.-C. et 430/425. Une structure comptant au moins trois espaces (édifice $A$, de 13,7 sur au moins $4 \mathrm{~m}$ ) fut construite sur la façade orientale de la zone fouillée, recouvrant partiellement les dépôts de la première phase. À l'intérieur des pièces 1 et 2 , à la fin de la période, furent rassemblés des ex-voto datables entre les termes chronologiques de la phase II, dont les pinakes étudiés par U. Spigo. Le dépôt, d'une épaisseur de quelque $0,8 \mathrm{~m}$, était scellé par des tuiles en terre cuite et semble être le fruit d'un acte unique d'accumulation. À son sommet, une statuette féminine en terre cuite, dont l'aspect rappelle un xoanon, reproduit peut-être l'image de la statue de culte du sanctuaire. À la fin de la phase II se situe la construction d'une structure à l'O (édifice $\mathrm{B}$, de $10,5 \times 6,5 \mathrm{~m}$ ), peut-être destinée à la conservation d'autres ex-voto.

La présence de céramique miniature et de nombreuses formes ouvertes est commune aux deux phases. Le sanctuaire s'est peut-être élevé aux limites de l'habitat, non loin d'une 
nécropole en usage vers $470 / 50$ av. J.-C. Les ex-voto retrouvés font penser à un probable culte à Déméter et à Koré : Spigo se montre toutefois prudent, notant la faible extension de la zone fouillee $\left(150 \mathrm{~m}^{2}\right)$ et la polyvalence des offrandes votives elles-mêmes. Certains pinakes révèlent aussi un culte à Zeus-Hadès, mais encore à Héra, Artémis, Dionysos et Hermès. La publication d'ensemble relative à toutes les données de la fouille permettra sans doute de mieux affronter le problème. Les pinakes, étroitement liés à ceux de Locres (certains sont issus des mêmes matrices), indiquent l'importance considérable de Perséphone dans l'aire de culte; il y a 20 types différents avec des représentations qui vont de scènes de danses à des rites près de navires et au rapt de Perséphone. D'après Spigo, le culte de Perséphone, outre son lien avec la sphère nuptiale, présente sur les pinakes des connotations spécifiquement chthoniennes. Sur un exemplaire au moins se trouverait une allusion au culte de Zeus Eleutherios, célébré après la chasse de Thrasybule (466 av. J.-C.). La composante thesmophorique est également présente sur quelques représentations, mais l'accent est principalement mis sur les rites prénuptiaux et sur la sphère "idéologique » d'Aphrodite, déesse vénérée à Naxos.

U. SPIGo, "I pinakes di Francavilla di Sicilia (parte I)", $B d A 111$ (2000), p. 1-60; (parte II) $B d A 113$ (2000), p. 1-78; $i d$., "I pinakes di Francavilla di Sicilia. Nuova classificazione e brevi note sugli aspetti cultuali", in Damarato (supra 14.03), p. 208-220.

14.05 - Catania - Université de Catane - Dans la synthèse des données des fouilles conduites dans la zone du monastère des Bénédictins sur la colline de Montevergine dans les années ' 80 , M. Frasca distingue deux phases urbanistiques différentes pour la période grecque. Au cours de la première, datée du vi ${ }^{\text {e }}$ s. à 476 av. J.-C., l'hypothèse de l'existence d'un bâtiment de culte repose sur des blocs en calcaire et des éléments architecturaux en terre cuite (parmi lesquels deux fragments de sima et huit de corniche), qui toutefois, vu leurs dimensions réduites, pourraient appartenir aussi à de simples maisons. Dans la seconde phase urbanistique (Ive s. jusqu'à 263 av. J.-C.), on attribue une fonction cultuelle à un bâtiment de $9,90 \times 4,60 \mathrm{~m}$, orienté $\mathrm{EO}$, à l'intérieur duquel du matériel votif a été mis au jour (statues féminines en terre cuite avec flambeau). Une fosse ronde peu éloignée $(1,70 \mathrm{~m}$ de large) était peut-être liée à l'édifice et couverte d'une structure en bois : il pourrait s'agir d'un culte destiné à une divinité chthonienne.

M. Frasca, "Sull'urbanistica di Catania in età greca", in Damarato (supra 14.03), p. 119-125.

14.06 - Syracuse - Soprintendenza ai Beni Culturali e Ambientali di Siracusa - Dans les fouilles menées à partir de 1992 et de 1996 avec extension à la partie centrale de la piazza Duomo ont été découverts les restes de deux bâtiments successifs, interprétés comme les premières structures de culte de la colonie. Le plus ancien, de la fin du vin ${ }^{\mathrm{e}} \mathrm{s}$. av. J.-C., de forme rectangulaire et orienté $\mathrm{E}-\mathrm{O}$, mesurait $9,20 \times 6 \mathrm{~m}$. Au cours du viI ${ }^{\mathrm{e}}$ s., la structure a été intégrée dans un autre édifice, reconstitué à partir des entailles dans la roche, de forme analogue mais de plus grandes dimensions $(16,20 \times 10,50 \mathrm{~m})$. L'intersection de l'axe routier NS d'Ortygie avec la limite méridionale de l'espace sacré, près de l'actuel Palazzo Arcivescovile, aurait été signalée (peut-être au $\mathrm{v}^{\mathrm{e}} s$. av. J.-C.) par deux piliers dont les bases ont été retrouvées. On avance aussi l'hypothèse que deux petites fosses remplies de fragments de céramique, d'os d'animaux et de cendres, mises au jour dans la même zone et datées du Bronze Ancien, sont elles aussi en relation avec des activités cultuelles. Parmi les découvertes, une onochoé proto-corinthienne avec représentation d'une Potnia therôn est interprétée comme le plus ancien témoignage du culte d'Artémis à Syracuse.

G. Voza (éd.), Siracusa 1999. Lo scavo archeologico di Piazza Duomo, Syracuse 1999; G. Voza, "Primi risultati dello scavo di piazza Duomo a Siracusa", in Un ponte fra l'Italia e la Grecia. Atti del Simposio in onore di Antonino Di Vita (Ragusa, 13-15 febbraio 1998), Padoue 2000, p. 131-138. 
- Soprintendenza ai Beni Culturali e Ambientali di Siracusa - En 1996 à Ortygie, dans la cour du Palazzo della Prefettura fut découverte une rangée de blocs en grès, appartenant à un bâtiment daté au moins du vi ${ }^{\mathrm{e}} \mathrm{s}$. av, J.-C. (peut-être une stoa). Un bloc est partiellement entaillé par le creusement d'un botbros contenant du matériel assigné à la période comprise entre le viI et le $\operatorname{III}^{\mathrm{e}}$ s. av. J.-C. : sa composition (vases en terre cuite, tuiles, objets et scories de fer) est analogue à celle du comblement des puits prétendument sacrés trouvés dans la zone de la piazza Duomo. Des petites fosses fouillées dans le terrain un peu plus au $\mathrm{N}$ proviennent aussi des éléments interprétés comme des témoignages de type cultuel. Selon une hypothèse, le bothros et les petites fosses seraient en relation avec l'édifice auquel appartenait la rangée en grès, auquel on attribue une fonction religieuse.

C. Ciurcina, "Notizie preliminari delle ricerche archeologiche nel cortile della Prefettura a Siracusa (anni 1996-1998)", in Damarato (supra 14.03), p. 86-91.

14.07 - Lentini - Dans une étude topographique du centre est mentionnée l'existence possible de deux sanctuaires des $\mathrm{vII}^{\mathrm{e}}-\mathrm{vI}^{\mathrm{e}} \mathrm{s}$. av. J.-C., identifiés lors d'une enquête en surface dans le quartier Sant'Antonio (sur la topographie du site, cf. aussi S. RizzA, Studi sulle fortificazioni greche di Leontini, Catane, 2000, p. 13-19).

F. VAlenti, "Note preliminari sulla topografia di Lentini dalla conquista romana all'età Tardo Antica", SicA 32 (1999) [2000], p. 169-180.

- Soprintendenza ai Beni Culturali di Siracusa et Università degli studi di Catania - Le journal local mentionne la découverte, à la suite d'une fouille de sauvetage, d'un intéressant sanctuaire dans la commune Scala Portazza, non loin du quartier Alaimo, où fut trouvée un dépôt votif, peut-être liée à un sanctuaire des Dioscures. Ont été mis au jour les restes d'un temple et de deux autels - l'un est du type rectiligne à gradins, avec un parapet sculpté portant métopes et triglyphes - à l'intérieur d'une zone limitée par un mur de temenos. Des deux phases identifiées, une pourrait dater du v $\mathrm{v}^{\mathrm{e}} \mathrm{s}$. av. J.-C., tandis qu'un four pour la cuisson de la céramique (et peut-être aussi pour les terres cuites architecturales), recouvert par le plus petit des deux autels, aurait été en usage entre la fin du vi ${ }^{\mathrm{e}}$ et le début du v $\mathrm{v}^{\mathrm{e}} \mathrm{s}$. av. J.-C.

La Sicilia, 15 marzo 2001, p. 34.

14.08 - Mineo (Piano Casazzi) - Des enquêtes de surface ont permis de relever deux espaces sacrés possibles, à l'E et à l'O de l'habitat. La zone occidentale est identifiée comme un «sanctuaire rupestre suburbain» situé dans une infractuosité, avec cinq édicules disposés en deux files: dans le matériel récupéré se trouve un fragment de protomé féminine en terre cuite de la fin de la période archaïque. Vu la proximité de l'espace funéraire, on a fait l'hypothèse d'une valeur chthonienne du culte rendu dans le petit sanctuaire.

R. Belfiore, "Il centro abitato indigeno-ellenizzato di Piano dei Casazzi (Mineo)", SicA 33 (2000), p. 259-276 (p. 266-268).

14.09 - Morgantina - Mission archéologique américaine - Une terre cuite sigillée en forme de parallélépipède trouvée au cours des fouilles de 1958 dans la zone du sanctuaire de Déméter et Perséphone représente ce que l'on interprète comme un autel au signe de Tanit. Avec quelques autres trouvailles, la terre cuite sigillée atteste l'existence d'un culte punique à l'intérieur de la Sịcile à la fin du $\mathrm{ni}^{\mathrm{e}}$ s. av. J.-C. et l'assimilation de Tanit à Déméter et Perséphone ( $c f$. M. Albertocchi, "Note di coroplastica punica: le figure femminili con 'collane di semi'", in M. Castoldr (éd.), Koinà. Miscellanea di studi archeologici in onore di Pietro Orlandini, Milan, 1999, p. 355-368).

M. Bell. III, "A stamp with the monogram of Morgantina and the sign of Tanit", in Damarato (supra 14.03), p. 246-254. 
14.10 - Géla - Soprintendenza ai Beni Culturali e Ambientali di Caltanissetta - Dans la zone du Bosco Littorio, au S de l'acropole de Mulino a Vento, les fouilles menées entre 1999 et 2000 ont conduit à la mise au jour de quelques chambres, interprétées comme des magasins liés à l'activité portuaire (port normalement situé - en l'absence de recherches spécifiques - près de l'embouchure du Gélas). Contre la paroi extérieure d'un des portiques étaient appuyés trois petits autels (ou plaques d'autel) en terre cuite, de grande dimension, avec décoration plastique et traces de polychromie. La première représente Méduse $(1,16 \mathrm{~m}$ de haut, $0,77 \mathrm{~m}$ de large à la base), avec Pégase et Chrysaor. Dans la seconde $(1,14 \mathrm{~m}$ de haut, $0,575 \mathrm{~m}$ de large à la base), la décoration se divise en deux registres : au registre supérieur, une lionne/panthère se saisit d'un veau, tandis qu'à l'inférieur apparaissent trois figures féminines debout de face, interprétées comme Déméter, Koré et Hécate (ou Aphrodite; pour une interprétation de la signification de la triade, P. Moreno, La bellezza classica, Turin, 2001, p. 129). Le troisième petit autel, de dimensions plus réduites $(0,53 \mathrm{~m}$ de haut, $0,43 \mathrm{~m}$ de large à la base), est la copie bien conservée d'un type déjà connu à Géla (De Miro, Studi Tardoantichi, 1986, p. 387-396) représentant Éos et Képhalos. Le contexte de la découverte semble dater du premier quart du v $v^{\mathbf{e}} \mathbf{s}$ av, J.-C. : stylistiquement, les deux premiers petits autels pourraient être toutefois plus anciens. Ces pièces, que l'on peut facilement rattacher à la production artisanale locale, présentent, outre les trous sur les étroites parois latérales (pour être suspendues) et postérieures (pour être adossées à un mur ?), des cavités sur la face supérieure également. Une publication exhaustive est attendue, qui tienne davantage compte du contexte de la trouvaille,

R. Panvini, "Gela arcaica e le tre are dall'emporio greco", in Gela arcaica. Are, divinità, tiranni, Rome, 2000, p. 23-36.

14.11 - Agrigente - Soprintendenza ai Beni Culturali ed Ambientali di Agrigento et Università di Messina - Parution de la publicaton définitive des fouilles conduites entre 1953 et 1996 dans le secteur compris entre la porte V à l'O et le sanctuaire de Zeus à l'E, situé au $\mathrm{S}$ de la plateia. Dans cet espace, qui a connu une fréquentation préhistorique, furent construits au milieu du $\mathrm{vi}^{\mathrm{e}} \mathrm{s}$. av. J.-C. un petit temple $(15,7 \times 6 \mathrm{~m})$ avec une entrée tournée vers le $\mathrm{N}$, et probablement un autre de même orientation mais de plus grandes dimensions ( $c a 24 \times 10,09 \mathrm{~m}$ ), dont sont seulement conservées des entailles dans la roche pour la pose des fondations. Le sanctuaire comprenait au $\mathrm{N}$ un espace pavé et un portique interprété comme une lesche; à l'E, on présume que s'élevait un petit bois. Intégré au schéma urbanistique régulier à la fin du $\mathrm{vi}^{\mathrm{e}} s_{\text {., }}$ le sanctuaire fut délimité à l'E par un mur de temenos le long du stenopos 3, probablement à l'occasion des travaux du sanctuaire voisin, celui de Zeus, après 480 av. J.-C. Après la destruction de Carthage en 406 av. J.-C., deux autels ont été érigés dans la zone des propylées du petit temple précédent, tandis qu'au ${ } \mathrm{II}^{\mathrm{e}} \mathrm{s}$. av. J.-C. un portique en $\mathrm{L}$ vient délimiter le sanctuaíre à l'E et au $\mathrm{N}$. Au cours du $\|^{\mathrm{e}} \mathrm{s}$. av, J.-C., on construit dans la partie méridionale du portique un édifice circulaire, tandis que six ou sept édicules sont alignés au $\mathrm{N}$ le long de la plateia. Seuls de petits portiques furent construits dans la zone à l'époque romaine, au $\mathrm{II}^{\mathrm{e}}-\mathrm{II}^{\mathrm{e}}$ s. ap. J.-C., avant qu'un nivellement général ne dissimule le sanctuaire. Sur la base des inscriptions sur vases $\mathrm{du} \mathrm{vI}^{\mathrm{e}}-\mathrm{v}^{\mathrm{e}}$ s. av. J.-C., le sanctuaire est attribué à Déméter et Perséphone qui auraient également été vénérées dans deux temene voisins à l'O de la porte $V$ : une tête en marbre du $v^{e}$ s. av. J.-C. appartenait probablement à la statue de culte représentant Déméter. Partant de l'hypothèse que le culte sicéliote des deux déesses se déroulait de manière analogue à celui d'Athènes, De Miro propose de voir dans trois temene de Déméter et Perséphone les lieux de culte respectifs des trois journées de fête en leur honneur. Il attribue en outre une valeur chthonienne au culte de Zeus également.

E. De Miro, Agrigento I. I santuari urbani. L'area sacra tra il tempio di Zeus e porta $V$, Roma, 2000. 
- Soprintendenza ai Beni Culturali e Ambientali di Agrigento - La presse locale a noté la découverte d'un petit temple in antis à peu de distance de l'église de San Biagio. Il serait lui aussi dédié à Déméter et daté des $\mathrm{vl}^{\mathrm{e}}-\mathrm{v}^{\mathrm{e}} \mathrm{s}$. av. J.-C.

La Sicilia 11 maggio 2001, p. 16.

14.12 - Menfi - Soprintendenza ai Beni Culturali e Ambientali di Agrigento - Au cours des fouilles menées en 1997 dans l'établissement de Montagnoli, on signale la découverte de la cabane 7, construite au viI ${ }^{\mathrm{e}} \mathrm{s}$. av. J.-C. et détruite, comme le reste de l'établissement, à la mi-vil ${ }^{e} s$. G. Castellana pense que cette structure, de forme plus ou moins circulaire (axes de 7,85 et $6,80 \mathrm{~m}$ ), avec une banquette le long de la partie orientale des murs, abritait aussi des cérémonies cultuelles. Mais le recours à la sphère religieuse ne paraît pas justifié par les pièces présentées (cruches, vaisselle, marmites, un curieux «plat 》 à décoration imprimée planté dans le pavement au centre de l'espace).

G. Castellana, "Nuovi dati sull'insediamento di Montagnoli presso Menfi", in Terze giomate internazionali di studi sull'area elima (Gibellina-Erice-Contessa Entellina 23-26 ottobre 1997), Pise/Gibellina, 2000, p. 263-271.

14.13 - Marineo - Soprintendenza ai Beni Culturali e Ambientali di Palermo - Dans une nouvelle série de travaux, entreprise en 1991, lors d'un sondage effectué le long du mur de fortification de Montagnola, fut découverte une petite structure parallélépipédique en pierre sèche; à côté d'elle se trouvaient deux jambières en bronze, trois casques (deux certainement chalcidiens) et une garniture en bronze provenant peut-être d'un bouclier de cuir; parmi les pièces en terre cuite, une cruche pleine d'ossements ovins et caprins et une marmite introduite dans un foyer. L'ensemble, datable de la fin du $\mathrm{vl}^{\mathrm{e}} \mathrm{s}, \mathrm{av}, \mathrm{J}$-C., est interprété comme un petit sanctuaire peut-être établi en l'honneur d'un héros local à l'occasion d'événements dramatiques dans la région, liés à la bataille d'Himère en 480 av. J.-C. On attendra une publication complète pour disposer de l'interprétation religieuse de l'ensemble.

F. Spatafora, "Indigeni, punici e greci in età arcaica e tardo-arcaica sulla Montagnola di Marineo e nella valle dell'Eleuterio", in Terze giornate internazionali di studi sull'area elima (supra 14.12), p. 895-918, spéc. p. 906-909.

14.14 - Solonte - Au cours de la fouille, menée en 1997, d'un four hellénistique pour céramique situé près de la pointe du promontoire de Solonte, ont été trouvés en remploi une stèle à trône et des fragments d'au moins un cippe à trône qui rendent probable l'existence d'un tophet punique dans la région.

C. Greco, "Solunto: nuovi dati dalla campagna di scavo 1997", in Terze giornate internazionali di studi sull'area elima (supra 14.12), p. 681-700.

14.15 - Palerme - Soprintendenza ai Beni Culturali e Ambientali di Palermo - Au cours des fouilles menées en 1996 et 1997, une partie de la nécropole punique près de la caserne Tuköry a été explorée et 35 autres tombes ont été mises au jour. Les sépultures sont tantôt des incinérations tantôt des inhumations; sept tombes à chambre avec dromos, trois enchytrismoi. Le matériel atteste une période d'utilisation comprise entre la fin du $\mathrm{vII}^{\mathrm{e}}$ et le $\mathrm{IV}^{\mathrm{e}}$ s. av. J.-C. : le matériel étrusco-corinthien et égyptien est également présenté. Les amphores (79\% grecques, $21 \%$ puniques) révèlent peut-être une influence grecque dans l'adoption du banquet funéraire.

C.A. Di Stefano, "Nuove scoperte nella necropoli punica di Palermo", in Terze giornate internazionali di studi sull'area elima (supra 14.12), p. 437-449; G. SArג̀, "Tipologia e cronologia delle anfore greche da trasporto della necropoli punica di Palermo (VII-IV secolo a.C.)", in Proceedings of the $X V^{\text {th }}$ International Congress of Classical Arcbaeology (Amsterdam, July, 12-17, 1998), Amsterdam, 1999, p. 349-352. 
14.16 - Monte Iato - Université de Zürich - Au cours des fouilles de 1995/97, on a pu vérifier que le temple hellénistique à oikos situé à l'angle S-O de l'agora avait été placé sur un édifice de plan analogue construit autour des années 480/470 av. J.-C. et pouvant remplir une fonction identique. Dans le quartier occidental, les fouilles de 1999 ont permis d'établir avec précision que le temple au NE de la Maison à péristyle 1 fut construit à la fin du $\mathrm{Iv}^{e} s$. av. J.-C. Ce temple s'élève sur les restes d'un édifice archaïque auquel se rapporte un groupe de phiales fragmentaires du début du $v^{e}$ s. av. J.-C. Ces vases et un petit animal en bronze sont considérés comme des objets votifs et on fait donc l'hypothèse que la structure archaïque sous le temple avait une fonction sacrée.

H.P. IsLER, "Monte Iato: scavi 1995-1997", in Terze giomate internazionali di studi sull'area elima (supra 14.12), p. 715-729; id., "Monte Iato: la ventottesima campagna di scavo", SicA, 31 (1998) [2000], p. 17-48; id., "Grabungen auf dem Monte Iato 1999", $A K, 43$ (2000), p. 110-120.

14.17 - Ségeste - En 1996 et 1997, des fouilies ont été conduites dans la nécropole localisée au cours des explorations du territoire de Ségeste, au pied de la colline du Thêâtre. La période d'utilisation du cimetière semble commencer peut-être à la fin du Ive s. av. J.-C. et se concentre sur le $\mathrm{III}^{\mathrm{e}}$ s. av. J.-C. pour s'arrêter à la fin de celui-ci. Les tombes mises au jour - de simples fosses en terre - sont principalement (85\%) orientée N-S. Les pratiques attestées sont soit l'inhumation (109 cas) soit la crémation (14 cas); on signale en particulier la découverte, à l'intérieur de la tombe $n^{\circ} 77$, d'un autel en calcaire couvert de stuc qui devait être situé près de la sépulture elle-même. Pour quelques-unes des 12 amphores gréco-italiques récupérées, une fonction d'epitymbion n'est pas à exclure.

B. BeCHTOLD, "Una necropoli ellenistica a Segesta (SAS 15). Rapporto preliminare delle campagne di scavo 1996 e 1997", in Terze giomate internazionali di studi sull'area elima (supra 14.12), p. 79-90.

- Au cours de la prospection de surface conduite sur le territoire de Ségeste, deux aires sacrées d'époque hellénistique ont été localisées, sur le sommet du mont Pisapia et près des Thermes de Ségeste. Dans les deux cas, l'interprétation se fonde sur la découverte d'éléments architecturaux : on fait l'hypothèse que le culte était pratiqué en relation, respectivement, avec le bois et avec les eaux curatives. Le sanctuaire près des Thermes de Ségeste pourrait avoir été en usage jusqu'au ive $s$. av. J.-C.

S. Bernardini, F. Cambi, A. Molinari, I. Neri, "Il territorio di Segesta fra l'età arcaica e il Medioevo. Nuovi dati dalla carta archeologica di Calatafimi", in Terze giornate intemazionali di studi sull'area elima (supra 14.12), p. 91-133.

14.18 - Sélinonte - Deux autels miniatures en pierre (GABrici, MAL 1927, 203, fig. 109 et Jameson, Jordan, Kotansky, A lex sacra from Selinous, 1993, p. 139-140, tav. 18b, 19) sont la reproduction d'autant d'autels du sanctuaire de la Malophoros de la deuxième moitié du $v^{e} s$. av. J.-C. : sur la base des deux copies, on peut supposer l'existence d'éléments en terre cuite situés sur la table pour déposer des braseros ou des grilles dans le but d'empêcher la chaleur d'abîmer la pierre de la table elle-même.

C. Zoppi, "L'altare lapideo -miniaturistico dal santuario della Malophoros di Selinunte", SicA 32 (1999) [2000], p. 55-58.

14.19 - Lilybaeum (Marsala) - Soprintendenza ai Beni Culturali e Ambientali di Trapani - Les fouilles menées en 1996 dans la nécropole de S. Maria della Grotta, outre un complexe de catacombes paléochrétiennes (dont certaines, avec peintures et mosaiques, ont été étudiées au cours de cette campagne de foulles), ont mis au jour des tombes quadrangulaires sans éléments de datation, qui se signalent par l'usage consistant à déposer le corps des défunts sur une épaisse couche de chaux placée sur le fond. 
R. Giglio, P. Vecchio, "Lilibeo (Marsala). Area di Santa Maria della Grotta e complesso dei Niccolini: recenti rinvenimenti archeologici", in Terze giornate internazionali di studi sull'area elima (supra 14.12), p. 655-680.

\section{Index géographique}

Atbènes. 14.11; Acropole 01.01; Agora 01.01; Aréopage 01.01; Céramique 01.02; Ilissos (fl.) 01.06; Makriyianni 01.01; Zappeion 01.06

Attique. 05.05; Gerakas 01.10; Kalamos 01.07; Rbamnonte 01.09; Prasiai 09.18; Salamine 01.12; Skala Oropou 01.08; Stavros 01.10; Thorikos 01.11

Péloponnèse. Achaïes : Ano Mazaraki 02.22; Koumari Aigialeias 02.21. Arcadie : Lousoi 02.25; Mantinée 02.23; Pbigalie (Kourdoubouli) 02.24; Stymphale 02.26. Argolide : Argos 02.06; Asiné 02.09; Chonikas 02.06; Dimaina 02.11; Épidaure Asiné 02.10; Tiryntbe 02.08. Corinthie : Corintbe 02.01; 05.05; Galatakia 02.03; Isthmia 02.02; Koukouyera (Mt) 02.04; Némée 02.04; plaine de Phlionte 02.05; Solygeia 02.03. Élide : Kombothékra 02.19; Olympie 02.20; Prassidaki 02.18. Laconie: Antidragonara (îlot) 02.15; Chousti (grotte de) 02.15; Cytbère 02.15; Geraki 02.14; Tsakona 02.13. Messénie : Messène 02.16; Ano Melpeia 02.17

Phocide. Delpbes 09.25

Grèce « de l'Ouest ». Acarnanie : Alyzeia 05.01; Drymonas 05.01; Stratos 05.02. Épire : Ambracie 05.03; Dodone 05.05; Paramythia [région de] 05.04; Thesprôtie 05.05. îles ioniennes : Céphalonie 05.10; Corcyre 05.07; Ithaque 05.09 (grotte de Drakaina); 05.10 (grotte de Polis); Leucade 05.08 (grotte de Voliatso). Illyrie méridionale : Apollonia 05.06

Macédoine. Agios Christophoros 07.05; Aigai 07.14; Akanthos 07.24; Aphytis 07.22; Apsalos, Almopia 07.16; Beroia 07.11; Dioiketerio 07.18; Dion 07.00; 07.17; Herakleia Linkestis 07.00; Kastoria 07.01; Kitrini Limni 07.06; Leukadia 07.09; Leukopetra 07.12; Melenikitsi 07.26; Mendè 07.20; Mitriko 07.27; Nea Roda 07.25; Oraiokastro 07.19; Ouranopolis 07.25; Pella 07.15; Perdikkas 07.04; Petres 07.02; Philippes 07.00; Polymylos 07.08; Poseidi 07.21; Ryakio 07.07; Skydra 07.10; Stobi 07.00; Thessalonique 07.00; 07.18; Torone 07.23; Vergina 07.13; Xirolimni 07.03

Thrace. Boudinoi 08.06; Gorna Krepost 08.05; Iasmos 08.04; Kossinthos 08.01; Maroneia 08.02; Mesembria 08.03

Iles de l'Égée. Amorgos 09.14; Andros 09.15; Délos 09.13; 09.16;09.17; 09.18; 12.05; Égine 09.27; Érétrie 07.10; Ios 09.09; Kalaureia 09.28; Kea 09.13; Kos 09.03; 09.4; 09.05; 09.06; Naxos 09.13; 09.20; 09.21; 09.22; Paros 09.13; 09.22; 09.23; Rbodes 09.05; 09.07; 09.08; 09.09; 09.10; 09.11; 09.12; Samos 11.10; 12.09; Samotbrace 09.02; Sipbnos 09.24; 09.25; Thasos 09.01; Théra 09.26

Crète. 12.05

Chypre. 09.16; Achna 11.03; Agia Irini 11.00; 11.04; Agia Varvara-Almyras 11.08; Alambra 11.00; Amathonte 11.00; 11.10; Arsos 11.00; Athienou-Malloura 11.05; Golgoi 11.00; Idalion 11.00; 11.07; 11.10; Kition 11.00; 11.04; 11.05; Kourion 11.00; 11.11; Lapétbos 11.00; Marion 11.00; 11.16; Nea-Paphos 11.15; Nicosie 11.01; Paleapaphos 11.00; 11.12; PrastioAgios Savvas tis Karonis 11.14; Pyrga 11.06; Rantidi 11.13; Salamine 11.00; 11.02; Tamassos $11.00 ; 11.09$

Asie Mineure. Bithynie : Daskyleion 12.09. Carie : Herakleia Salbakè 12.02. Éolide: Kymè 12.08. Ionie : Claros 12.06; Didymes 12.04; Éphèse 12.05; 12.09; Milet 12.03; 12.04. Troade : Troie 07.23 


\section{Étrurie 12.05}

Grande Grèce. Crotone 13.05; Cumes 13.06; Herakleia 13.03; Hipponion 13.07; Locres 13.01; 14.04; Medma 13.08; Métaponte 13.02; Paestum 13.01; Sybaris 13.04; Tarente 13.09

Sicile. Agrigente 14.11; Catania 14.05; Francavilla 14.04; Géla 14.10; Lentini 14.07; Lilybaeum 14.19; Lipari 14.01; Marineo 14.13; Menfi 14.12; Messina 14.02; Mineo (Piano Casazzi) 14.08; Morgantina 14.09; Monte Iato 14.16; Naxos 14.03; 14.04; Palerme 14.15; Ségeste 14.17; Sélinonte 14.18; Solonte 14.14; Syracuse 12.05; 14.06

\section{Index thématique}

activités métallurgiques : $11.04 ; 11.08 ; 11.10$

agogè : 02.12

animaux « sacrifiés »; bovins 11.04; 11.10; caprins 11.04; 11.05; 11.10; chien 13.01; daims 11.04; lièvres 11.04; ossements $01.01 ; 01.08 ; 02.16 ; 09.13$; 11.04; 11.05; 11.10; 13.01; 13.05; $14.03 ; 14.06$; 14.13 ; ovins $11.01 ; 11.04 ; 11.05 ; 11.10 ; 13.01$; poissons 11.04 ; porcins 13.01

animaux votifs : $02.08 ; 05.07 ; 09.03 ; 14.16$; aigle 11.06 ; bélier 11.01 ; canard 07.08 ; cheval 11.01; 11.06; dromadaire 11.10 ; oiseaux 01.10 ; 11.01 ; porcs 09.15 ; serpents 07.15 ; taureaux 11.10 ; 11.11

armes votives : $02.13 ; 12.03 ; 14.13$; boucliers 02.13 ; boucliers miniatures 07.15 ; flèches (pointes de) 02.13; lances 02.13; 14.03 (pointes de); miniatures 13.05

atelier de sanctuaire : 11.16

autels : 01.01; 01.08; 05.04; 05.06; 07.02; 07.18; 09.14; 11.01; 12.03; 12.07; $14.02 ; 14.07 ; 14.09$ (décoré et peint); bothros $05.10 ; 11.01 ; 11.16 ; 13.03 ; 14.06$; de cendres $11.11 ; 13.01$; grilles 14.18 ; fosses $05.06 ; 07.27 ; 11.15 ; 13.05 ; 14.05 ; 14.06$; miniatures $07.15 ; 14.18$; portatif 11.10 ; table d'offrandes $07.08 ; 11.10$

bain rituel : 13.01

céramique/« vaisselle » : 01.10; 01.12; 02.20; 07.15; 09.20;11.00; 11.15; 13.01; amphores 01.12; $08.05 ; 13.08$; coupes $02.07 ; 13.02 ; 13.08 ; 14.03$; cratères 02.07 ; cratérisques $13.05 ; 14.04$; cruches 13.02; dinos 11.10; hydries 13.05 ; kernoi 01.02 ; 01.11; kotyles 13.05 ; 13.08 ; kylikes 13.03; 14.04; lécythes 02.25 ; onochoés $05.04 ; 13.03$; 14.06; olpai 13.05 ; 14.04; patère 05.04; 13.03; phiales 07.15 (miniature); 14.16; skyphoi 01.00; 02.07; 13.07; vases à fig. rouges 01.05 ; vases à parfum 05.01 ; vases miniatures $01.01 ; 02.03 ; 02.06 ; 02.08 ; 13.03 ; 13.04 ; 13.08$; 14.04

char nuptial : 05.07

chœurs : 05.10 (féminin); 09.17

concours : 02.12 .

contexte funéraire : $11.10 ; 13.09 ; 14.08$; banquets funéraires $09.07 ; 11.10 ; 14.15$; couronnes d'or 09.12 ; cultes funéraires $01.02 ; 07.15 ; 07.18 ; 07.23 ; 08.01 ; 09.21 ; 09.22$; defixio 07.19 ; enclos 01.05; 09.14; fosses 09.07; 09.22; incinération 09.21; inhumation 14.01; stèles 09.04; tophet 11.10; 14.14; tombes 01.02; 01.05; 02.03; 02.07; 02.09 (mycéniennes); 02.07; 07.09; $07.18 ; 09.12 ; 09.14 ; 09.23 ; 11.00 ; 11.02 ; 11.12 ; 14.01 ; 14.15 ; 14.17 ; 14.19$

continuité cultuelle : 11.07

cultes de carrefour : 01.01

cultes de souverains : 09.14;09.25

cultes domestiques : 01.01

cultes funéraires ( $c f$. contexte funéraire)

cultes hérö̈ques : 02.07; 02.16;07.23;09.20;09.22; 13.01

cultes thérapeutiques : 13.06 
dépôt votif (cf. ex-voto)

desservants ( $c f$. prêtres/prêtresses)

divinités/héros :

Achéloos 01.06

Adonis $11.00 ; 11.07 ; 11.10$

Aléa 02.15

Aphrodite $02.16 ; 07.09 ; 07.15 ; 07.18 ; 07.19 ; 08.03 ; 09.23 ; 09.26 ; 11.00 ; 11.07 ; 11.09 ; 11.10$; 12.02; 14.01; 14.04; 14.10; Ourania 13.01; Pandamos 09.05; Pontia 09.05

Apollon 02.01; 05.09; 07.00; 08.06; 09.01; 09.01; 12.01; 12.02; 12.04; 12.06; 13.05; Agyieus 01.01; Citharède 07.03; 07.13; Délien 09.18; Erethimios 09.10; Hylatès 11.00; 11.11; Lykios 07.13; Maleatas 02.10; Pythien 09.17; 09.19; Sôter 09.19;

Ariane 02.16

Aristoménès 02.16

Artémis $02.22 ; 02.25 ; 05.01 ; 05.07 ; 07.06 ; 09.14 ; 09.15 ; 09.24 ; 11.00 ; 11.10 ; 12.02 ; 12.05 ; 12.06$; $12.07 ; 13.02 ; 13.03 ; 13.09 ; 14.01 ; 14.04 ; 14.06$; Choria 02.11; Ekvateria 09.24; Elaphebolia; Ephesia 12.07; Laphria 02.16; Limnatis 02.19; Orthia 11.00

Astarte $11.04 ; 11.05 ; 11.10$

Athéna $01.02 ; 02.18 ; 02.24 ; 02.25 ; 05.05 ; 07.15 ; 07.18 ; 09.23 ; 09.24 ; 11.00 ; 11.15 ; 12.02 ; 12.07$; 14.01; Pallènè 01.10; Parthénos 07.19; Polias 01.01; 09.19; Poliouchos 12.03

Attis 07.15

Baal 11.04

Bendis (Artémis) 11.00; 13.09

Bès 11.00

Cavalier thrace 08.04

Chrysaor 14.10

Cybèle 02.16;07.00; 07.18; 12.07; 12.08; 12.09

Darron 07.15

déesse aux bras levés $11.04 ; 11.14$

déesse courotrophe $09.23 ; 11.00 ; 11.01 ; 12.08 ; 14.01$

déesse gravida 11.04

Déméter 01.02; 01.11; 02.01; 02.03; 05.10; 09.14; 14.04; 14.09; 14.10; 14.11; Malophoros 14.18

Diane 05.04

Dionysos $01.01 ; 01.08 ; 01.12 ; 02.16 ; 07.15 ; 07.18 ; 07.22 ; 08.06 ; 09.01 ; 09.11 ; 09.13 ; 12.01$; $13.07 ; 13.08 ; 14.04$

Dioscures 13.09; 14.07

Enodia 07.11

Éos 14.10

Éros 07.15; 07.18; 12.02

Géryon $11.00 ; 11.06$

Grands dieux 09.02

Hadès $12.02 ; 13.08 ; 14.04$

Hathor 11.12

Hécate $01.01 ; 07.00 ; 14.10$

Hélios 09.11

Héra $02.03 ; 02.07 ; 11.10 ; 12.02 ; 14.03 ; 14.04$

Héraclès 01.00; 05.03; 05.07; 07.00; 07.04; 11.00; 12.02; Kynagidas 07.07

Hermès $01.01 ; 07.04 ; 07.16 ; 11.00 ; 14.01 ; 14.04$ 
Héros Cavalier 07.23

Hyakinthos 13.09

Hygie 11.10

Isis 07.00; 07.11; 07.26; 09.06; 09.14; 12.08; 14.01

Képhalos 14.10

Koré 01.02; 02.03; 14.04; 14.10 (cf. Perséphone)

Léda 14.01

Létô 12.02

Leucippides 11.10

Méduse 14.10

Melqart 11.00; 11.04

Ménélas $c f$. Ménélaion

Mère des dieux 07.12 (Autochtone); 07.15; 12.08

Muses 01.06

Niké 07.08; 07.18

Nymphes 01.06; 05.08; 05.09; 05.10; 12.01; 12.04

Opheltès 02.04

Osiris 11.10

Palaimon 02.02

Pan 01.06; 01.12; 05.09; 05.10;09.01;09.25; 11.00

Pégase 14.10

Perséphone 05.10; 07.19; 11.09; 14.09; 14.11 (cf. Koré)

Phytalmios 09.19

Polyboia 13.09

Poséidon 01.02; 02.16; 05.03; 07.10; 07.22; 09.28; Gaieochos 02.15; Hippios 02.23

Potnia therôn $09.24 ; 11.00 ; 14.06$

Priape 01.12;

Sérapis $07.26 ; 08.02 ; 09.06 ; 09.14$

Tanit 14.09

Télesphoros 01.01

Tritopatores 13.01

Tyché 07.00

Zeus 02.06; 05.02; 07.00; 07.02; 07.17; 07.18; 11.02; 12.02; 13.03; 14.04; 14.10; Ammon 07.22;

Eleutherios 14.04; Hellanios 09.27; Hypsistos 07.01; 07.05; Labranios 11.10;

Naios/Naos 05.05; Olympios 07.17; Sôter 02.16; 02.24

encens : 11.00

ex-voto et mobilier cultuel : 05.09; 09.16; 11.00; aegyptiaca 11.00; anatomiques 13.06; bagues 05.09; bateaux 11.10; bijoux 11.06; chaudrons 11.00; couteaux en bronze 02.13; dépôt votif 01.02; 01.03; 01.05; 02.03; 02.05; 02.08; 05.01; 05.08; 09.24; 11.07; 11.08; 11.10; $12.08 ; 13$ (passim); encensoirs 11.00; 11.16; épingles 02.24; 11.10; flambeau 14.05; fosses votives 05.10 ; 14.01; gorgone 09.23 ; grappes 07.15 ; lamelles oraculaires 05.05 ; lampes $01.01 ; 07.15 ; 11.01 ; 11.05 ; 13.01$; mains 01.02 ; masques $11.02 ; 11.03 ; 11.04 ; 14.01$ (de théâtre); moule 05.07; obeloi 11.16; œufs 07.15; objets en bronze 02.08; 02.18; oreille 07.26; perirrbanteria 02.10 ; 02.25 ; phalloi 07.08 ; 09.23; plaques 02.16 ; 14.01 ; 14.04 ; poids de métier à tisser 13.03; protomés $02.25 ; 05.10 ; 14.04 ; 14.08$; reliefs : 01.07; 07.00; 07.01; $07.06 ; 07.07 ; 07.16 ; 07.22 ; 09.15 ; 09.18$; rhytons 12.03 ; ruches 01.12 ; sceaux $05.05 ; 11.00$; 11.06; statuettes/figurines 01.02; 01.10 (oiseaux); 02.01; 02.03; 02.05; 02.06; 02.07 (déesse trônant); $02.07 ; 07.15 ; 11.01 ; 11.10$ (cavaliers); 02.13 (ithyphalliques); 02.13 (femmes nues); 02.16; 02.19; 02.19; 05.01; 05.04 (bronze); 05.07 (femme assise sur une lionne); 05.08; 05.09; 05.10; 07.01; 07.09 (ivoire); 07.18; 09.03; 09.24; 11 (passim); 13 (passim); 1.4 
(passim); stèles : 02.26 (aniconiques); 05.10; 07.02; 07.11; trident en bronze 05.07 ( $c f$. animaux votifs, armes votives, autels, statues)

fêtes: 11.10; Anthestéries 09.23; Apatouries 01.00; Dionysies 09.24; Euaggelia 09.25; mystères d'Éleusis 01.03; Thesmophories 14.04; 14.11

fumigations : 11.00

libations : 01.00; 02.07; 02.16; 09.04; 13.01; 14.01; 14.04

musiciens : $11.06 ; 11.10$

noms de personnes : Cimon 11.16; Euripide 01.12; Dionysios fils d'Aristoménès; Praulos 05.09; Ptolémée Ier 11.16; Thrasybule 14.04; Titus 11.10

oracles : 12.01

palmier : 09.18; 11.10

prémices : 13.03

prêtres/prêtresses : 07.11;07.15; 09.05; 09.11; 11.00; 12.01

repas rituel (cf. contexte funéraire) : 09.07

rites de passage : $13.01 ; 14.03$

sacrifices : $01.08 ; 12.03 ; 14.03$; hécatombes 07.17 ( $c f$. animaux sacrifiés)

sanctuaires : adyton 02.02; Archilocheion 09.23; Artémision 05.07; 12.05; 12.09; Asclépieion 09.09; Athénaion 12.03; bois sacré 07.22; 09.08; bûcher 11.10; Delphinion 12.03; 12.04; Dionysion 09.11; Éphésion 12.07; foyer/pyrai 01.01; 07.21; 09.14; 09.22; grotte 01.12; 02.15; 05.08; 07.22; 11.10; 13.04; hécatompédon 02.22; Héraion 12.09; 13.01; berôon 02.16; 09.23; $12.01 ; 14.13$; bestiatorion ( $c f$. salle de banquet infra); hypètre $02.07 ; 05.06 ; 07.22 ; 08.05$; 09.22 ; 11.11; hypogée 11.15; 13.01; koreion 14.01; leschè 14.11; mégaron 02.08; Odysseion 05.09; palatiaux 11.00; pompeion 09.27; prostôon 02.22; puits 13.01; 14.06; Pythion 09.01; rural 01.12; 05.01; salle de banquet $07.15 ; 09.27 ; 13.01 ; 13.08$; source $01.12 ; 13.01$; temple passim; Thesmophorion 09.15

sphinx (acrotère) : 02.01

statues : 01.12; 02.16; 08.03; 09.01; 09.11; 11.00 (passim); de culte : 02.24; 14.04; 14.11; korai $09.15 ; 11.10 ; 11.16 ; 12.04$; kouroi $09.15 ; 09.23 ; 14.04$; tête en bronze $01.04 ;$ xoanon 14.04 (cf. divinités/héros; ex-voto)

technites de Dionysos : 09.25 